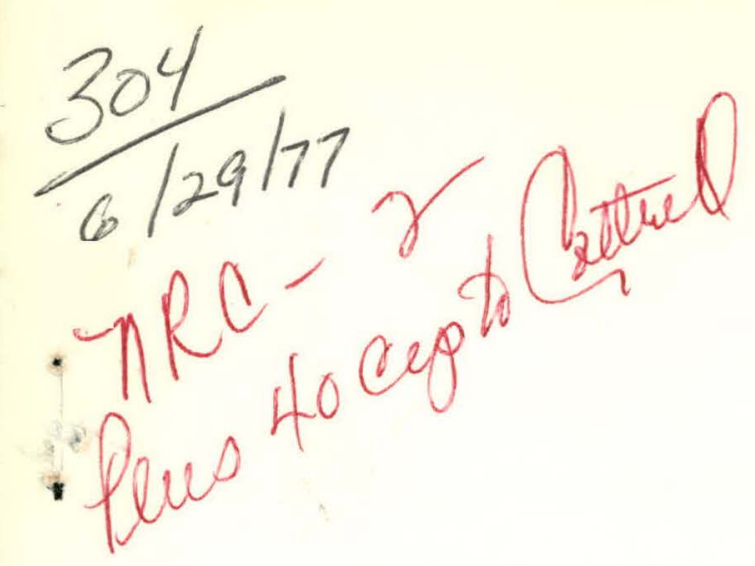

TREE-NUREG-1058 for U.S. Nuclear Regulatory Commission

\title{
SEMISCALE MOD-1 SYSTEM RESPONSE DURING THE ECC BASELINE TEST SERIES (DESIGN OF THE MOD-1 BASELINE ECC TEST)
}

\author{
MICHAEL A. LANGERMAN
}

June 1977

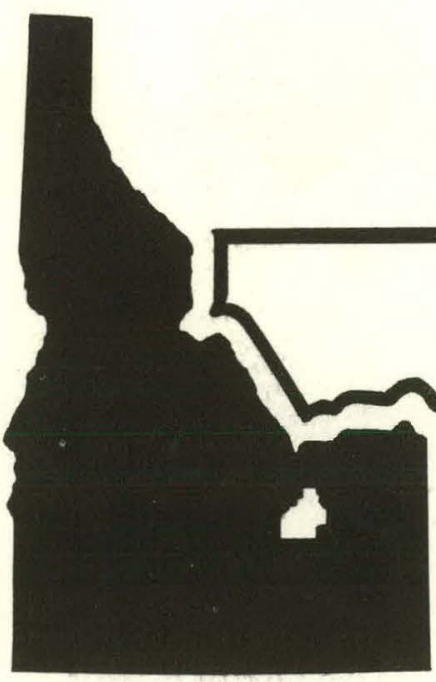

\section{$\prod_{f} E \Sigma[G$ Idaho, Inc.}




\section{DISCLAIMER}

This report was prepared as an account of work sponsored by an agency of the United States Government. Neither the United States Government nor any agency Thereof, nor any of their employees, makes any warranty, express or implied, or assumes any legal liability or responsibility for the accuracy, completeness, or usefulness of any information, apparatus, product, or process disclosed, or represents that its use would not infringe privately owned rights. Reference herein to any specific commercial product, process, or service by trade name, trademark, manufacturer, or otherwise does not necessarily constitute or imply its endorsement, recommendation, or favoring by the United States Government or any agency thereof. The views and opinions of authors expressed herein do not necessarily state or reflect those of the United States Government or any agency thereof. 


\section{DISCLAIMER}

Portions of this document may be illegible in electronic image products. Images are produced from the best available original document. 
Printed in the United States of America Available from

National Technical Information Service

U.S. Department of Commerce

5285 Port Royal Road

Springfield, Virginia 22161

Price: Printed Copy $\$ 5.00$; Microfiche $\$ 3.00$

"The NRC will make available data tapes and operational computer codes on research programs dealing with postulated loss-of-coolant accidents in light water reactors. Persons requesting this information must reimburse the NRC contractors for their expenses in preparing copies of the data tapes and the operational computer codes. Requests should be submitted to the Research Applications Branch, Office of Nuclear Regulatory Research, Nuclear Regulatory Commission, Washington, D.C. 20555."

\section{NOTICE}

This report was prepared as an account of work sponsored by the United States Government. Neither the United States nor the Energy Research and Development Administration, nor the Nuclear Regulatory Commission, nor any of their employees, nor any of their contractors, subcontractors, or their employees, makes any warranty, express or implied, or assumes any legal liability or responsibility for the accuracy, completeness or usefulness of any information, apparatus, product or process disclosed, or represents that its use would not infringe privately owned rights. 
TREE-NUREG-1058

\section{SEMISCALE MOD-1 SYSTEM RESPONSE DURING THE ECC BASELINE TEST SERIES (DESIGN OF THE MOD-1 BASELINE ECC TEST)}

Approved:

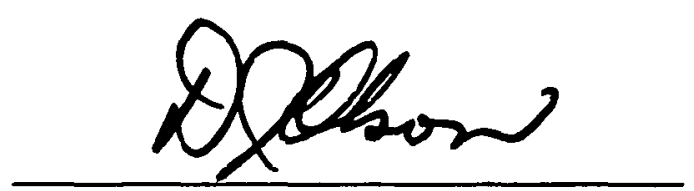

D. J. Olson, Manager

Semiscale Program

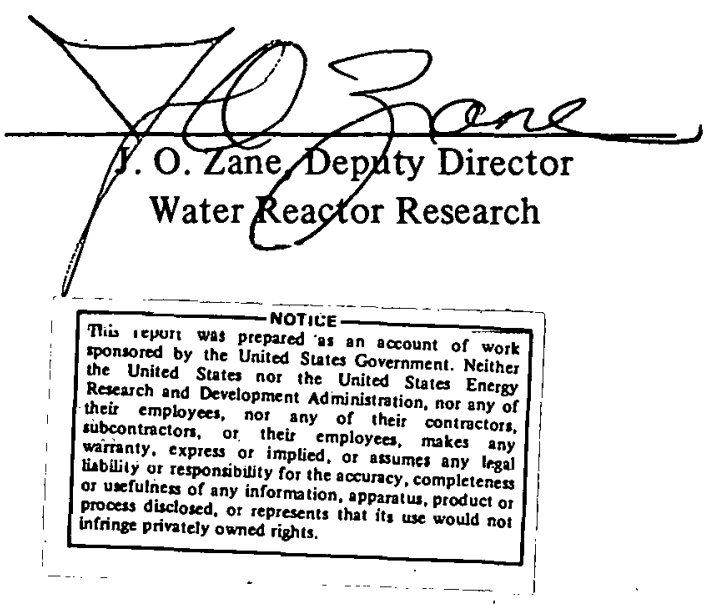




\section{SEMISCALE MOD-1 SYSTEM RESPONSE DURING THE ECC BASELINE TEST SERIES (DESIGN OF THE MOD-1 BASELINE ECC TEST)}

by

Michael A. Langerman

EG\&G IDAHO, INC.

June 1977

PREPARED FOR THE

U.S. NUCLEAR REGULATORY COMMISSION

AND

ENERGY RESEARCH AND DEVELOPMENT ADMINISTRATION

IDAHO OPERATIONS OFFICE

UNDER CONTRACT NO. EY $76 \cdot C \cdot 07 \cdot 1570$ 


\section{ACKNOWLEDGMENTS:}

The author wishes to express his thanks to the Semiscale leest Support Branch personnel for their" efforts in conducting the tests and for acquisition; verification, and: documentation of the data; to the personnel of the Semiscale Data Processing Section for providing data processing support; to C. E: Cartmill and D. J. Hansen for technical support; to K. A. Dietz for editing and improving the quality of the report; and to Keri Johnston and Elinor Witbeck for typing the various drafts. 


\begin{abstract}
The baseline ECC test which is to be used in comparison with future Semiscale Mod-1 ECC related tests is specified using results from the baseline ECC test series. Test results which led to the selection of appropriate baseline ECC conditions are evaluated. The major parameters investigated include the effects of (a) ECC system specifications including ECC system scaling, and lower plenum ECC injection, (b) lower plenum scaling, and (c) unpowered rods simulating the effects of PWR control rod guide tubes and instrument thimbles.
\end{abstract}




\section{SUMMARY}

The Semiscale Mod-1 program is designed to investigate the behavior of a pressurized water reactor PWR system model during a hypothesized loss-of-coolant accident. The Mod-1 system is a scaled down model of a PWR that simulates the principal physical features of a nuclear plant, and is designed such that all facets of the accident may be investigated. Nuclear heating is simulated in the tests by a core composed of an array of electrically heated rods. The core is contained in a pressure vessel which also includes a downcomer, lower plenum, and upper plenum. The system piping is arranged in a 1-1/2-loop configuration with the intact loop containing an active steam generator and pump, and with the broken loop containing passive simulators for the steam generator and pump.

The baseline ECC test series was the fourth group of tests conducted in the Semiscale Mod-1 experimental program and was the first group of tests designed to study the integral blowdown-reflood response of the Semiscale system. The primary objective of this test series was to provide a test which would serve as a baseline for future emergency core coolant (ECC) related Semiscale Mod-1 tests. This objective was met by investigating the sensitivity of the Mod-1 system response, particularly the system conditions at the initiation of core reflood, to changes in parameters that strongly influence ECC related behavior. The results of this investigation were then evaluated relative to expected PWR response and conclusions were reached as to the appropriate conditions for the baseline ECC test. The major parameters investigated included the effects of (a) ECC system specifications including ECC system scaling, and lower plenum injection, (b) lower plenum scaling, and (c) unpowered heater rods.

The Semiscale Mod-1 system was arranged in a cold leg break configuration for all tests conducted in this series. The procedure followed in the approach to each test was: (a) the system was brought up to pressure $(2250 \mathrm{psig})$, desired flow rate, and an isothermal temperature of about $544^{\circ} \mathrm{F}$; (b) core power was increased in successive steps to about $1.6 \mathrm{MW}$; (c) core power and core flow rate were adjusted to attain the desired core differential temperature of about $66^{\circ} \mathrm{F}$ and the system was allowed to equilibrate; and (d) after the desired initial steady state conditions had been attained, the system was subjected to decompression by introducing a leak in the broken loop cold leg. As the test proceeded, ECC was injected into the intact and broken loop cold legs. During two of the tests conducted, ECC was also injected into the lower plenum. The evaluation of the test results which is summarized in the following paragraphs, led to the design and performance of the baseline ECC test (Test S-04-6) which incorporated the following parameters. (a) The high pressure injection system and accumulator flow rates were system volume scaled to provide a proper system depressurization rate and the low pressure injection system flow rate was vessel area scaled to provide proper downcomer refill characteristics. The volume of water in the accumulator was increased from the system volume scaled value to account for the oversized Mod-1 downcomer volume. (b) The lower plenum volume was system volume scaled to a PWR to provide typical core behavior and a representative system depressurization rate. (c) Four unpowered heater rods were used in the Mod-1 core to simulate the influence of control rod guide tubes and instrument thimbles in a PWR core. 
Various methods of scaling the Mod-1 ECC systems from PWR ECC systems are available and each method produces different injection parameters (flow rate, ...) which in turn can affect the overall Mod-1 system response in varying degrees. To assess the degree of these potential effects and to determine an appropriate method for scaling ECC systems in future Mod-1 testing, Tests S-04-1 and S-04-2 of the ECC baseline test series were conducted under opposite extremes in ECC scaling criteria. The two extremes of scaling, system volume scaling and downcomer volume scaling, provided both high and low injection rates for comparison purposes. Downcomer volume scaling the ECC parameters resulted in about twice the ECC flow rate as did system volume scaling the parameters. Although the results from these two'tests indicated that the method of ECC scaling did not significantly influence core behavior, it did affect the Mod-1 system conditions at the initiation of core reflood. Therefore, specifications regarding ECC scaling for future Mod-1 testing were made on the basis of obtaining end-of-refill conditions in the Mod-1 system that best represent expected end-of-refill conditions in a PWR. The controlling system variable in this respect was found to be the rate of system depressurization which was a function of the ECC injection rate. Since the system depressurization rate was the controlling factor in initiating core reflood and since the depressurization rate in turn was sensitive to the ECC injection rate, system volume scaled accumulator ECC parameters were considered preferable to downcomer volume scaled parameters because the system volume scaled ECC injection rates are properly proportioned to those of the larger systems. However, system volume scaling the accumulator liquid volume resulted in a relatively low downcomer head during the early periods of core reflood. Therefore, the conclusion was that to best simulate the expected PWR accumulator behavior with the Mod-1 system, the initial liquid volume of the Mod-1 accumulator should be increased above the system volume scaled value so as to ensure completion of vessel refill and yet maintain the system volume scaled injection rate to ensure a representative system decompression period. In addition, the low pressure injection system for future Mod-l testing was specitied to be vessel area scaled. This scaling method accounts for the distorted Mod-1 downcomer and core flow areas and was considered to provide proper downcomer refill characteristics and core flooding rates during the latter periods of core reflood.

To assess the Mod-1 downcomer hot wall effects on achieving similarity with calculated PWR system response, Test S-04-3 was conducted with lower plenum ECC injection. Lower plenum ECC injection was used in this test so as to initiate core reflood at a time consistent with PWR calculations. Although core reflood in Test S-04-3 did start at a time consistent with PWR calculations, the results produced by forcing reflood in this manner were extremely difficult to interpret, with the primary complications arising in the mechanisms controlling the downcomer liquid behavior and the subsequent core quench behavior. To program such downcomer behavior into system calculational codes would be extremely difficult and time consuming. Consequently, lower plenum injection, as a means of initiating core reflood at a time consistent with PWR calculations, was eliminated as an option for future Mod-1 testing.

Prior to the Mod-1 baseline ECC test series, the Mod-1 lower plenum was scaled from the LOFT facility and consequently was larger in length to diameter ratio and total volume than a PWR scaled lower plenum. To assess the effects that this large lower plenum has on 
the Mod-1 system response and to determine whether this distortion must be taken into account in future Mod-1 testing, Test S-04-4 was conducted with a lower plenum which had a length to diameter ratio and total fluid volume that more closely represents the PWR. scaled lower plenum, and the data obtained were compared with data from Test S-04-3 which had the LOFT scaled lower plenum. The results indicated that the Mod-1 system response was sensitive to the size of the lower plenum with the data from the test with the PWR scaled lower plenum indicating a higher core flow rate during system depressurization and also a higher system depressurization rate. Since the depressurization rate was shown to affect core reflood times and the higher core flow rate produced better core cooling prior to reflood, the PWR scaled lower plenum was specified for future Mod-1 testing.

Since $10 \%$ of the total fuel rod locations in a PWR core may be passive rod locations, two tests (Tests S-04-5 and S-04-6) were conducted to determine the sensitivity of the Mod-1 core to unpowered Mod-1 heater rods and thus determine the necessity of unpowering Mod-1 heater rods to represent passive rod locations in a PWR core. The results from these tests indicated that the Mod-1 core was definitely sensitive to unpowered rods with the primary effect observed in the tendency to shift the DNB (departure from nucleate boiling) behavior on those rod surfaces that shared a subchannel with unpowered heater rods from early DNB to delayed DNB or early DNB with rewet. The net result was that more energy was removed from the core shortly after rupture in the test with unpowered rods and consequently lower initial rod reflood temperatures were reached and thus earlier rod quench times were observed.'Therefore, unpowering Mod-1 heater rods to represent passive rod locations in a PWR was considered a necessary approach for futureMod-1 testing. 


\section{CONTENTS}

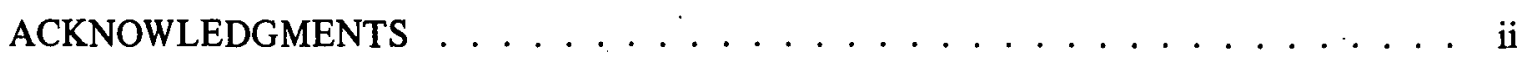

ABSTRACT $\ldots \ldots \ldots \ldots \ldots \ldots \ldots \ldots \ldots$

SUMMARY $\ldots \ldots \ldots \ldots \ldots \ldots \ldots \ldots \ldots \ldots \ldots$

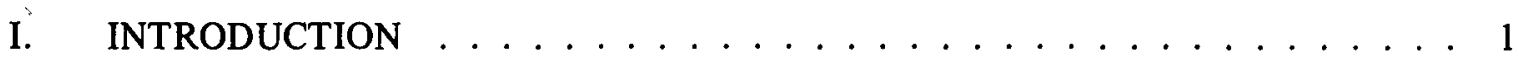

II. ECC BASELINE TEST SERIES DESIGN $\ldots \ldots \ldots \ldots \ldots$

1. TEST SERIES DESIGN RATIONALE . . . . . . . . . . . . 3

2. SERIES TEST SPECIFICATIONS ............... 5

III. TEST RESULTS . . . . . . . . . . . . . . . . . . . 9

1. EFFECTS OF ECC SYSTEM SPECIFICATIONS ON MOD-1 SYSTEM RESPONSE . . . . . . . . . . . . . . . . 9

1.1 Effects of ECC System Scaling on the Mod-1 System Response . . . . . . . . . . . . . . . . . . 9

1.2 Effects of Lower Plenum ECC Injection on the Mod-1 System Response . . . . . . . . . . . . . . 22

2. EFFECTS OF THE LOWER PLENUM VOLUME ON THE MOD-1 SYSTEM RESPONSE . . . . . . . . . . . . . . . . . . . 29

3. EFFECTS OF UNPOWERED HEATER RODS ON THE MOD-1 SYSTEM RESPONSE . . . . . . . . . . . . . . . 35

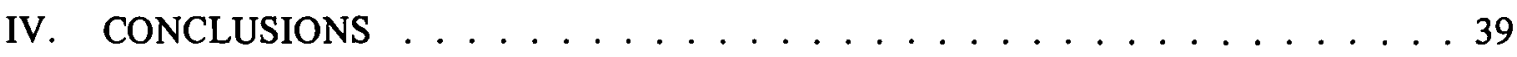

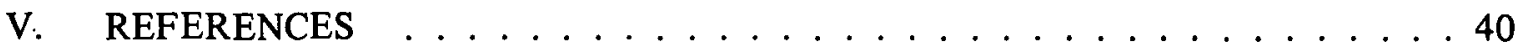

APPENDIX A - SEMISCALE MOD-1 SYSTEM DESCRIPTION

FOR THE ECC BASELINE TEST SERIES . . . . . . . . . . . . . . . . 41

A-1. REFERENCE ....................... 50

APPENDIX B - ECC SCALING METHODS FOR THE

ECC BASELINE TEST SERIES . . . . . . . . . . . . . . . . . 51 
1. ACCUMULATOR SCALING (INTACT LOOP) . . . . . . . 53

1.1 Scaling the Accumulator Liquid Volume . . . . . . . . . . . 54

1.2 Accumulator Line Resistance . . . . . . . . . . . . . . . 55

1.3 Downcomer Hot Wall Effects . . . . . . . . . . . . 58

1.4 Accumulator Gas Volume . . . . . . . . . . . . . . . . 58

1.5 Scaling Compromises for the Mod-1 Baseline

ECC Test (Test S-04-6) . . . . . . . . . . . . 660

2. SCALING THE HIGH PRESSURE INJECTION SYSTEM (HPIS)

AND THE LOW PRESSURE INJECTION SYSTEM (LPIS) . . . . . . . . . 60

2.1 System Volume Scaling .................. 61

2.2 Duwncunner Volume Scaling ............... 61

2.3 Vessel Area Scaling . . . . . . . . . . . . 62

APPENDIX C - CORE ROD CONFIGURATION FOR THE MOD-1

BASELINE ECC TEST (TEST S-04-6) . . . . . . . . . . . 63

\section{FIGURES}

1. Core power control for the baseline ECC tests . . . . . . . . . . . 8

2. Effect of system and downcomer volume scaling of ECC accumulator flow_rate evidenced in system pressure near the vessel side break - Tests S-04-1 and S-04-2 . . . . . . . . . . . . . 11

3. Volumetric flow near the core inlet reflecting differences in steam condensation rates - Tests $\mathrm{S}-04-1$ and $\mathrm{S}-04-2 \ldots \ldots . \ldots 12$

4. Cladding temperature at the 33-in. elevation on Rod B3 - Tests

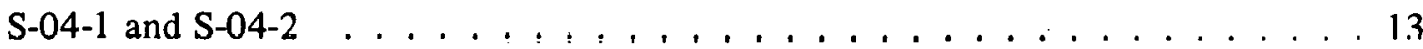

5. Cladding temperature at the 20-in. elevation on Rod E2 - Tests

S-01-1 and $\mathrm{S} 04-2 \ldots \ldots \ldots \ldots$

6. System pressure near the vessel side break, suppression tank (simulated containment) pressure, and the fluid density in the lower plenum 172 in. below the cold leg centerline - Test S-04-1 . . . . . . . 14

7. System pressure near the vessel side break, suppression tank (simulated containment) pressure, and the fluid density in the lower plenum 172 in. below the cold leg centerline - Test S-04-2 . . . . . . . 14 
8. System pressure near the vessel side break, suppression tank (simulated containment) pressure, and the fluid velocity in the downcomer 40 in. below the cold leg centerline - Test S-04-2 . . . . . . . 15

9. Collapsed downcomer liquid level - Tests S-04-1 and S-04-2 . . . . . . . 16

10. Fluid density near core inlet - Tests S-04-1 and S-04-2 . . . . . . . 17

11. Initial reflood cladding temperatures and final rod quench temperatures (5- to 30-in. elevations) - Tests S-04-1 and S-04-2 . . . . . . . . 19

12. Core reflood rate (5- to 30 -in. elevations) - Tests $\mathrm{S}-04-1$ and $\mathrm{S}-04-2 \ldots \ldots \ldots . \ldots . \ldots . \ldots 20$

13. System pressure and fluid density near the vessel side break - Test S-04-2

14. System pressure near the intact loop vessel inlet - Tests

$\mathrm{S}-04-1$ and $\mathrm{S}-04-2 \ldots \ldots \ldots 22$

15. Volumetric flow rate near the core inlet - Tests

$\mathrm{S}-04-2$ and $\mathrm{S}-04-3 \ldots \ldots \ldots . \ldots . \ldots . \ldots 23$

16. System pressure in the upper plenum - Tests

$\mathrm{S}-04-2$ and $\mathrm{S}-04-3 \ldots \ldots \ldots . \ldots 24$

17. Initial reflood cladding temperatures - Tests

$\mathrm{S}-04-2$ and $\mathrm{s}-04-3 \ldots \ldots \ldots \ldots . \ldots . \ldots . \ldots 25$

18. Fluid density near the core inlet showing effect of lower plenum ECC injection - Test $\mathrm{S}-04-3 \ldots \ldots 26$

19. Effective fluid density at various downcomer intervals - Test S-04-3 . . . . . 27

20. Core reflood rate (6- to 20 -in. elevations) - Tests S-04-2 and S-04-3 . . . . . 28

21. Cross section of vessel with lower plenum filler . . . . . . . . . . . 30

22. Vulumelric flow rate near the core inlet reflecting effect of lower plenum volume - Tests $\mathrm{S}-04-3$ and S-04-4 . . . . . . . . . . . 33

23. System pressure near the intact loop vessel inlet - Tests

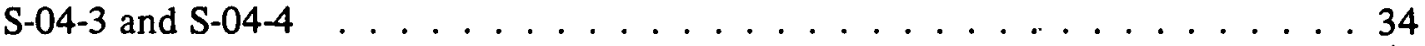

24. Semiscale Mod-1 heated core -1 ests $\mathrm{S}-04-5$ and $\mathrm{S}-04-6 \ldots . . \ldots 36$ 
25. Cladding temperature at the 25 -in. elevation on Rod D6 - Tests $\mathrm{S}-04-5$ and $\mathrm{S}-04-6 \ldots \ldots . \ldots . \ldots . \ldots 37$

26. Cladding temperature at the 14-in. elevation on Rod D2 - Tests

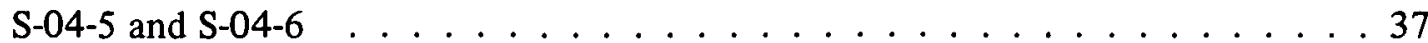

27. Initial reflood cladding temperatures - Tests S-04-5 and S-04-6 . . . . . . 38

A-1. Semiscale Mod-1 system configuration for the baseline ECC test series . . . . . . . . . . . . . . . . . . . . 44

A-2. Vessel cross section and core layout . . . . . . . . . . . . 45

A-3. Semiscale Mod-1 electric heater rod . . . . . . . . . . . . . . . 46

A-4. Semiscale Mod-1 vessel with core . . . . . . . . . . . . . . 47

A-5. Semiscale Mod-1 heater rod axial power distribution . . . . . . . . . 48

A-6. Semiscale Mod-1 heater core, plan view showing instrumentation . . . . . . . . 49

C-1. Typical $15 \times 15$ PWR rod array assembly showing passive rod locations ................... 65

C-2. Core heater configuration for ECC baseline - Test S-04-6 . . . . . . . . 66

\section{TABLES}

I. ECC Related Parameters for Baseline ECC Test Series . . . . . . . . . . . 6

II. Summary of Select Test Parameters and Results . . . . . . . . . . . . . . 10

III. Summary of Midcore Cladding Temperature Behavior in Tests $\mathrm{S}-04-3$ and $\mathrm{S}-04-4 \ldots \ldots . \ldots . \ldots . \ldots . \ldots . \ldots$ 


\section{SEMISCALE MOD-1 SYSTEM RESPONSE DURING THE ECC BASELINE TEST SERIES (DESIGN OF THE MOD-1 BASELINE ECC TEST)}

\section{INTRODUCTION}

The Semiscale Mod-1 experimental program conducted by EG\&G Idaho, Inc. is part of the overall U.S. Nuclear Regulatory Commission (NRC) and Energy Research and Development Administration sponsored research and development program to investigate the behavior of the pressurized water reactor (PWR) system during a hypothesized loss-of-coolant accident (LOCA). The Semiscale Mod-1 program is intended to provide transient thermal-hydraulic data from a simulated LOCA using a small-scale experimental nonnuclear system. The Semiscale Mod-1 program is a major contributor of experiment data that provide a means of evaluating the adequacy of the overall system analytical models as well as the models of the individual system components. Selected experimental data produced by this program will also be used to aid other Energy Research and Development Administration-Nuclear Regulatory Commission sponsored experimental programs, such as the Loss-of-Fluid-Test (LOFT) Program [1], in optimizing test series, selecting test parameters, and evaluating test results.

The Semiscale Mod-1 tests are performed with an experimental system that simulates the principal physical features of a nuclear plant but which is much smaller in volume. Nuclear heating is simulated in the tests by a core composed of an array of electrically heated rods. The core is contained in a pressure vessel which also includes a downcomer, lower plenum, and upper plenum. The system piping is arranged in a 1-1/2-loop configuration with the intact loop containing an active steam generator and pump, and with the broken loop containing passive simulators for the steam generator and pump.

The haseline ECC test series was the fourth group of tests conducted in the Semiscale Mod-1 experimental program and was the first group of tests designed to study the integral blowdown-reflood response of the Semiscale system. The primary objective of this test series was to provide a test which would serve as a baseline for future ECC related Semiscale Mod-1 tests. The appropriate conditions for this baseline test were determined through an evaluation of the sensitivity of the Mod-1 system response, particularly the system conditions at. the initiation of core reflood, to changes in parameters that strongly influence ECC related behavior. The major parameters investigated included the effects of (a) ECC system specifications including system scaling, and lower plenum ECC injection, (b) lower plenum scaling, and (c) unpowered Mod-1 heater rods.

This report specifies the baseline ECC test to be used in comparison with subsequent Mod-1 tests and presents the evaluation which led to determination of the appropriate baseline ECC conditions. The evaluation presented is predominately based on differential comparisons of data from two or more tests and shows the influence on system behavior of 
the major parameters investigated. The analyses of the results from the baseline test have been reported in Reference 2 .

Section II of this report describes the ECC related parameters evaluated during this test series and those specifications which were incorporated into the Mod-1 baseline ECC test. Also discussed are the specific tests conducted for this evaluation. Results from the analysis of test data are presented in Section III. Appendix A contains a description of the Semiscale system configuration for the baseline ECC tests series, Appendix B discusses the ECC system scaling methods used in specifying ECC system parameters, and Appendix C presents the criterion for selection of unpowered heater rods in the Mod-1 core. 


\section{ECC BASELINE TEST SERIES DESIGN}

The rationale used in the design of the baseline ECC test series that culminated in the baseline ECC test is discussed in the initial section. The specifications which describe the major parameters for the tests of the series follow.

\section{TEST SERIES DESIGN RATIONALE}

The major objective of the baseline ECC test series was to provide a test that would serve as a baseline for comparison with future Semiscale Mod-1 ECC related tests. This objective was accomplished by designing a test using the results from a series of tests which investigated the sensitivity of the Mod-1 system response to several parameters that strongly influence ECC related phenomena. Three specific areas investigated were (a) ECC system specifications including ECC system scaling, and lower plenum ECC injection, (b) lower plenum scaling, and (c) unpowered Mod-1 heater rods.

The scaling of ECC system flow rates and injected accumulator water volumes was investigated because of the large influence these parameters can have on the resulting system response. The magnitude of the ECC flow rates can influence the condensation rates occurring within the system and therefore can influence the system depressurization rate, the direction and magnitude of the flow within the system, the downcomer refill behavior and subsequently the core flow and heat transfer during reflood. The volume of water which is initially available for injection from the accumulator tank is particularly important in determining the retill characteristics of the downcomer.

Several different methods were considered to be appropriate for scaling ECC system flow rates and injected accumulator water volumes from a PWR to the Semiscale system. Of these several methods, two were chosen for experimental investigations on the basis that one method, designated system volume scaling, would provide injection rates that are properly scaled to larger systems whereas the other method, designated downcomer volume scaling, would produce relatively large injection rates and the two methods combined would provide a wide range of injection rates for a system sensitivity analysis. Further details on these methods and their application to the Mod-1 system are presented in Appendix B.

An investigation of the use of lower plenum ECC injection to provide typical core reflood initiation times was also conducted. The time of initiation of core reflood in the Mod-1 system is delayed in comparison with the calculated reflood initiation time in a PWR due to the delay in ECC delivery to the lower plenum that occurs as a result of the Semiscale downcomer countercurrent flow and hot wall effect [3]. A later reflood initiation time may cause the core temperatures at reflood initiation to be somewhat higher which would result in higher peak reflood temperatures and longer quench times. Therefore, a test 
was specified which included a short period of ECC injection directly in to the lower plenum so as to fill the lower plenum and a sufficient portion of the downcomer during the downcomer hot wall portion of the test such that core reflood would begin at the same time as the calculated core reflood time for a PWR.

The second major ECC related parameter investigated in the ECC baseline test series was the influence of lower plenum scaling. The Semiscale Mod-1 system is scaled from the LOFT[1] facility and consequently the volumes and dimensions of various system components do not correspond precisely to the PWR scaled values. In particular, the volume of the Mod-1 lower plenum is about a factor of two larger than the PWR scaled volume and the ratio of length to diameter is about 3.5 times larger than the PWR value. Since the lower plenum communicates directly with the core and downcomer, the phenomena occurring within the lower plenum can strongly influence the core and downcomer behavior. The scaling of the physical size, volume and dimensions, of the lower plenum would be expected, therefore, to influence the core flow behavior and the quality and velocity of the fluid in the downcomer as well as the amount of fluid that is required to initiate core reflood. The effect on system response of lower plenum scaling was, therefore, investigated to determine the proper lower plenum size to be used for the baseline ECC test and future Mod-1 tests.

The presence of control rod guide tubes and instrument thimbles in a PWR fuel rod bundle influences the local subchannel fluid behavior and consequently the local fuel rod heat transfer. The effect of these unheated, relatively cold rods would be to improve the local heat transfer and thereby reduce the average core temperatures during the refill and reflood periods. These reduced average core temperatures could increase the effectiveness of the injected ECC in cooling and quenching the core. Therefore, the effect of unheated rods on the core and system response was investigated in two Semiscale Mod-1 tests.

The influence of the ECC related parameters on the Mod-1 system behavior was investigated by conducting six tests. An evaluation of the test results is presented in Section III. This evaluation led to the design and performance of the baseline ECC test (Test S-04-6) which incorporated the following parameters. (a) The high pressure injection system (HPIS) and accumulator flow rates were system volume scaled to provide proper condensation related phenomena and the low pressure injection system (LPIS) flow rate was vessel area scaled to provide proper downcomer refill characteristics during the latter periods of core reflood. The volume of water in the accumulator was increased from the system volume scaled value to account for the oversized Mod-1 downcomer volume. (b) The lower plenum was scaled to a PWR to provide typical core behavior. (c) Four unpowered heater rods were used in the Mod-1 core to simulate the influence of control rod guide tubes and instrument thimbles in a PWR core. Injection into the lower plenum to provide typical reflood initiation times was not used in the baseline test because of the complex downcomer phenomena and subsequent core behavior that occur as a result of this injection. 


\section{SERIES TEST SPECIFICATIONS}

The baseline ECC test series included six tests that were conducted under similar operating conditions. Pertinent information describing the ECC related parameters that were employed and evaluated in this test series is summarized in Table I. Tests S-04-1 through S-04-3 were conducted primarily to determine the sensitivity of the Mod-1 system response, particularly the sensitivity of system conditions at the initiation of reflood, to changes in ECC specifications. Test S-04-1 was conducted with the ECC injection parameters system volume scaled. The ECC injection parameters for Test S-04-2 and S-04-3 were downcomer volume scaled. In addition, Test S-04-3 included ECC injection into the vessel lower plenum to simulate the proper time of reflood initiation in a PWR. Test S-04-4 was essentially a repeat of Test S-04-3 with the exception of the reduced lower plenum volume and length to diameter ratio. The lower plenum volume for Test S- $04-4$ was only $48 \%$ of the lower plenum volume for Tests S-04-1 through S-04-3 and the length to diameter ratio resembled more closely that of a PWR. Tests S-04-5 and S-04-6 were specifically designed to investigate the effect of unpowered rods on core and system response. All 40 rods were powered for Test S-04-5 whereas Rods C3, F3, D5 and F6 were left unpowered for Test S-04-6 to simulate the control rod guide tubes and instrument thimbles in a typical PWR fuel assembly. The lower plenum volume for Tests S-04-5 and S-04-6 was the same reduced lower plenum volume used for Test S-04-4.

With the exception of Test S-04-6, all tests in this series were conducted with a flat radial power profile. The power density at the high power zone of the heater rods was about $11.5 \mathrm{~kW} / \mathrm{ft}$. For Test S-04-6, Rods D-4, E4, and E5 were operated at a $5 \%$ higher peak power density $(12.1 \mathrm{~kW} / \mathrm{ft})$ than the remaining 33 rods to simulate the radial power profile near a control rod guide tube in a PWR fuel assembly. The total power supplied to the core varied for the tests between 1.44 and $1.59 \mathrm{MW}$ depending on the number of powered rods. The core power control for the tests is shown in Figure 1.

The test sequence for the integral blowdown-reflood experiments was essentially the same for all tests. Warmup to the initial test conditions was accomplished with the core heater rods. The system fluid was circulated through the intact loop and vessel at a rate sufficient to establish the desired core differential temperature. Heatup of the broken loop piping was accomplished with bypass lines which served to allow temporary circulation through the broken loop. Once the initial conditions were established and the system had reached equilihrium, the tests were initiated by breaking rupture discs in both the vessel inlet side and vessel outlet side of the broken loop. ECC injection began when the system pressure at the injection location fell to a preset value. The ECC injection rates themselves were controlled by adjusting the hydraulic resistance of the injection line prior to each test. 
TABLE I

ECC RELATED PARAMETERS FOR BASELINE ECC TEST SERIES

\begin{tabular}{|c|c|c|c|c|c|c|}
\hline & \multicolumn{6}{|c|}{ Test } \\
\hline & S-04-1 & S-04-2 & $\underline{S-04-3}$ & $\underline{5-04-4}$ & $\underline{S-04-5}$ & S-04-6 \\
\hline \multicolumn{7}{|l|}{ ECC Injection Scaling } \\
\hline \multicolumn{7}{|l|}{ Intact loop accumula:or } \\
\hline Liquid volume ( $\mathrm{ft} \bar{i}$ i & 2.55 & 4.61 & 3.57 & $3.5 ?$ & 3.10 & 2.90 \\
\hline Actuation pressure (Fsia) & 545 & $61) 4$ & 620 & 550 & 608 & 607 \\
\hline Injection rate (gpm) & 25 & 42 & 42.2 & 42 & 23 & 23 \\
\hline \multicolumn{7}{|l|}{ Intact loop LPIS } \\
\hline Actuation pressure (fsia) & 208 & 196 & 186 & 150 & 212 & 212 \\
\hline Injectior rate (gp $n)$ & 2.7 & 5 & 6 & 6 & 4.7 & 4.7 \\
\hline \multicolumn{7}{|l|}{ Broken loof accumulator } \\
\hline Liquid velume $\left(\mathrm{ft}^{2}\right)$ & & 1.23 & 1.12 & 1.12 & 0.58 & 0.58 \\
\hline Injection rate (gpm) & 8 & $: 4.9$ & NA & 14.8 & 9 & 7.8 \\
\hline Actuation pressure (psia) & 425 & 435 & 587 & 550 & 612 & 612 \\
\hline \multicolumn{7}{|l|}{ Broken loof LPIS } \\
\hline Actuation pressure (psia) & 57 & $\measuredangle 0$ & 68 & 162 & 117. & 212 \\
\hline Injection rate (gpm) & 1 & 1.7 & 1.4 & 1.8 & 1.2 & 1.2 \\
\hline
\end{tabular}


TABLE I (continued)

\begin{tabular}{|c|c|c|c|c|c|c|}
\hline \multirow{3}{*}{ Lower Plenum ECC Injection. } & \multicolumn{6}{|c|}{ Test } \\
\hline & \multirow[t]{2}{*}{$S-04-1$} & \multirow[t]{2}{*}{$5-04-2$} & \multirow[t]{2}{*}{$\underline{s-04-3}$} & \multirow[t]{2}{*}{ S-04-4 } & \multirow[t]{2}{*}{$\underline{S-04-5}$} & \multirow[t]{2}{*}{$\underline{S-04-6}$} \\
\hline & & & & & & \\
\hline Lower plenum accumulator & none & none & & & none & none \\
\hline $\begin{array}{l}\text { Irijection start } \\
\text { time (sec) }\end{array}$ & & & 38 & 39 & & \\
\hline $\begin{array}{l}\text { Injection stop } \\
\text { time }(\mathrm{sec})\end{array}$ & & & 53 & 53 & & \\
\hline Liquid volume $\left(\mathrm{ft}^{3}\right)$ & & & 1.48 & 1.48 & & \\
\hline Injection rate $(\mathrm{gpm})$ & & & 47 & 47 & & \\
\hline \multicolumn{7}{|l|}{ Lower Plenum Volume } \\
\hline Lower plenum volume $\left(\mathrm{ft}^{3}\right)$ & 0.80 & 0.80 & 0.80 & 0.38 & 0.38 & 0.38 \\
\hline \multicolumn{7}{|l|}{ Unpowered Rods } \\
\hline $\begin{array}{l}\text { Number of core heater } \\
\text { rods powered }\end{array}$ & 38 & 38 & 39 & 37 & 40 & 36 \\
\hline
\end{tabular}




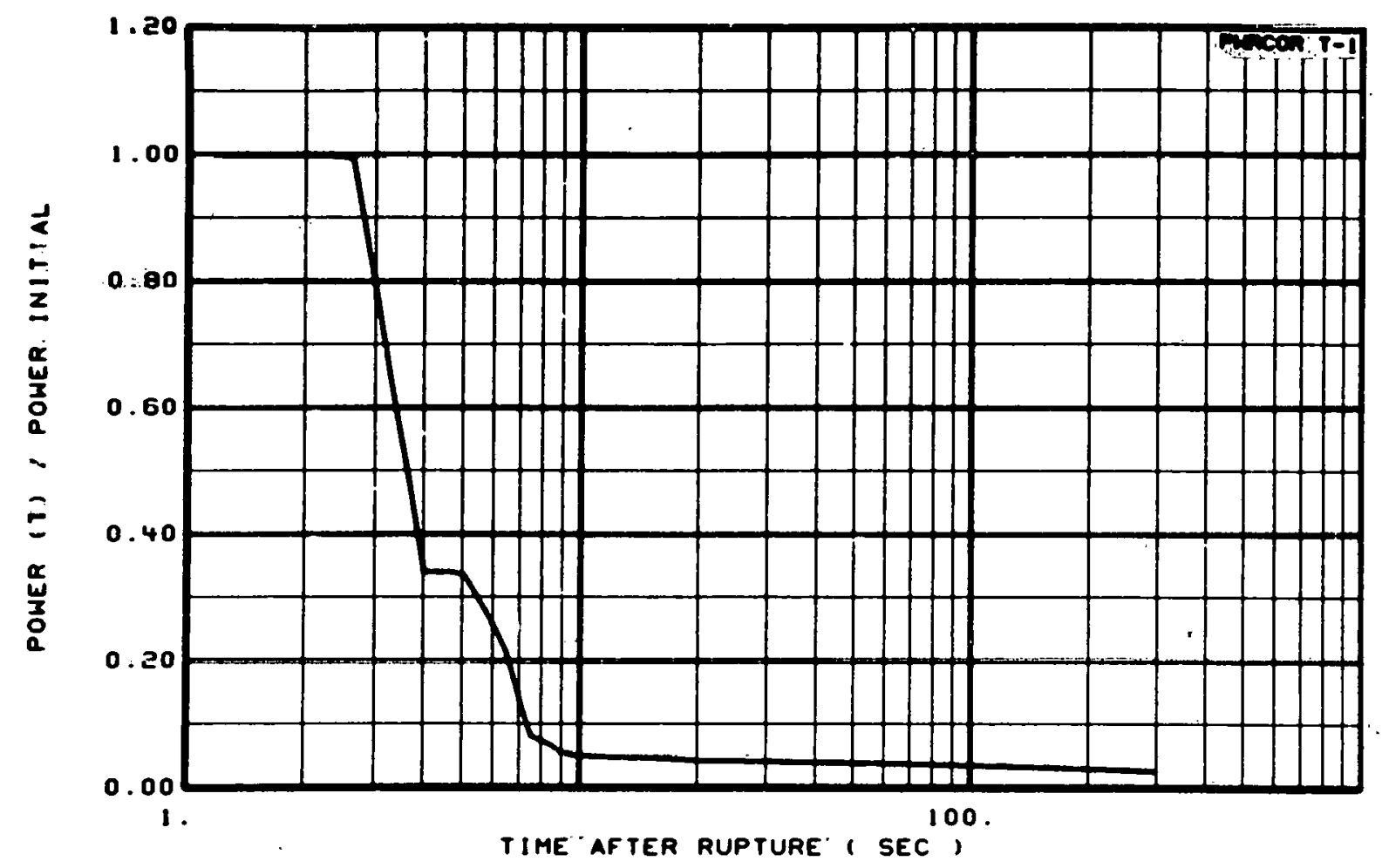

Fig. 1 Core power control for the baseline ECC tests. 


\section{TEST RESULTS}

The following sections present an evaluation of the thermal-hydraulic response of the Mod-1 system during the ECC baseline test series with emphasis placed on the ECC related phenomena discussed in Section II. The first section discusses the influence that different ECC specifications have on the system response and includes an evaluation of two ECC system scaling methods and also an evaluation of lower plenum accumulator ECC injection. The second section discusses the sensitivity of the Mod-1 system response to a reduction in lower plenum fluid volume and length to diameter ratio and the third section discusses the effects on core behavior resulting from unpowered Mod-1 heater rods. To aid in comparing the system behavior of the tests conducted during the ECC baseline test series, Table II presents a summary of select test parameters and results for each test. The system configuration used in these tests is described in Appendix A. References 4 through 8 present the data obtained from the tests.

\section{EFFECTS OF ECC SYSTEM SPECIFICATIONS ON MOD-1 SYSTEM RESPONSE}

The effects on the Mod-1 system response due to different ECC specifications were evaluated using results from Tests S-04-1, S-04-2, and S-04-3. A discussion of the influence of ECC system scaling methods on system response is presented first and is followed by a discussion of the influence of lower plenum accumulator ECC injection on system response.

\subsection{Effects of ECC System Scaling on the Mod-1 System Response}

Various methods of scaling the Mod-1 ECC systems from a PWR system are available and each method produces different injection parameters (flow rate, . . ) which in turn can affect the overall Mod-1 system response in varying degrees. To assess the degree of these potential effects on the Mod-1 system response, two tests (Tests S-04-1 and S-04-2) were conducted under opposite extremes in ECC scaling criteria. (Appendix B discusses the considerations involved for these two scaling extremes.)

Other than for slight differences in core power, Tests S-04-1 and S-04-2 were conducted under the same conditions except that in Test S-04-1 the Mod-1 ECC parameters were system volume scaled whereas in Test S-04-2 the parameters were downcomer volume scaled as described in Appendix B. These scaling techniques resulted in ECC injection rates for Test S-04-1 which were about half the magnitude of the ECC injection rates for Test S-04-2 (Table II). The predominate influence on system response resulting from the different scaling methods was found to be the intact loop accumulator water volume and injection rate, with no detectable influence from the broken loop ECC systems or the intact loop high pressure injection system (HPIS) observed. Therefore, the following discussion is 


\section{TABLE II}

\section{SUMMARY OF SELECT TEST PARAMETERS AND RESULTS}

\begin{tabular}{|c|c|c|c|c|c|c|}
\hline \multirow{3}{*}{ Core (flat radial power profile) [a] } & \multicolumn{6}{|c|}{ Test } \\
\hline & $S-04-1$ & $5-04-2$ & $5=04-3$ & S- $-04-4$ & $S-04-5$ & $S-04-6$ \\
\hline & \\
\hline Initial Power (I:W) $[\mathrm{l}]$ & 1.47 & 1.54 & 1.57 & 1.53 & 1.59 & 1.44 \\
\hline Rod Peak Power Densities $\left(\frac{\mathrm{kW}}{\mathrm{ft}}\right)$ & 11.1 & 11.7 & 11.5 & 11.9 & 11.4 & $12.1 / 11.4$ \\
\hline Unoowered Heater Rods $[c]$ & Rods 45 and 07 & Rods 45 and $D 7$ & Rod E4 & Rods $\mathrm{D1}, \mathrm{DB}$, and $\mathrm{H} 4$ & $-\cdots$ & $\operatorname{Rods} \mathrm{C3}, \mathrm{DE}, \mathrm{F3}$, and $\mathrm{F6}$ \\
\hline System pressure (psia) & 2263 & 2263 & 2258 & 2263 & 2267 & 2252 \\
\hline $\begin{array}{l}\text { Intact loop cold leg } \\
\text { fluid temperature }\left({ }^{\circ} \mathrm{F}\right)\end{array}$ & 542 & 542 & 543 & 541 & 541 & 543 \\
\hline $\begin{array}{l}\text { Intact loop cold leg } \\
\text { flow rate }(\mathrm{gpm})\end{array}$ & 143 & 145 & 150 & 143 & 158 & 141 \\
\hline $\begin{array}{l}\text { Simulated containment } \\
\text { pressure (Dsia) }\end{array}$ & 37 & 37 & 38 & 34 & 35 & 35 \\
\hline \multicolumn{7}{|l|}{ ECC intact loop and ressel\}) } \\
\hline \multicolumn{7}{|l|}{ Accumulatur } \\
\hline Location $[d]$ & $\mathrm{al}$ & CL & $C L, L P$ & $\mathrm{CL}, \mathrm{LP}$ & $\mathrm{CL}$ & $\mathrm{CL}$ \\
\hline Initial water volume $\left(\mathrm{ft}^{3}\right)$ & 2.55 & 4.61 & $3.57,1.48$ & $3.57,1.48$ & 3.1 & 2.9 \\
\hline Water injection began (sec) & 17 & 17 & 16,38 & 16,39 & 17 & 17 \\
\hline Average water flow rate (gpm) & 25 & 42 & 42,47 & 42,47 & 23 & 23 \\
\hline Nitrogen injection began (sec) & 62 & 69 & 53 & 53 & 77 & 69 \\
\hline Nitrogen injection ended (sec) & 98 & [e] & [e] & $n 2$ & 95 & 95 \\
\hline \multicolumn{7}{|l|}{ LP19 } \\
\hline Kätë (gpow) & 2.1 & 3 & 6 & 5 & 4.1 & 4.1 \\
\hline Injection began (sec) & 25 & 25 & 25 & 25 & 25 & 25 \\
\hline System depressururization tíne (seç). & 48 & 42 & 40 & 40 & $4 i$ & $4 \dot{2}$ \\
\hline Lower plenum refill began (sec) & 38 & 32 & 41 & 42 & 31 & 34 \\
\hline Core reflood began (sec) & 61 & 55 & 45 & 45 & 61 & 57 \\
\hline Lower plenum volume $[f]$ & LUFI & Lur I & Lorl & PWK & PWK & PWR \\
\hline \multicolumn{7}{|c|}{$\begin{array}{l}\text { [a] In Test } S-04-6 \text { one of the high power rods was unpowered. In a PWR, the active rods adjacent to a passive rod have a slightly higher power; therefore, } \\
\text { to simulate this effect, the power to the three remaining high power rods was increased slightly corresponding to the } 12.1 \mathrm{~kW} / \mathrm{ft} \text { peak power density. }\end{array}$} \\
\hline \multicolumn{7}{|c|}{ [b] The initial powers reported here are slightly different from those reported previously and are based on later analysis of test resuits. } \\
\hline \multicolumn{7}{|c|}{ [c] In all tests except Test $5-04-6$ these unpowered rods resulted due to inadvertent failures prior to rupture. } \\
\hline \multicolumn{7}{|c|}{ [d] CL denotes cold leq in.lection and $C L$. $L P$ denotes both cold leg and lower plenum ECC inilection. } \\
\hline \multicolumn{7}{|c|}{ [e] In Tests $S-04-2$ and $S-04-3$ the nitrogen injection continued after $100 \mathrm{sec}$ at a rate of 20 to $30 \mathrm{gpm}$. } \\
\hline \multicolumn{7}{|c|}{ [f] The Mod-1 lower plenum volume was scaled, depending upon the test, after either the LOF or PHR facility. } \\
\hline
\end{tabular}

limited primarily to the effects of the intact loop accumulator parameters on system response with brief mention of the intact loop low pressure injection system (LPIS) and its effects on system response.

The depressurization rate of the Mod-1 systems was designed to be similar to that in larger systems by scaling the simulated break area with specially designed break nozzles. However, the accumulator ECC injection rate was also found to affect the system 
depressurization rate[3]. This effect is illustrated in Figure 2 which compares the pressure histories in Tests S-04-1 and S-04-2 which had accumulator ECC injection rates of 25 and $42 \mathrm{gpm}$, respectively. Shortly after the accumulators began injecting water into the cold leg (about $17 \mathrm{sec}$ after rupture), the depressurization rate of the system in Test S-04-2 was greater than the depressurization rate in Test S-04-1. The larger depressurization rate in Test S-04-2 was caused by a higher rate of steam condensation in the vessel inlet annulus which resulted from the higher accumulator liquid injection rate. The dependence of the system depressurization upon ECC injection is discussed in Reference 3 and the effect of the system depressurization rate upon general system response, particularly the initiation of lower plenum refill, is discussed in the following paragraphs.

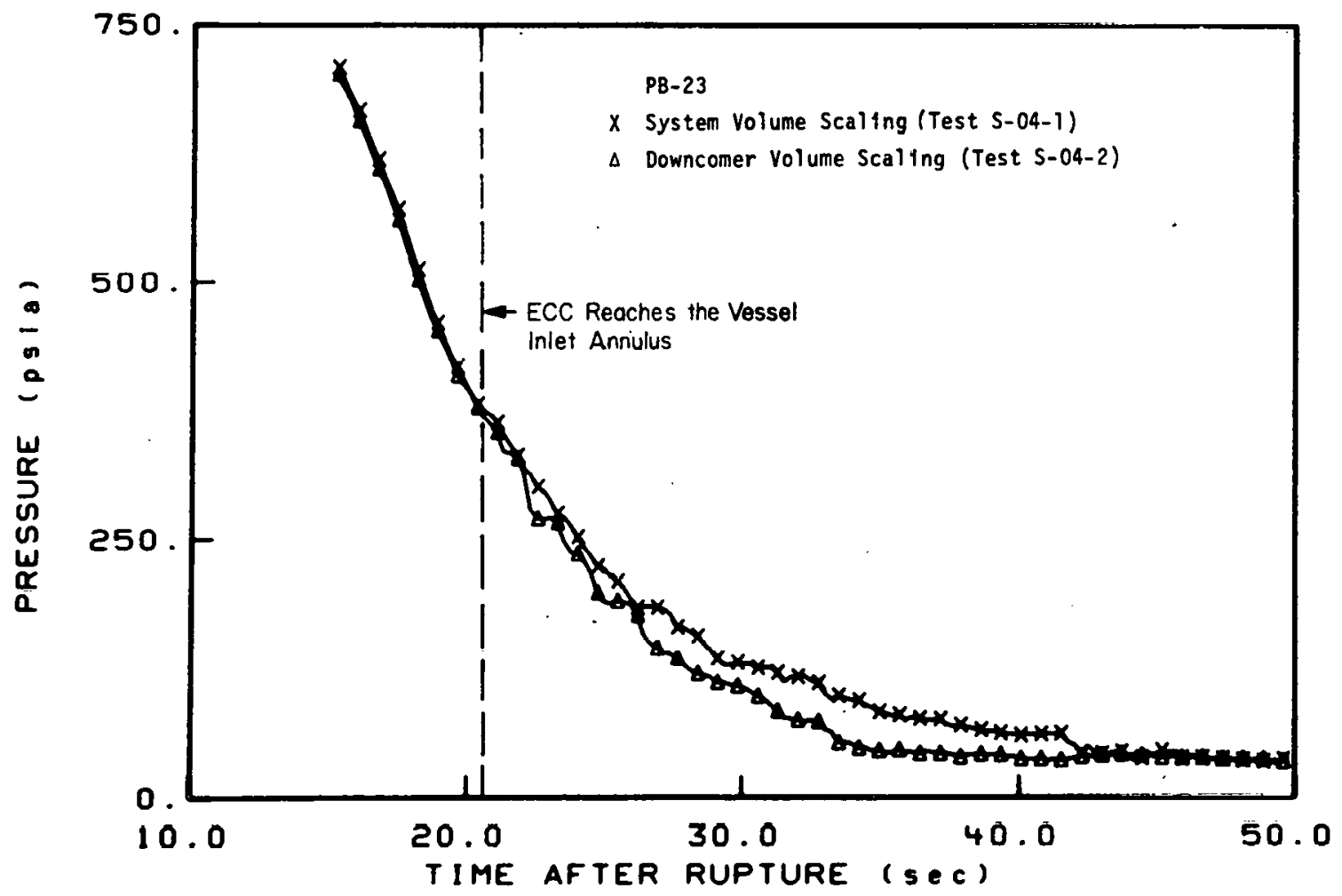

Fig. 2 Effect of system and downcomer volume scaling of ECC accumulator flow rate evidenced in system pressure near the vessel side break - Tests S-04-1 and S-0,4-2.

Differences in the steam condensation rates in the vessel inlet annulus after accumulator injection began in Tests S-04-1 and S-04-2 are reflected in the differences in core inlet volumetric flow rates shown in Figure 3. Shortly after subcooled ECC reached the inlet annulus (between 20 and $22 \mathrm{sec}$ after rupture), condensation of steam flowing up the downcomer created a localized low pressure area which caused an increase in the reversed core flow rate in each test. The higher rate of steam condensation that occurred during Test S-04-2 caused substantially more fluid to flow from the core upward toward the inlet annulus than occurred in Test S-04-1. The resulting higher core flow rate in Test S-04-2 caused better rod-to-fluid heat transfer at core elevations above the high power zone as 


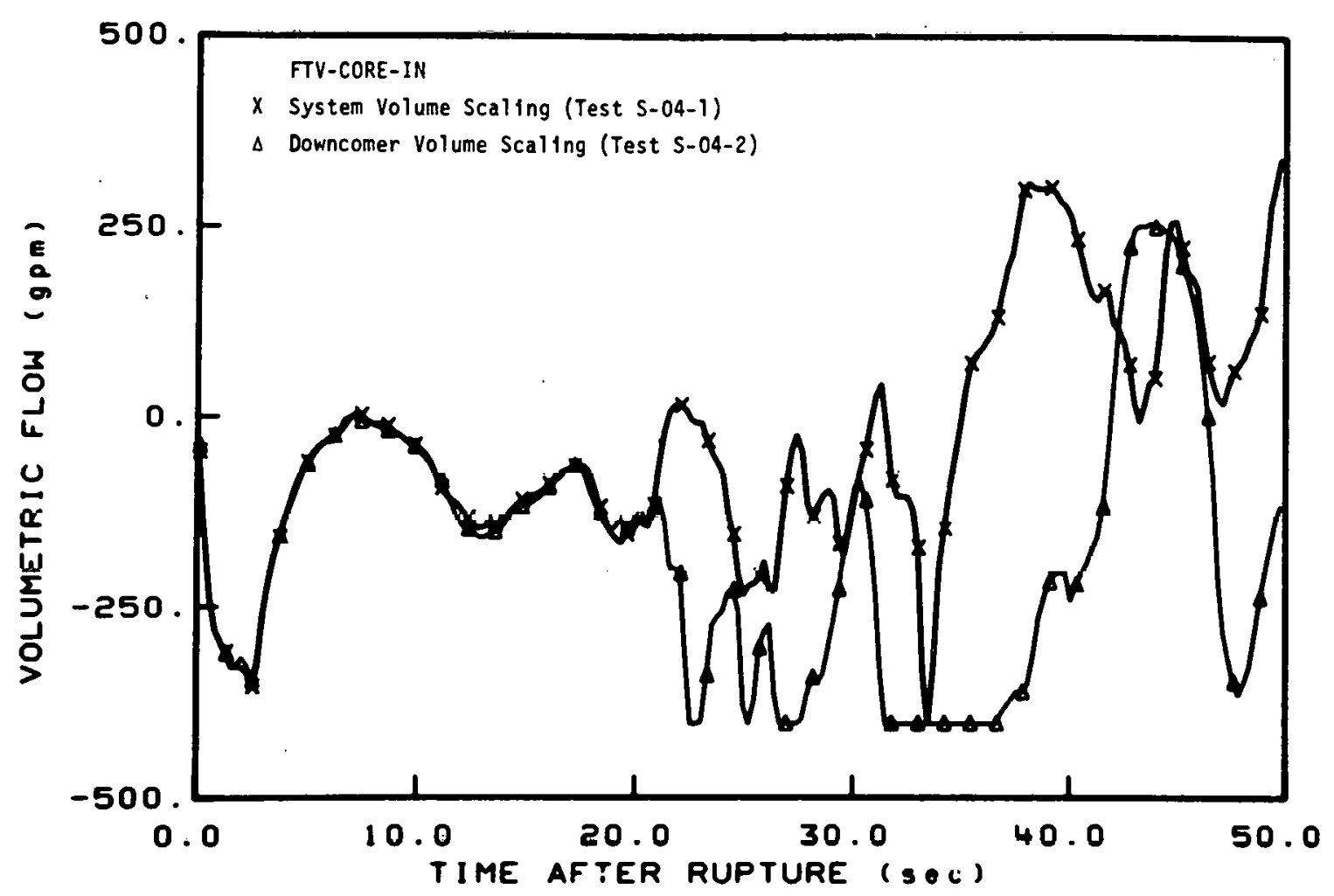

Fig. 3 Volumetric flow near the core inlet reflecting differences in steam condensation rates - Tests S-04-1 and S-04-2.

illustrated in Figure 4. However, as indicated in Figure 5, this effect was not evident at core elevations below the high power zone and is due to the slightly higher core power in Test S-04-2 (Table II) coupled with lower rod-to-tlu1d heat transfer potential as the fluid absorbed energy (increased in quality) flowing down the core. The benefits of high core flow were offset by the slightly higher core power, as reflected in the data obtained below the high power zone throughout the depressurization phase of Test S-04-2 and consequently no significant effect on the core rod temperatures below this zone due to the ECC scaling inetliuds was apparcint.

The different system depressurization rates in Tests S-04-1 and S-04-2 affected the duration of the Mod-1 downcomer countercurrent flow [3] and the time at which the downcomer hot wall delay time[3] began. The time at which the pressure near the cold leg break in Tests S-04-I and S-04-2 rcached the simulated containment pressure was 48 and $42 \mathrm{sec}$, respectively, as shown in Figures 6 and 7. These figures also indicate that the times at which the lower plenum began to refill in each test lagged the time at which the simulated containment pressure was reached by about $10 \mathrm{sec}$. This period is a reflection of the Mod-1 downcomer hot wall delay time and it appeared insensitive to the magnitude of the ECC flow rate (scaling method). The Mod-1 hot wall delay phenomenon is also evident in Figure 8 which shows the system pressure versus the fluid velocity in the downcomer at the 


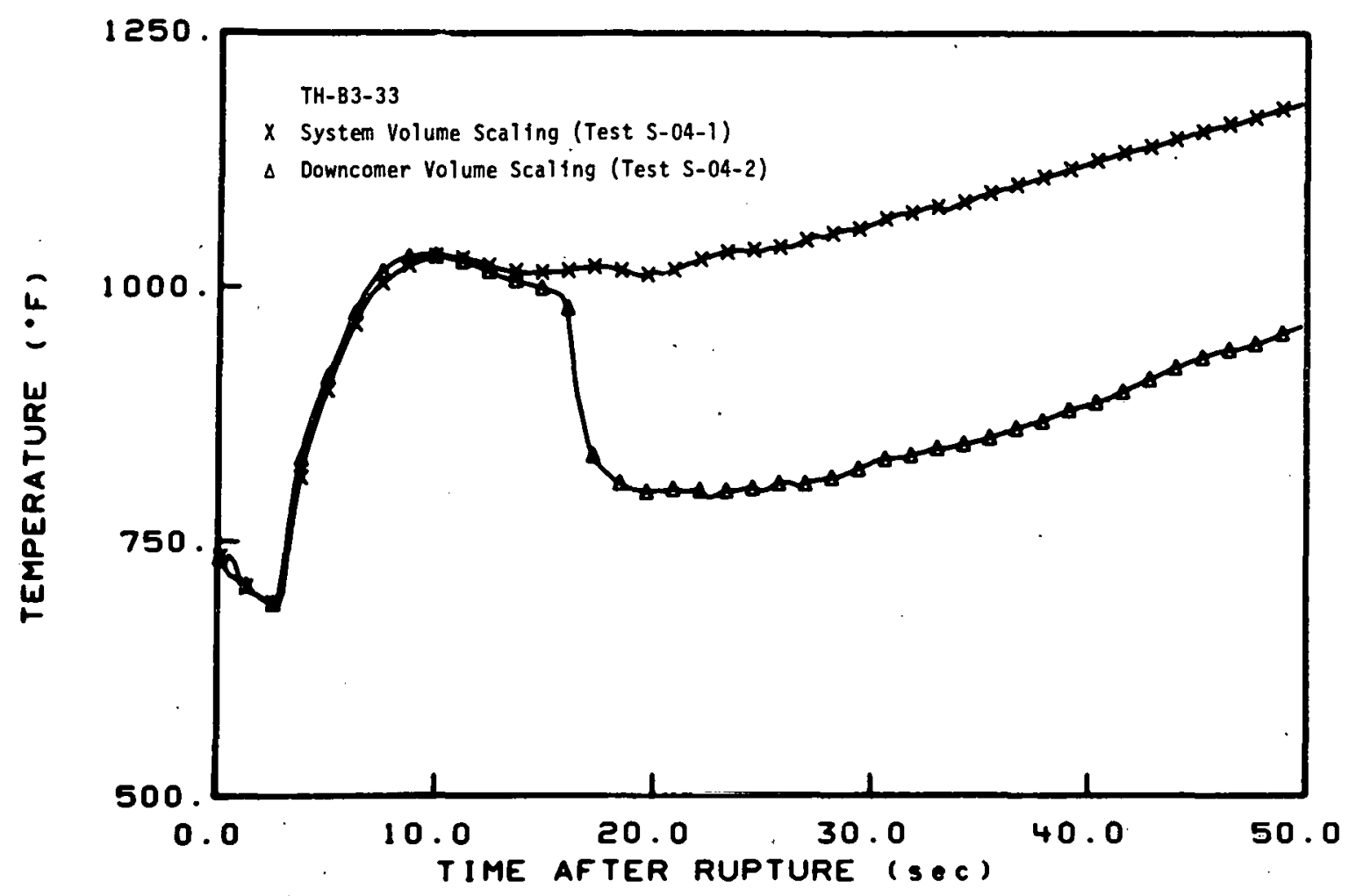

Fig. 4 Cladding temperature at the 33-in. elevation on Rod B3 - Tests S-04-1 and S-04-2.

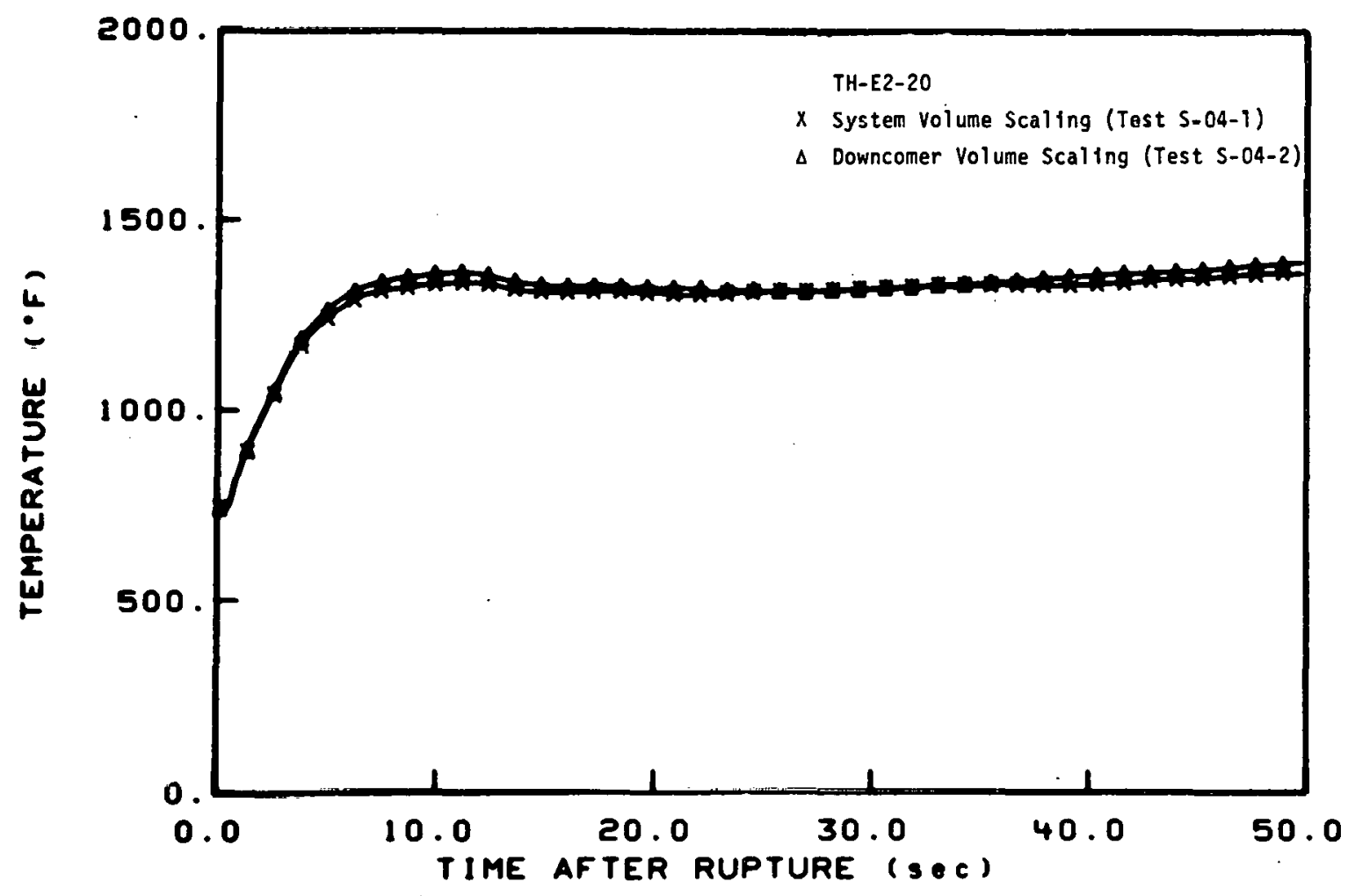

Fig. 5 Cladding temperature at the 20-in. elevation on Rod E2 - Tests S-04-1 and S-04-2. 


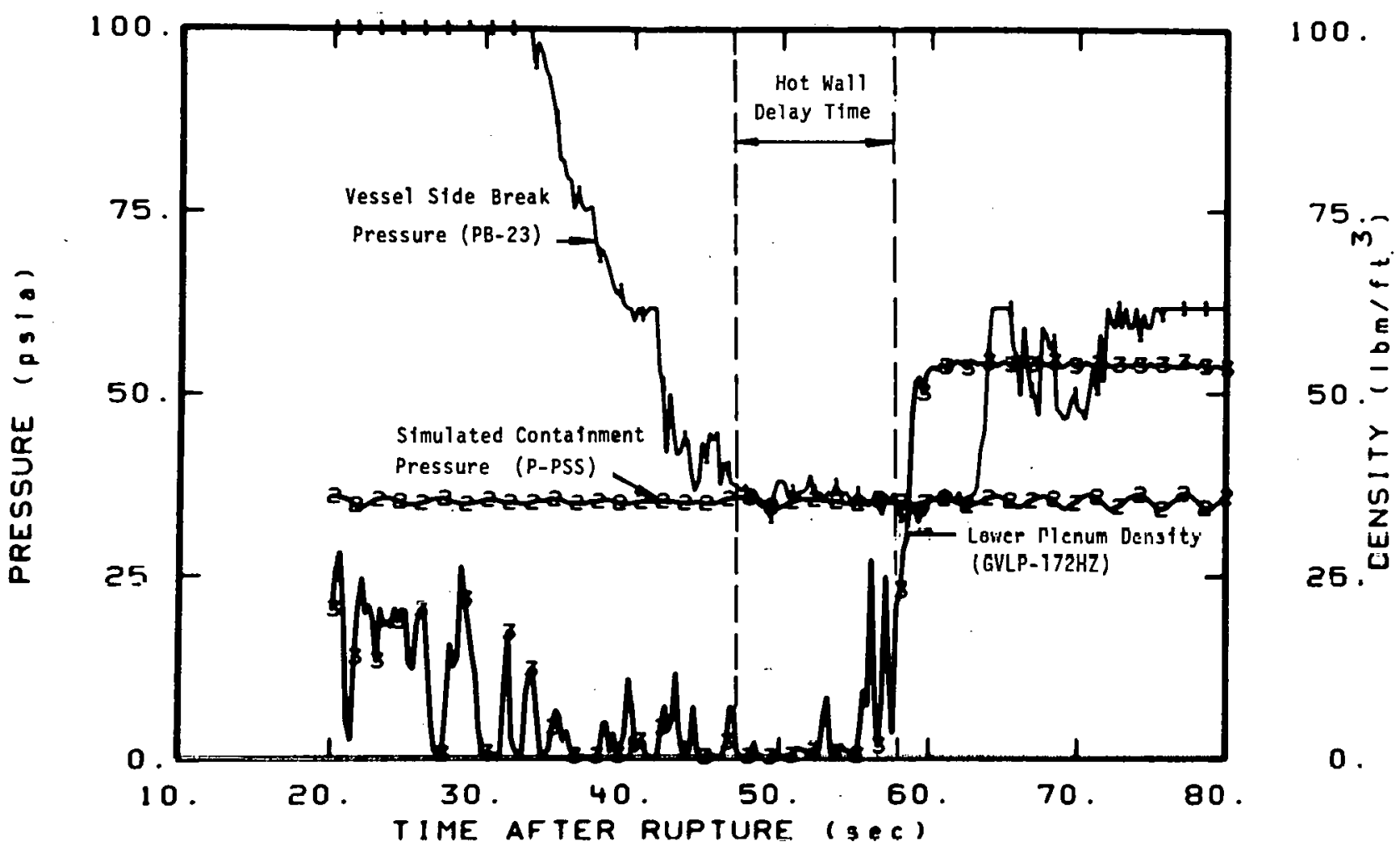

Fig. 6 System pressure near the vessel side break, suppression tank (simulated containment) pressure, and the fluid density in the lower plenum 172 in. below the cold leg centerline - Test S-04-1.

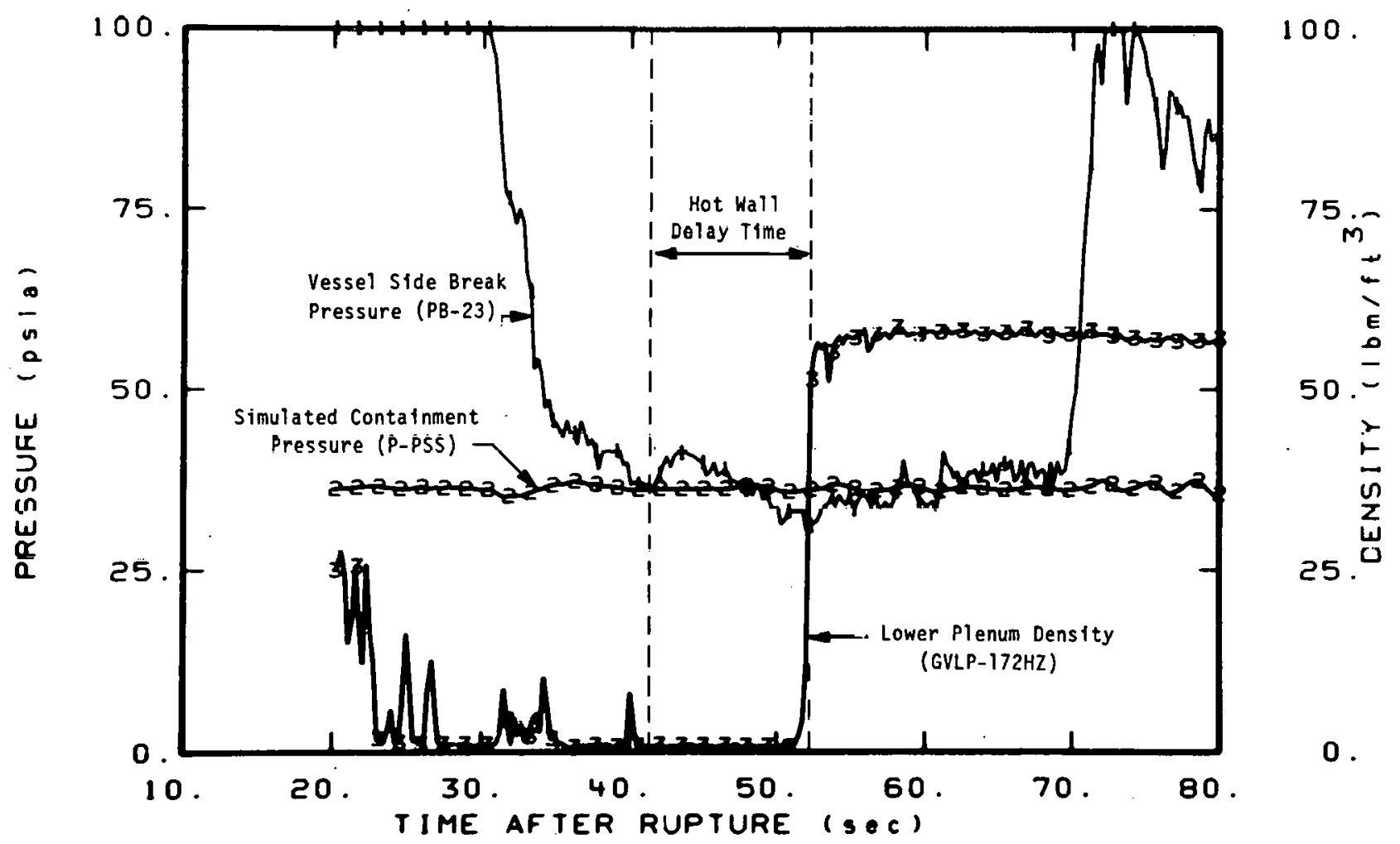

Fig. 7 System pressure near the vessel side break, suppression tank (simulated containment) pressure, and the fluid density in the lower plenum 172 in. below the cold leg centerline - Test S-04-2. 


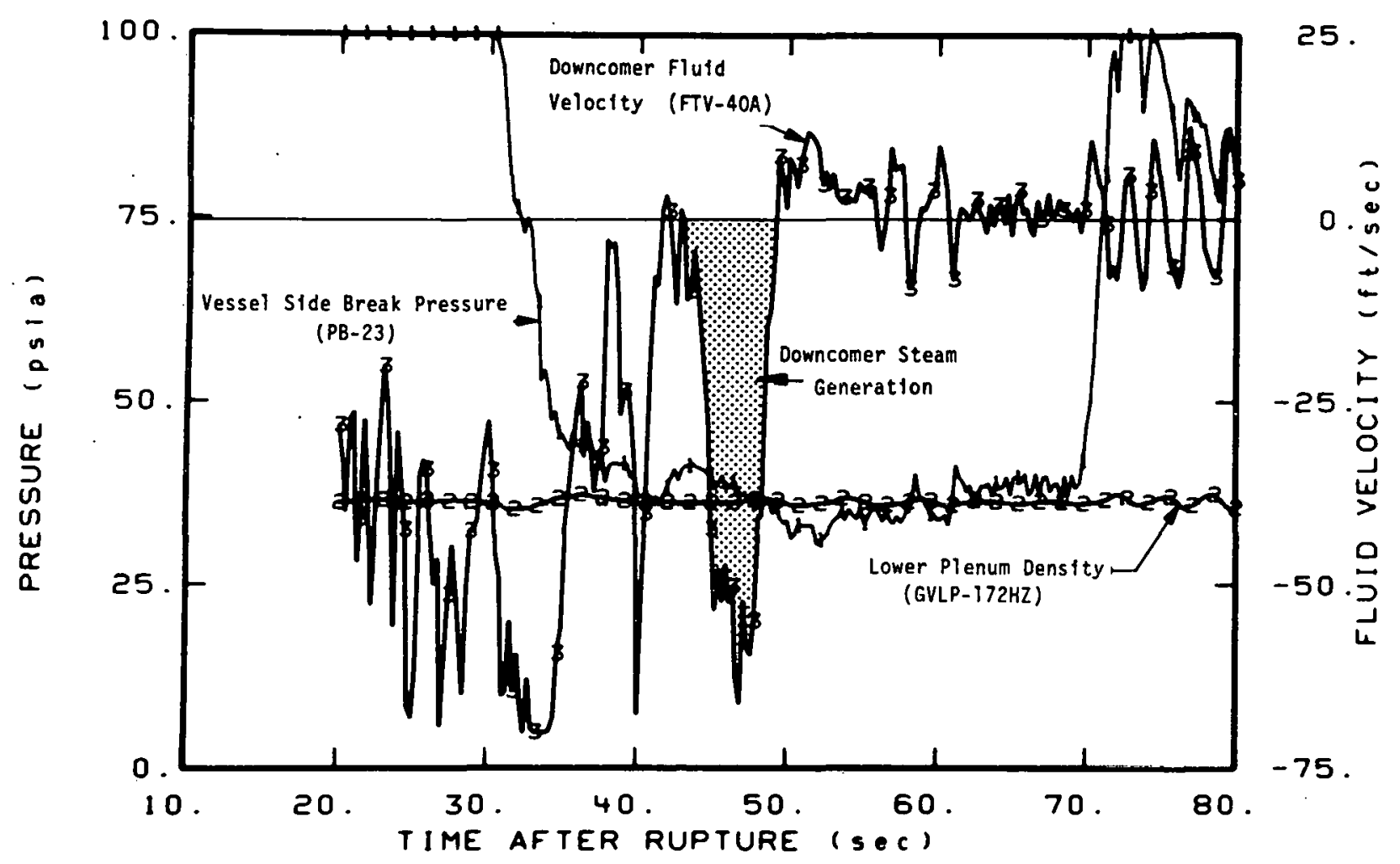

Fig. 8 System pressure near the vessel side break, suppression tank (simulated containment) pressure, and the fluid velocity in the downcomer 40 in. below the cold leg centerline - Test S-04-2.

40-in. elevation in Test S-04-2. This figure shows that when the system had reached the simulated containment pressure $(42 \mathrm{sec})$, the high velocity countercurrent flow in the downcomer diminished and a positive fluid velocity was observed at the 40-in. downcomer elevation. However, as the subcooled ECC came into contact with the hot downcomer walls, steam was generated and it began flowing up the downcomer, giving rise to the negative fluid velocity between 41 and $49 \mathrm{sec}$ and again restricting ECC from entering the lower plenum. As energy was removed from the Mod-1 downcomer walls by steam generation, the liquid head in the upper portion of the downcomer increased. As indicated in Figure 8, the ECC liquid front reached the 40-in. downcomer elevation by $49 \mathrm{sec}$ and by $52 \mathrm{sec}$ the 10 -sec hot wall delay time was over in Test S-04-2 and the lower plenum began to refill.

The different ECC scaling methods used in these tests resulted in significant differences in downcomer behavior after lower plenum refill began. Figure 9 compares the downcomer liquid level behavior under each scaling method. The ECC scaling rationale applied to Test S-04-1 did not account for any Mod-1 system scaling compromises other than the increase in ECC bypass caused by the hot wall delay phenomenon. Since the Mod-1 downcomer is disproportionately large relative to that of the scaled PWR downcomer, the accumulator ran out of water shortly after lower plenum refill began (about $58 \mathrm{sec}$ ) and did not finish filling the downcomer. As a result, a relatively low downcomer liquid level was available to drive core reflood. In Test S-04-2 however, the oversized Mod-1 downcomer volume was accounted for in the ECC scaling method and as a result the accumulator liquid was sufficient to completely fill the downcomer after lower plenum refill had started (about $52 \mathrm{sec}$ ). The effect that the different downcomer liquid levels had on the resulting core response is discussed in the following paragraphs. 


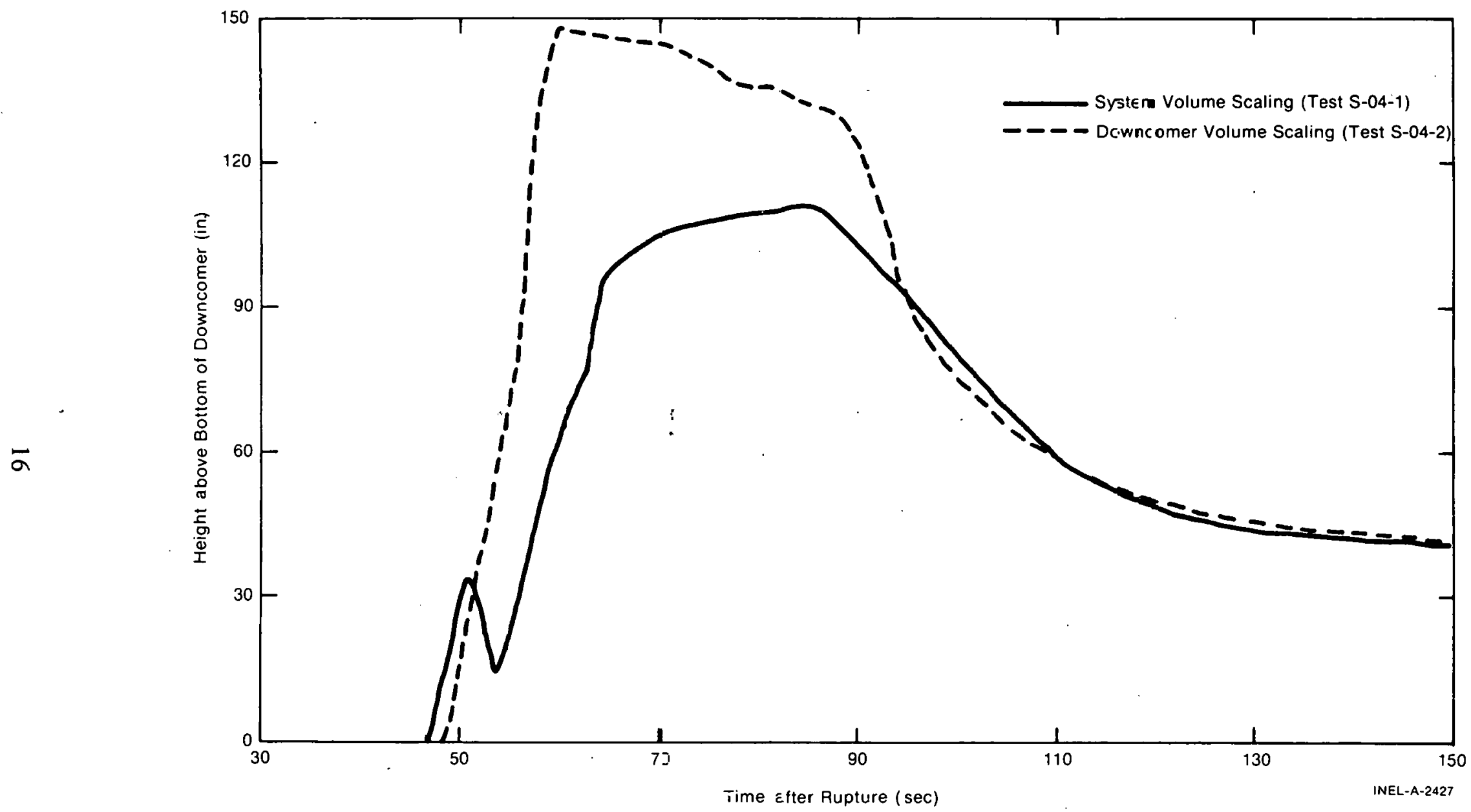

Fig. 9 Collapsed døuncomer liquid level - Tests S-04-1 and S-04-2. 
The time of core reflood initiation was found to be influenced only slightly by the method of ECC scaling. The core inlet density (used to indicate core reflood time) in Tests S-04-1 and S-04-2 is compared in Figure 10. The first indication of significant ECC liquid reaching the core inlet was at about $61 \mathrm{sec}$ in Test S-04-1 and at about $55 \mathrm{sec}$ in Test S-04-2. Although the ECC injection rate in Test S-04-1 was about half of what it was in Test S-04-2, the difference in times at which lower plenum refill began (Table II) and core reflood began, (Table II and Figure 10) indicates that about $3 \mathrm{sec}$ was required to fill the lower plenum in each test. That the lower plenum refill time is the same for both tests is attributed to the fact that most of the liquid required to fill the lower plenum had accumulated in the downcomer and upper annulus during the hot wall portion of the tests. Once the hot wall delay ended, this water dropped into the lower plenum initiating core reflood. The remainder of the vessel refill was a direct function of the different scaling methods and resulted in the different downcomer liquid levels shown in Figure 9. Therefore, the difference in time required to initiate core reflood between Tests S-04-1 and S-04-2 (about $6 \mathrm{sec}$ ) was directly related to the difference in the initiation time of downcomer liquid penetration, which was a function of the time required to depressurize to the simulated containment pressure.

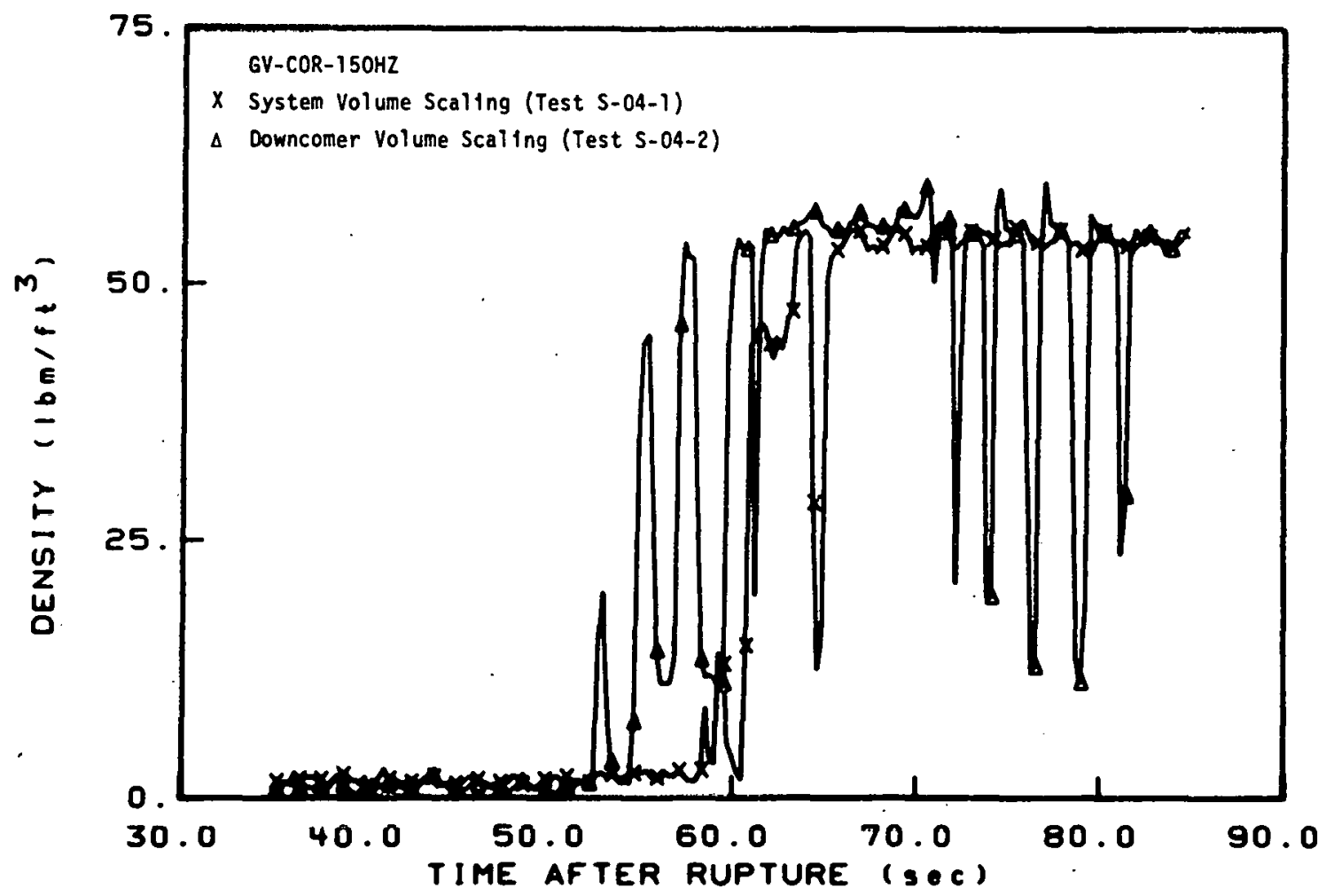

Fig. 10 Fluid density near core inlet - Tests $\$-04-1$ and $S-04-2$. 
The response of the core cladding temperaturcs during reflood was also found to be influenced only slightly by the method of ECC scaling. The initial rod reflood temperatures and final quench temperatures for selected heater rods in Tests S-04-1 and S-04-2 are compared in Figure 11 for the 5- to 30 -in. core elevations $[\mathrm{a}]$. As previously mentioned, the benefits of the higher core flow rate during system depressurization in Test S-04-2 were not evidenced in the rod temperatures below the core high power zone. This result is illustrated in Figure 11 which shows the rod temperatures just prior to reflood in each test and indicates that the rod temperatures below the 28 -in. core elevation were somewhat higher in Test S-04-2 than in Test S-04-1. Nevertheless, the difference in rod temperatures is not substantial, indicating no significant effects on initial rod reflood temperature due to the different ECC scaling methods. The quench temperatures, also shown in Figure 11, indicate further similarities in the core thermal response between Tests S-04-1 and S-04-2 as the reflood portions of the tests progressed. Finally, Figure 12 compares the corresponding quench times, and despite differences in ECC injection rates and initial downcomer driving heads, the initial core flooding rates were essentially the same in both cases.

Although the downcomer liquid levels at the initiation of core reflood differed significantly depending upon the method of scaling the ECC systems (Figure 9), this difference was only temporary and did not last long enough to substantially influence the initial core flooding rate. As indicated in Figure 9, the downcomer liquid heads began to decrease sharply in each test at about $85 \mathrm{sec}$ and soon afterward the magnitudes of the liquid heads were essentially the same inboth tests. This downcomer behavior is attributed to a mass depletion phenomenon resulting from disproportionately high heat transfer rates from the Mod-1 downcomer walls and is discussed in detail in Reference 2. The LPIS system in each test had actuated prior to the start of downcomer mass depletion (Table II) and was injecting liquid at a rate of about $2.7 \mathrm{gpm}$ in Test S-04-1 and at a rate of about $5.0 \mathrm{gpm}$ in Test S-04-2. Although the rate of LPIS flow did not appear to influence the downcomer mass depletion phenomena it does account for the differences in core flooding rate during the latter periods of the tests.

The effect on core thermal response due to the system pressurization which took place when nitrogen injection from the accumulator began was also investigated in Tests S-04-1 and S-04-2. The degree of pressurization of the system was found to be a function of the distribution of ECC liquid within the vessel and the intact loop cold leg. In Test S-04-2 the intact loop cold leg from the ECC injection port to the inlet annulus and the downcomer were full of water prior to nitrogen injection and consequently an incompressible liquid front was present from the ECC injection port to the core inlet. As a result, when nitrogen injection began and condensation ceased in the intact loop cold leg, the

[a] The data have been fit with a least squares approximation in each case and the data were chosen in an attempt to eliminate localized rod effects. These localizcd cffects were minimized by excluding data that exhibited different behavior such as delayed DNB or rod rewet during the early portion of one test but not in the other. Furthermore, only the lower half of the core is discussed since this portion of the core undergoes the most degradation in rod-to-fluid heat transfer during the test and, therefore, provides an indication of the severity of the different ECC scaling methods on the Mod-1 core response. 


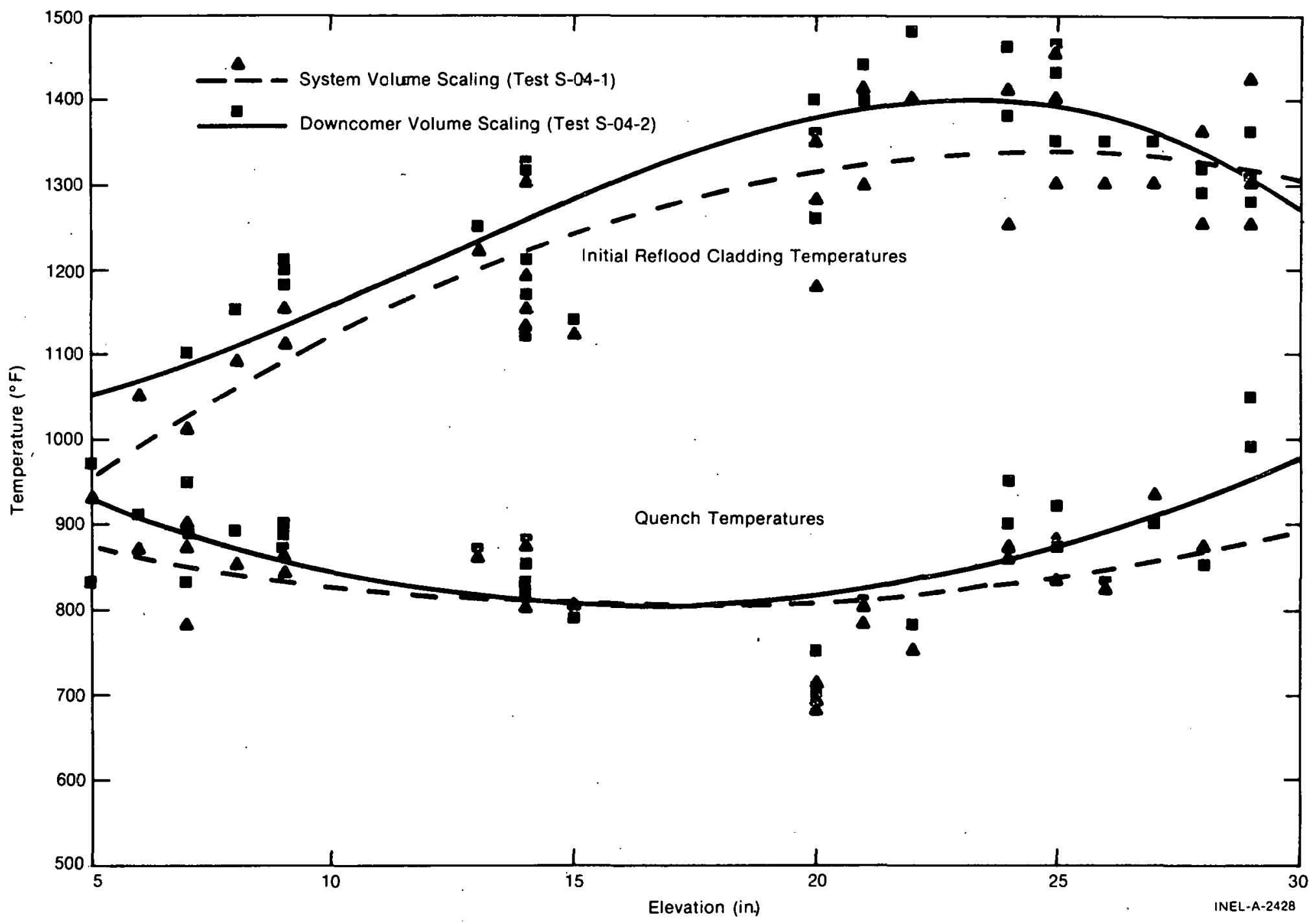

Fig. 11 Initial reflood cladding temperatures and final rod quench temperatures (5- to 30-in. elevations) - Tests S-04-1 and S-04-2. 


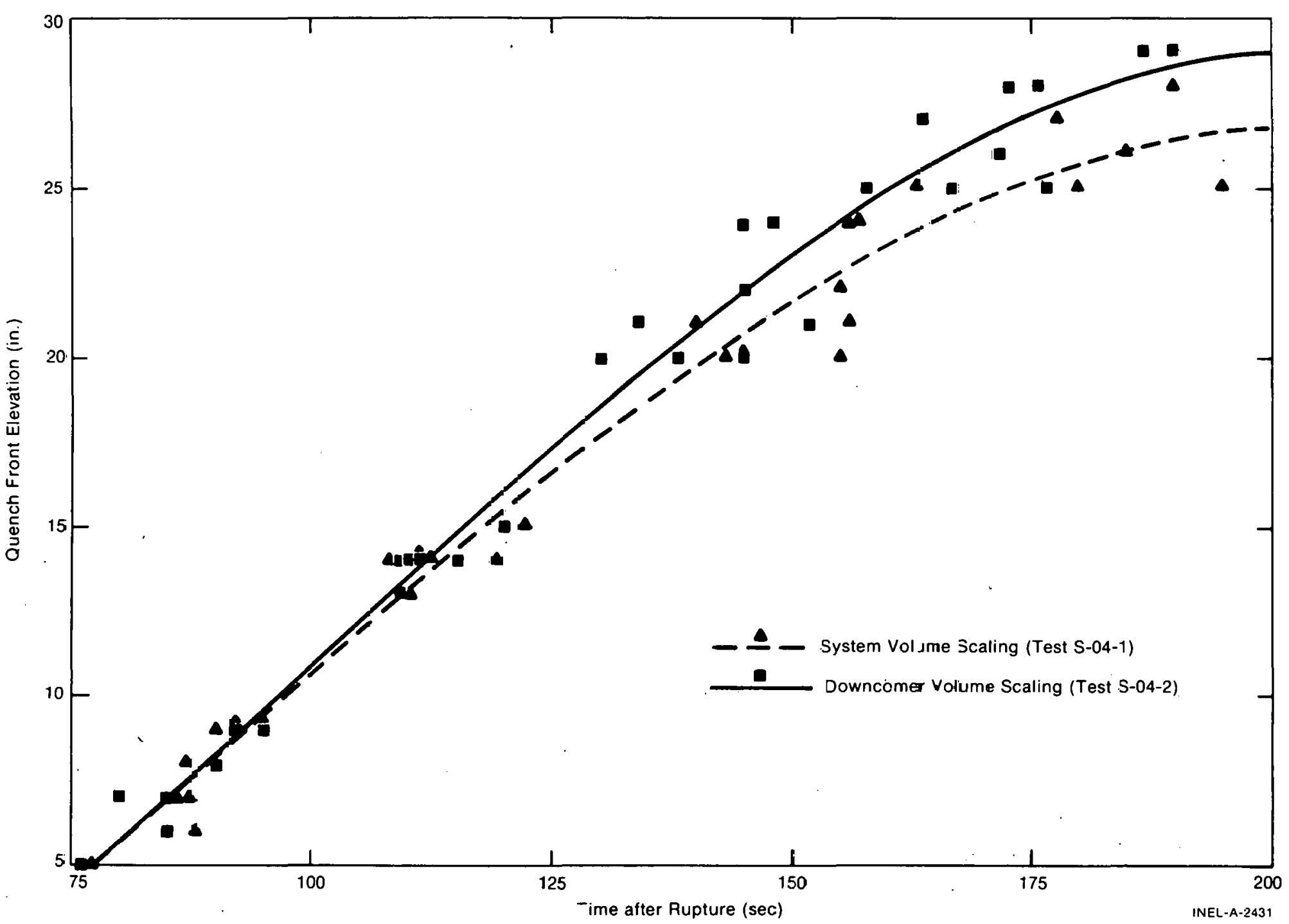

Fig. 12 Core reflood rate ( 5 - to 30-in. elevations) - Tests S-04-1 and S-0<-2 
liquid level in the core increased significantly. This surge in the core liquid level produced a high generation of steam which was suppressed from flowing through the intact loop by the existence of the liquid plug in the cold leg. The net result was a significant increase in system pressure until the liquid plug in the cold leg was passed out the break as illustrated in Figure 13 for Test S-04-2. A comparison of the system pressurization for Tests S-04-1 and S-04-2 shown in Figure 14 illustrates the effect the filled downcomer in Test S-04-2 had on the increase in system pressure. Although past analyses have established a relationship between system pressure and quench temperature [9], the higher system pressure in Test S-04-2 prior to $120 \mathrm{sec}$ did not appear to significantly affect rod quench temperatures (Figure 11).

In summary, the results from Tests S-04-1 and S-04-2 indicate that the Mod-1 core response during reflood was not significantly influenced by the method of scaling the ECC systems. However, the system conditions at the initiation of reflood were somewhat sensitive to the method of ECC system scaling, and specifications regarding ECC scaling for future Mod-1 tests were made on the basis of obtaining end-of-refill conditions in the Mod-1 system that best represent expected end-of-refill conditions in a PWR. The controlling system variable in this respect was found to be the ECC injection rate and the effect the : injection rate had on the system depressurization rate and subsequently the time to core: reflood. Since system volume scaling results in ECC injection rates that are scaled to produce typical condensation and depressurization rates, this method of scaling was specified for future Mod-1 tests, with two exceptions. Because the system volume scaled

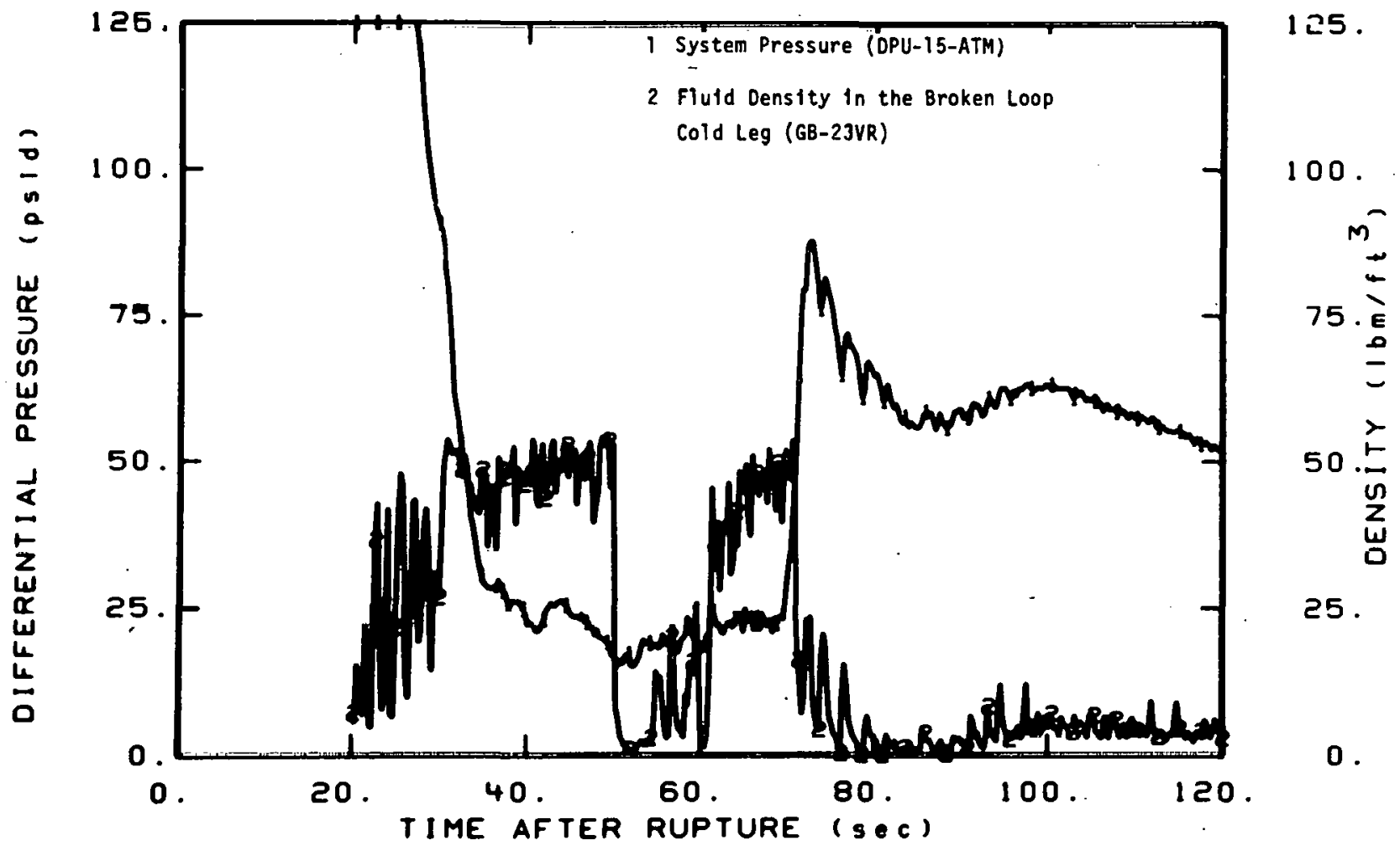

Fig. 13 System pressure and fluid density near the vessel side break - Test S-04-2. 


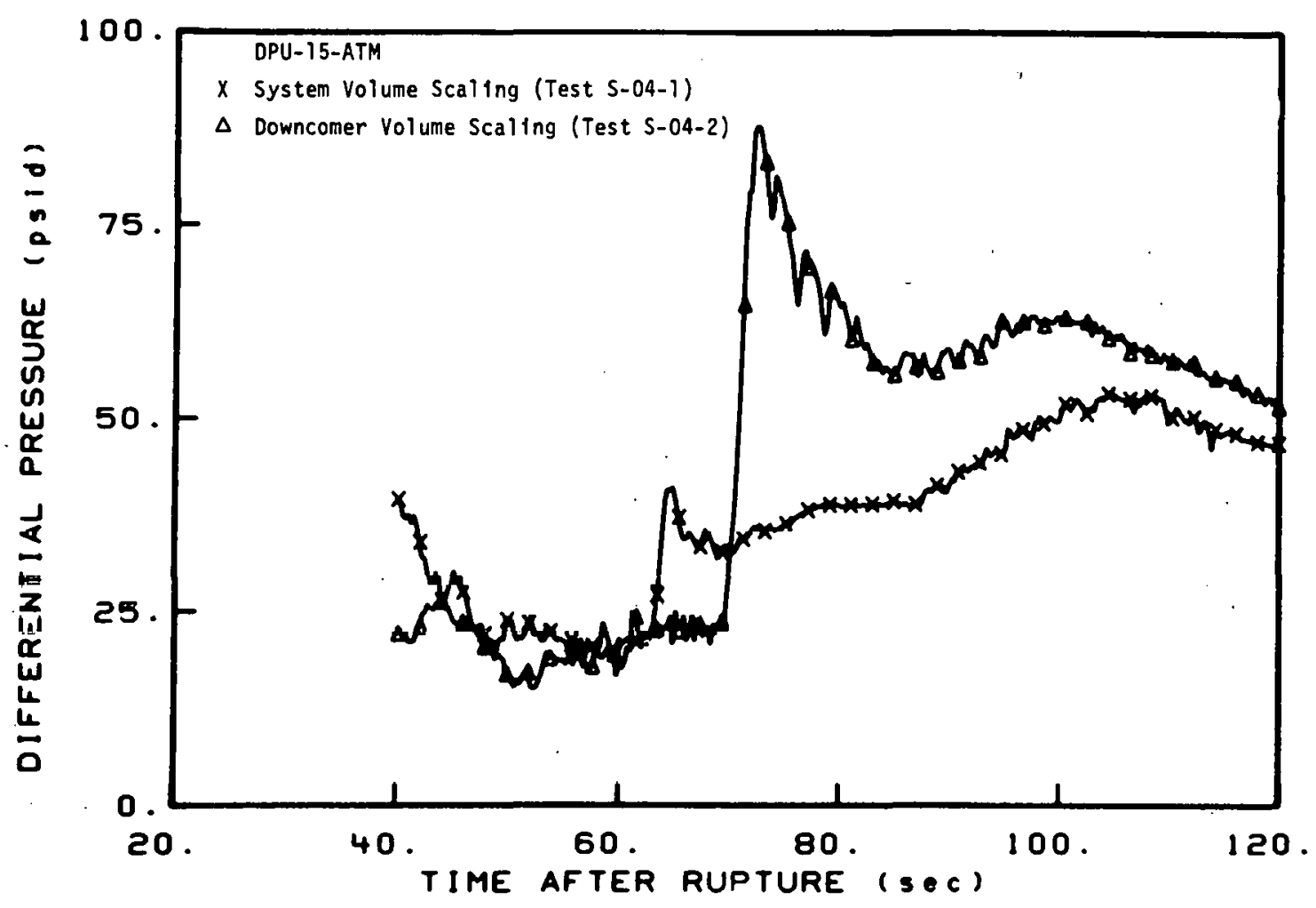

Fig. 14 System pressure near the intact loop vessel inlet - Tests S-04-1 and S-04-2. .

accumulator liquid volume resulted in a relatively low downcomer head at the initiation of core reflood, the accumulator liquid volume for future Mod-1 tests was specified to be increased to a volume greater than the scaled volume in the manner discussed in Section 1:5 of Appendix B so as to ensure completion of vessel refill. In addition, the LPIS system for future tests was specified to be vessel area scaled in the manner discussed in Section 2 of Appendix B. This method of scaling accounts for the distorted Mod-1 downcomer and core flow areas and is expected to provide proper downcomer refill characteristics and proper core flooding rates during the latter periods of core reflood.

\subsection{Effects of Lower Plenum ECC Injection on the Mod-1 System Response}

The ECC scaling methods used in Test3 S-04-1 and S-04-2 accounted for the extcnded period of ECC bypass in the Mod-1 system resulting from the downcomer hot wall delay time by increasing the liquid inventory in the accumulator in the manner discussed in Appendix B. Nevertheless, the initiation of reflood in the Mod-1 system was still delayed by about $11 \mathrm{sec}$ in Test S-04-2, relative to the calculated initiation of reflood in a PWR. Test S-04-3, therefore, was conducted in an effort to assess the effect that the delay in reflood initiation has on the subsequent system response, and to determine whether lower plenum ECC injection was a viable alternative for minimizing these effects. Calculations indicated that to initiate core reflood in the Mod-1 system at a time consistent with that expected in a PWR, lower plenum injection would have to begin at $38 \mathrm{sec}$ and end at $52 \mathrm{sec}$. The ECC 
scaling during this test was the same as that used for Test S-04-2 [a] (downcomer volume scaling) and the volume of water injected into the lower plenum was based on the criterion that the total volume injected into the system would be the same in both Tests S-04-2 and S-04-3. Therefore, the data from Test S-04-2 are used as the basis upon which the effectiveness of lower plenum ECC injection in Test S-04-3 is evaluated.

The effect of lower plenum injection was evaluated by comparing system conditions in Test S-04-3 with those in Test S-04-2. Prior to the time that ECC was injected into the lower plenum, the volumetric core flow rates in the tests were similar as shown in Figure 15 as were the system depressurization rates as shown in Figure 16. However, the rod temperature distribution at the initiation of core reflood was less severe in Test S-04-3 than in Test S-04-2 as shown in Figure 17. This variability in rod temperatures at the initiation of core reflood was not an effect of lower plenum injection but is attributed to the sensitivity of the Mod-1 system response to slight variations in initial operating conditions. The primary effect of lower plenum ECC injection, however, was to cause core reflood to take place at about $45 \mathrm{sec}$ after rupture as indicated by the core inlet fluid density shown in Figure 18. This reflood time was $10 \mathrm{sec}$ earlier than the reflood time of Test S-04-2 and is consistent with the test objective of eliminating the hot wall delay time. However, forcing core reflood in this manner resulted in data that were extremely difficult to interpret.

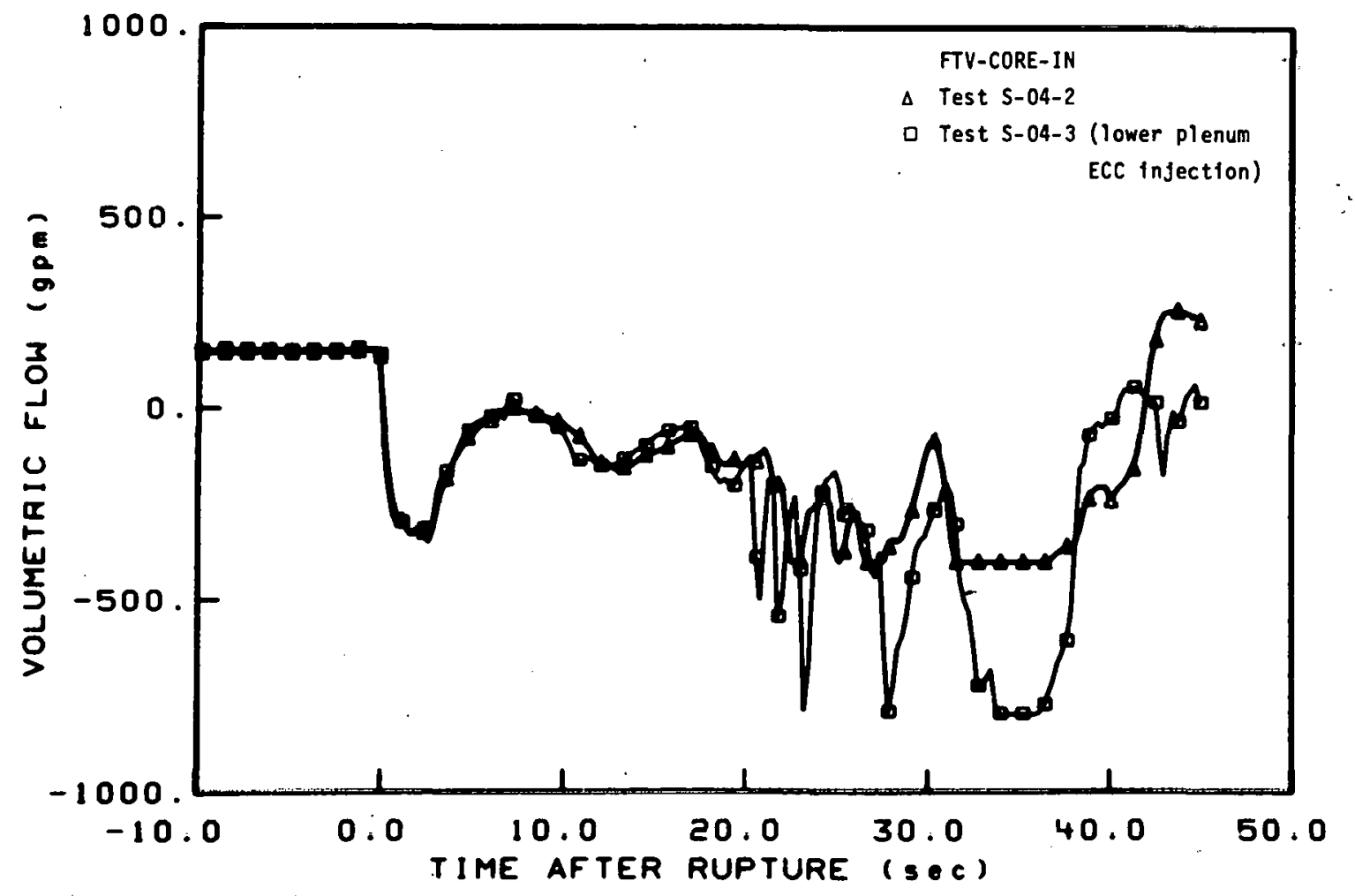

Fig. 15 Volumetric flow rate near the core inlet - Tests S-04-2 and S-04-3.

[a] Although the analysis of data from Tests S-04-1 and S-04-2 concluded system volume scaling was preferable to downcomer volume scaling, this conclusion was not reached until after Test S-04-3 had been conducted. 


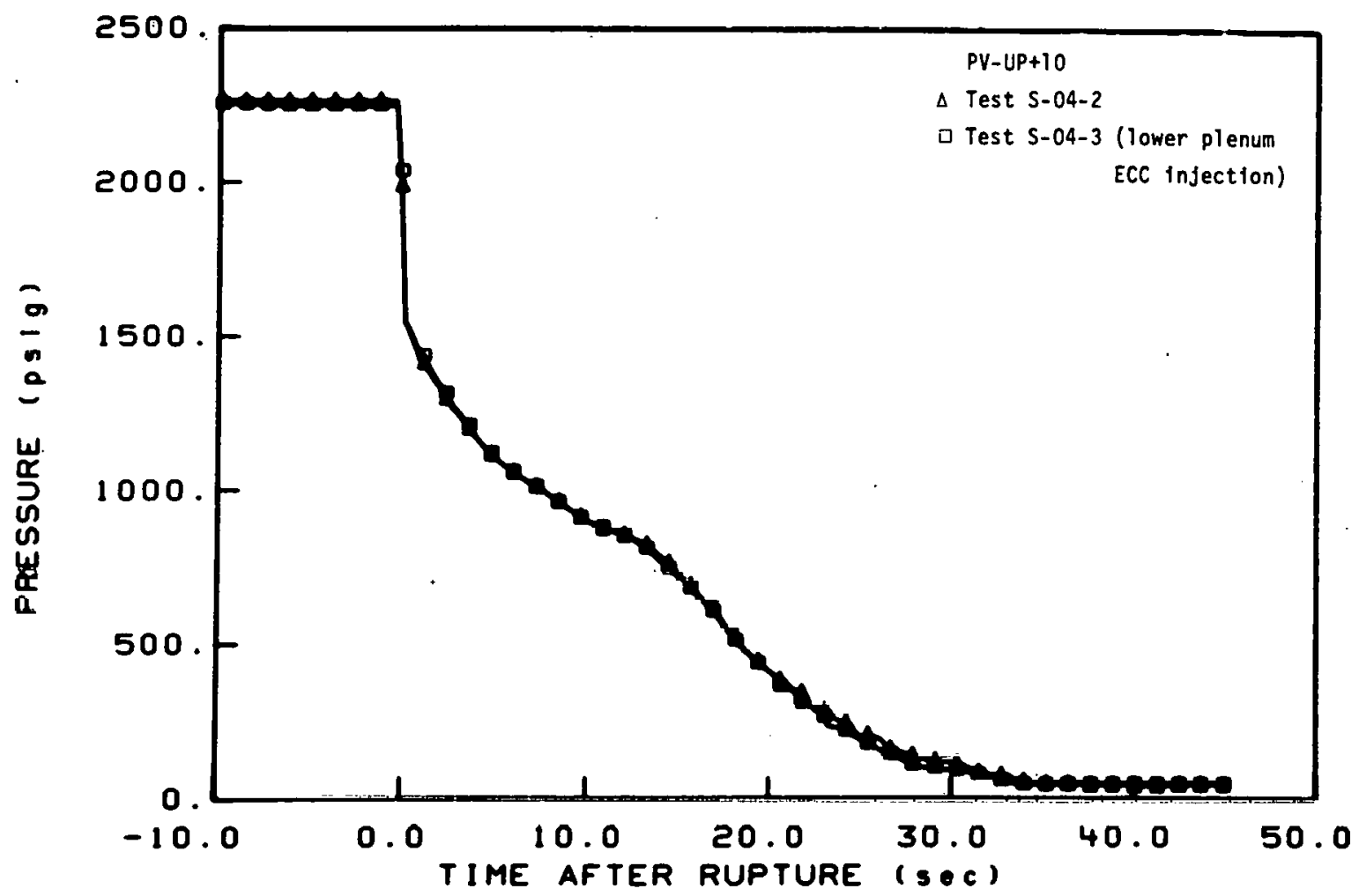

Fig. 16 System pressure in the upper plenum - Tests S-04-2 and S-04-3.

Many complications arose from injecting ECC into the lower plenum in Test S-04-3, the most important of which was the very complex nature of the mechanisms controlling the downcomer liquid level. Figure 19 shows variations in the effective downcomer density as calculated from the differential pressure measurements along the length of the downcomer. This figure indicates that the downcomer began filling from both ends at a very high rate and began depleting at a time earlier than in Tests S-04-1 or S-04-2 (Figure 9). This downcomer head behavior resulted in the random core quench behavior indicated by the data in Figure 20. This figure shows the core quench front elevation versus time for the same rod measurement locations of Figure 17 and shows that the high reflood rate in Test S-04-3 was accompanied with a much higher degree of data scatter than exhibited by the data of "lest $\mathrm{S}-04-2$.

In summary, the downcomer behavior in Test S-04-3 resulting from lower plenum injection made the data extremely complex and difficult to interpret. To calculate such behavior with system calculational codes would require development of special models that would only be required for predicting Semiscale behavior and would, therefore, decrease the reliability of the data for the purposes of computer code evaluation. Consequently, lower plenum injection, as a means of initiating core reflood at times consistent with PWR calculations, was eliminated as an option for future Mod-1 tests. 


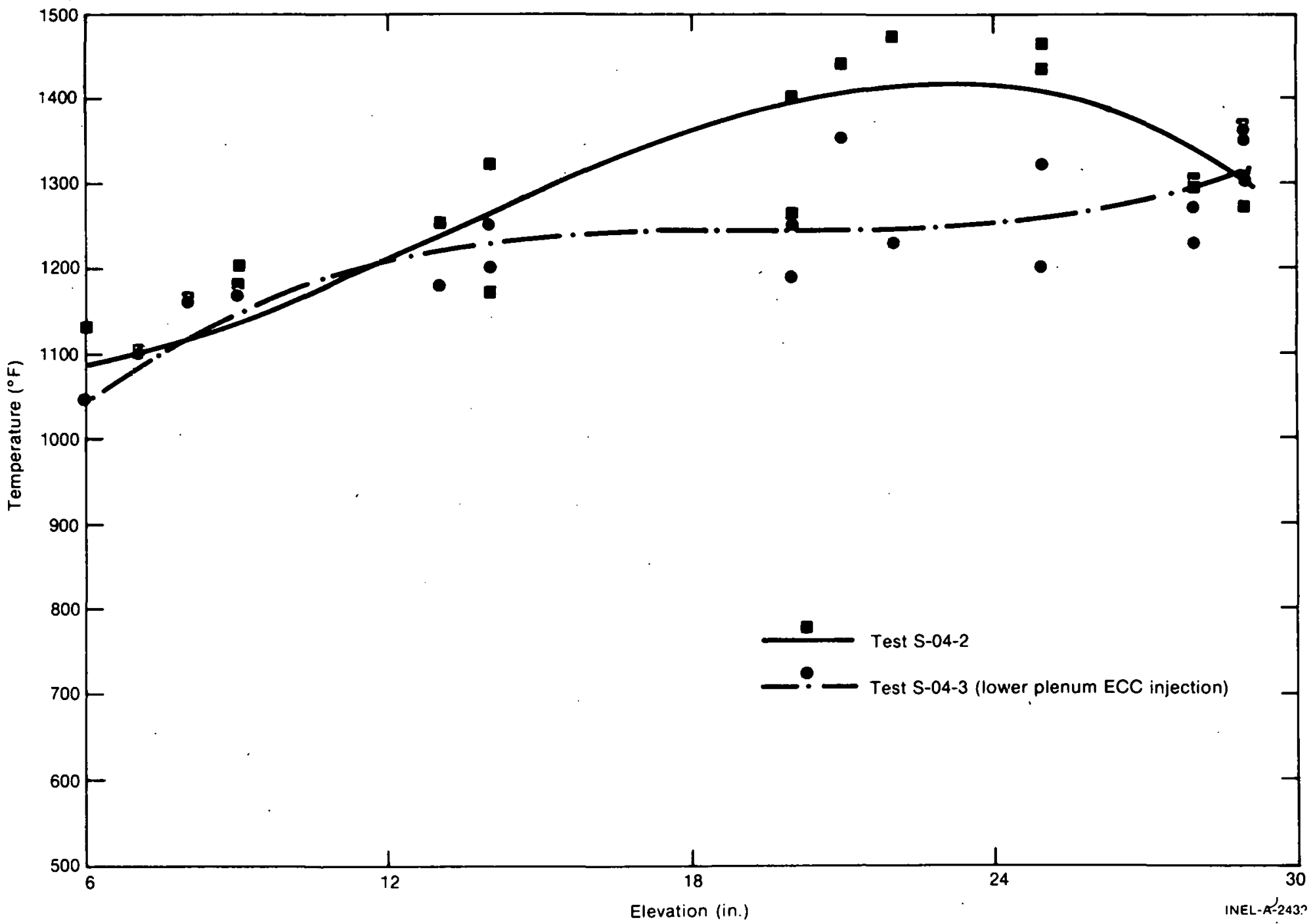

Fig. 17 Initial reflood cladding temperatures - Tests S-04-2 and S-04-3 


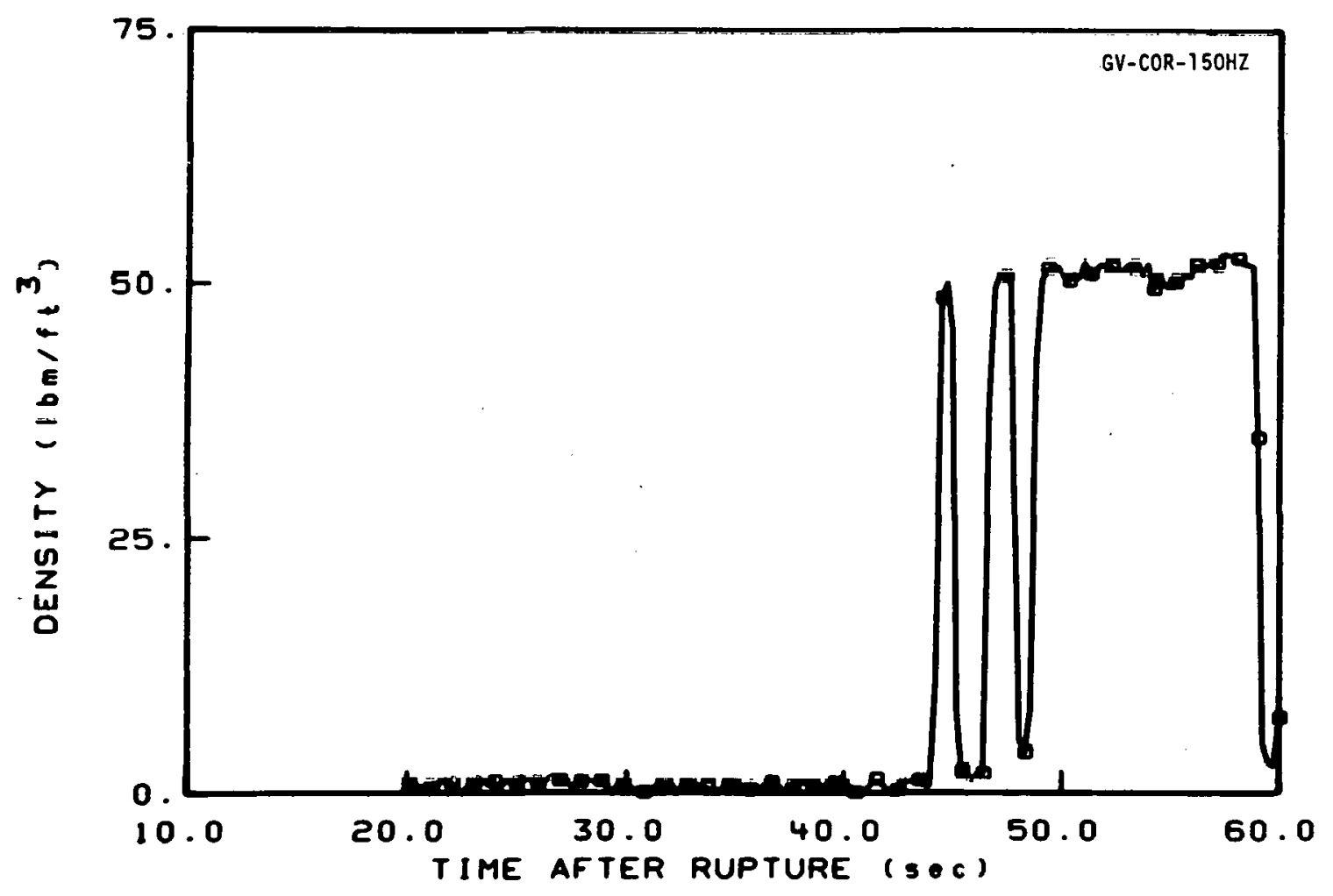

Fig. 18 Fluid density near the core inlet showing effect of lower plenum ECC injection - Test S-04-3. 


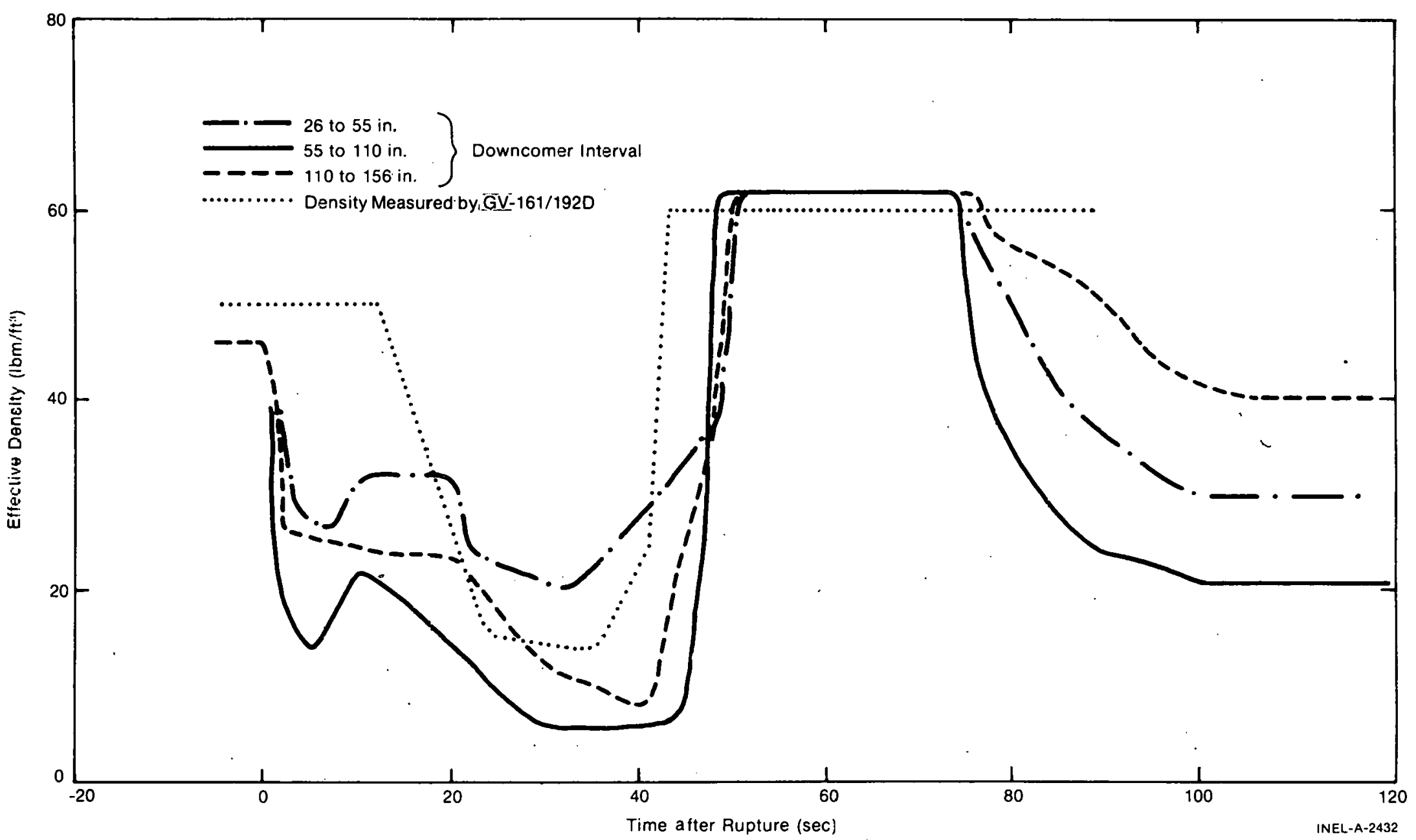

Fig. 19 Effective fluid density at various downcomer intervals - Test S-04-3. 


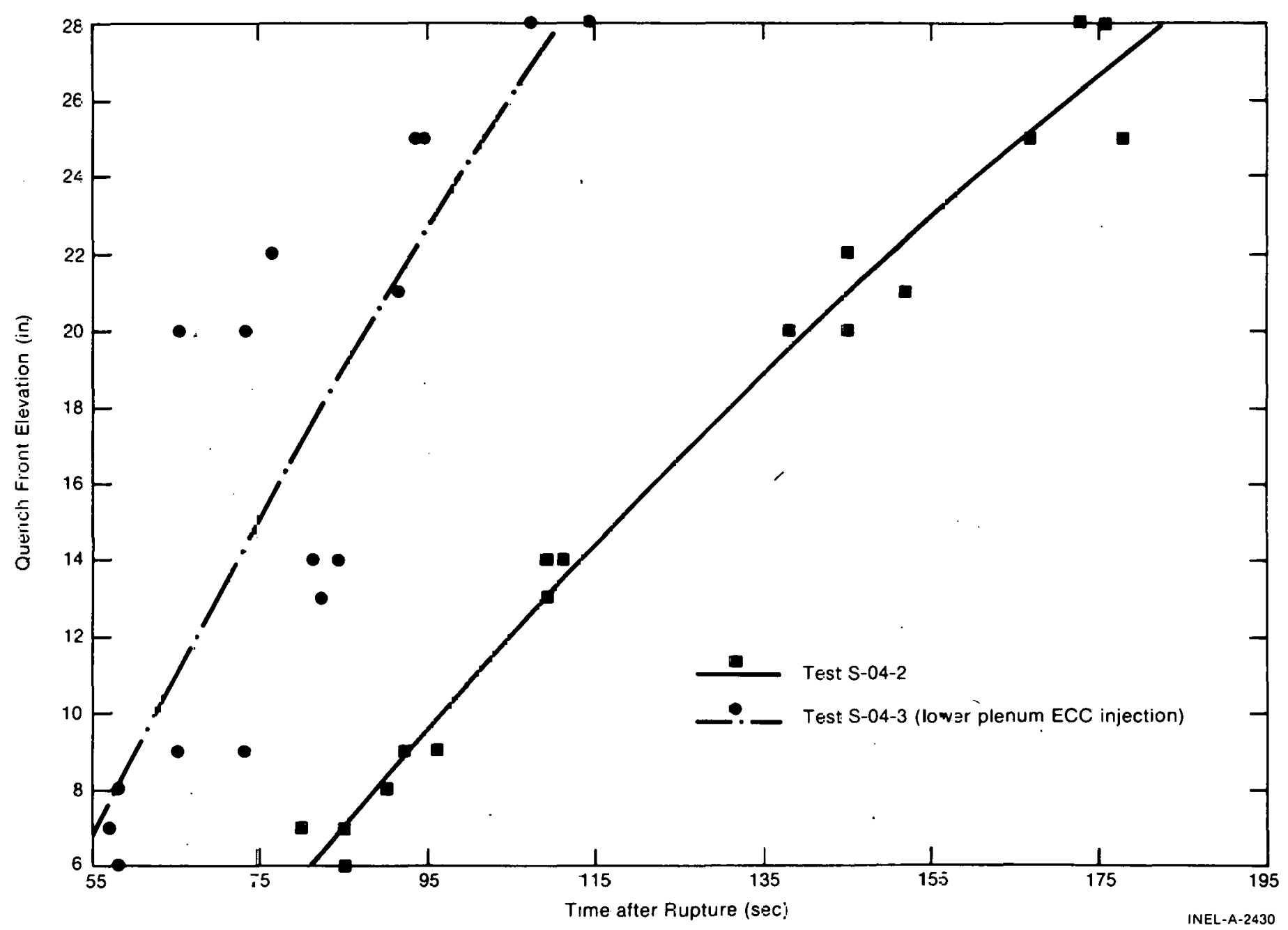

Fig. 20 Core reflood zate (6-to 20-in. elevations) - Tests $S-04-2$ and S-04-3. 


\section{EFFECTS OF THE LOWER PLENUM VOLUME ON THE MOD-1 SYSTEM RESPONSE}

Prior to the Mod-1 baseline ECC test series, the Mod-1 lower plenum was scaled from the LOFT facility. Since this method of scaling resulted in a large lower plenum fluid volume and length to diameter ratio relative to the PWR scaled values, a test (Test S-04-4) was conducted to assess the effect this atypical lower plenum volume has on the Mod-1 system response and to determine whether this distortion must be taken into account in future Mod-1 ECC related tests. Test S-04-4 was conducted with a filler piece in the lower plenum (Figure 21) so as to reduce both the volume and the length to diameter ratio to values which more closely represent the scaled PWR lower plenum, and the results obtained from this test are compared with results from Test S-04-3 (LOFT scaled lower plenum) to determine the sensitivity of the Mod-1 response to the size of the lower plenum. With the exception of the lower plenum scaling, both tests were conducted under similar operating conditions (Table II).

Although Test S-04-4 was conducted for the specific purpose of determining the effect of lower plenum scaling on the Mod-1 system response, unpowered rods made isolation of this effect, with respect to core thermal response, difficult. However, as will be discussed in the following section, differences in measured core response due to unpowered heater rods were apparent, for the most part, only in temperature measurements taken on rods that have a common subchannel with an unpowered rod. Therefore, the locations of the sample rod temperatures used for comparison in this analysis were chosen on the basis that they were not sharing a subchannel with an unpowered heater rod. Since four different unpowered rods existed in the two tests (one rod in Test S-04-3 and three rods in Test S-04-4) only a limited number of rod temperature measurements were available for direct comparison, and consequently, a data sample representative of the lower core was not assembled as done in previous sections. Instead, this analysis compares rod measurements directly between tests at core elevations ranging between the 6- and 33-in. elevations.

Table III compares the peak rod temperatures (occurring at about $10 \mathrm{sec}$ after rupture) at various core locations between Tests S-04-3 and S-04-4 and indicates that the cladding temperatures were, for the most part, higher in Test S-04-4 than in Test S-04-3. However, by the time the accumulator began injecting ECC $(17 \mathrm{sec})$, most of the rod temperatures in Test S-04-4 were lower than those in Test S-04-3. The lower rod temperatures in Test S-04-4 just prior to accumulator ECC injection indicate better rod-to-fluid heat transfer took place in the test with the smaller lower plenum between 10 and $17 \mathrm{sec}$ after rupture. This apparent improvement in core heat transfer in Test S-04-4 during this time is attributed to the higher core flow behavior that resulted from the PWR scaled lower plenum volume.

The effect on the hydraulic response of the system of reducing the lower plenum volume and length to diameter ratio in Test S-04-4 was most evident in the resulting core flow. Figure 22 compares the volumetric core inlet flows in Tests S-04-3 and S-04-4. This 


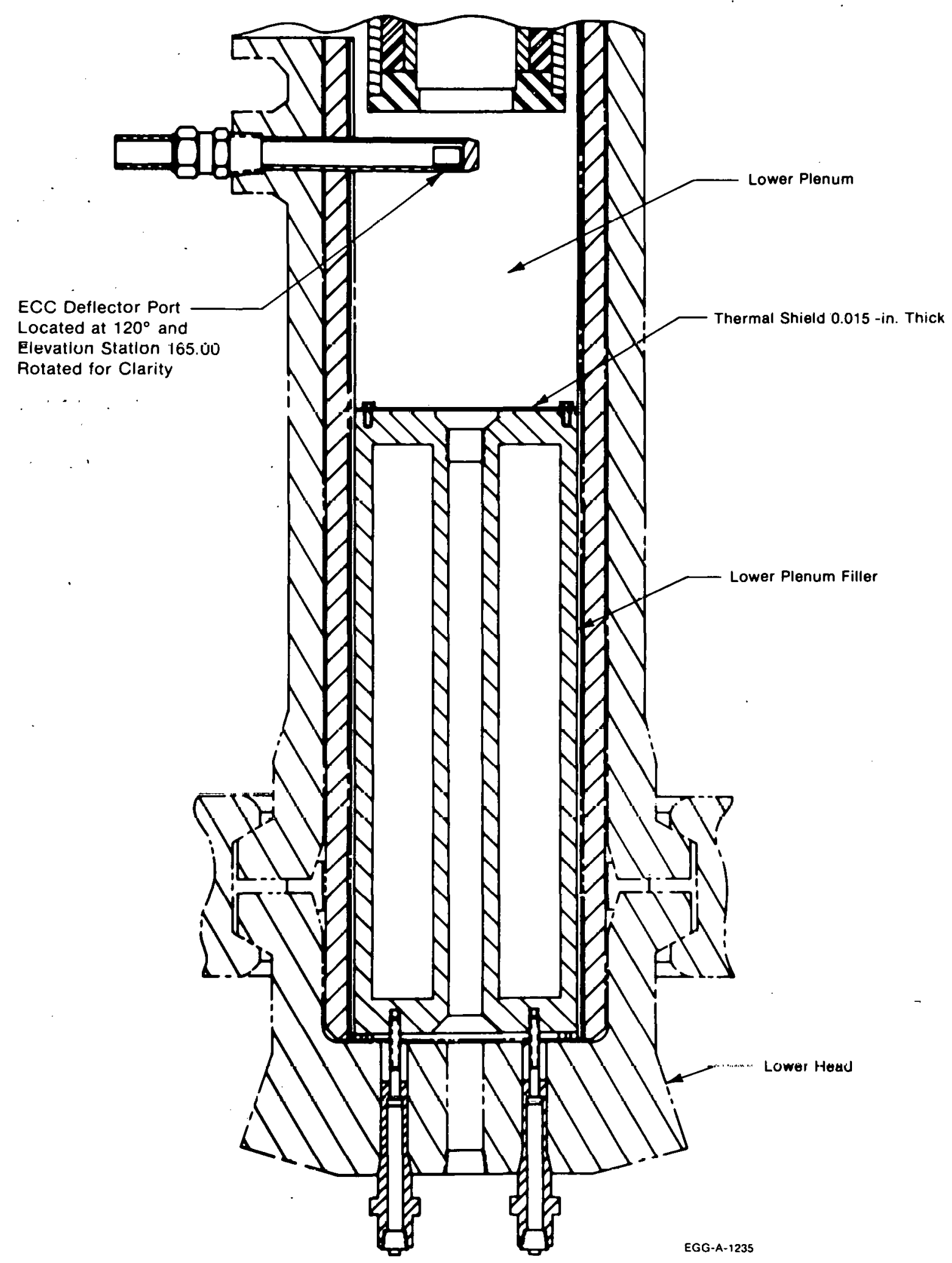

Fig. 21 Cross section of vessel with lower plenum filler. 
TABLE III

SUMMARY OF MIDCORE CLADDING TEMPERATURE BEHAVIOR IN TESTS S-04-3 AND S-04-4

\begin{tabular}{|c|c|c|c|c|c|c|c|c|c|}
\hline \multirow[t]{2}{*}{ Rod Thermocouple } & \multicolumn{3}{|c|}{$\begin{array}{c}\text { Peak Temperature } \\
\text { within } 10 \mathrm{sec} \text { of rupture }\left({ }^{\circ} \mathrm{F}\right)\end{array}$} & \multicolumn{3}{|c|}{$\begin{array}{l}\text { Temperature Prior to } \\
\text { Accumulator Injection }\left({ }^{\circ} \mathrm{F}\right)\end{array}$} & \multicolumn{3}{|c|}{ Quench Time (sec) } \\
\hline & S-04-3 & Tes & $S-04-4$ & $S-04-3$ & Tes & $\mathrm{S}-04-4$ & $5-04-3$ & Tes & S-04-4 \\
\hline $\mathrm{TH}-\mathrm{C} 5-28$ & 1100 & $<$ & 1150 & 1100 & $>$ & 1090 & 114 & $>$ & 98 \\
\hline TH-A5-29 & 1455 & $>$ & 1450 & 1360 & $>$ & 1330 & 154 & $>$ & 98 \\
\hline TH-B6-29 & 1440 & $<$ & 1450 & 1380 & $>$ & 1300 & 111 & $>$ & 85 \\
\hline TH-B5-33 & 1020 & $<$ & 1030 & 1020 & $>$ & 700 & 105 & $>$ & 56 \\
\hline $\mathrm{TH}-\mathrm{C} 3-28$ & 1085 & $<$ & 1130 & 700 & $<$ & 1060 & 60 & $<$ & 68 \\
\hline TH-D3-29 & 1075 & $<$ & 1090 & 1020 & $=$ & 1020 & 62 & $<$ & 80 \\
\hline TH-B3-32 & 995 & $<$ & 1020 & 685 & $>$ & 670 & 62 & $>$ & 57 \\
\hline TH-E2-33 & 1010 & $=$ & $1010^{\circ}$ & 520 & $>$ & 500 & 73 & $<$ & 85 \\
\hline TH-E6-28 & 1095 & $<$ & 1135 & 1120 & $>$ & 1100 & 107 & $<$ & 109 \\
\hline TH-F5-33 & 1070 & $<$ & 1120 & 1060 & $>$ & 980 & 98 & $<$ & 193 \\
\hline TH-D6-14 & 1260 & $<$ & 1265 & 1240 & $>$ & 1200 & 90 & $>$ & 75 \\
\hline TH-E2-20 & 1340 & $<$ & 1345 & 1270 & $>$ & 1230 & 72 & $>$ & 65 \\
\hline
\end{tabular}


TA3LE III (continued)

\begin{tabular}{|c|c|c|c|c|c|c|c|c|c|}
\hline \multirow[t]{2}{*}{ Rod Thermocouple } & \multicolumn{3}{|c|}{$\begin{array}{r}\text { Peak Temperature }\left({ }^{\circ} \mathrm{F}\right) \\
\text { within } 10 \text { sec of rupture } \\
\end{array}$} & \multicolumn{3}{|c|}{$\begin{array}{l}\text { Temperature Prior to } \\
\text { Accumulator Injection }\left({ }^{\circ} \mathrm{F} \text {; }\right.\end{array}$} & \multicolumn{3}{|c|}{ Quench Time (sec) } \\
\hline & S-04-三 & Tes & $5-07-4$ & S-04-3 & Tes & S-04-4 & S-04-3 & Test & $S-04-4$ \\
\hline TH-F6-9 & $\lcm{\square 25}$ & $<$ & 1130 & 1140 & $>$ & 1100 & 65 & $>$ & 55 \\
\hline TH-E6-8 & 1140 & $<$ & 1145 & 1140 & $>$ & 1110 & 57 & $>$ & 55 \\
\hline TH-F2-7 & -000 & $=$ & 1000 & 1000 & $>$ & 970 & 57 & $<$ & 60 \\
\hline TH-F3-6 & -040 & $<$ & 1050 & 1030 & $>$ & 1020 & 57 & $>$ & 55 \\
\hline
\end{tabular}




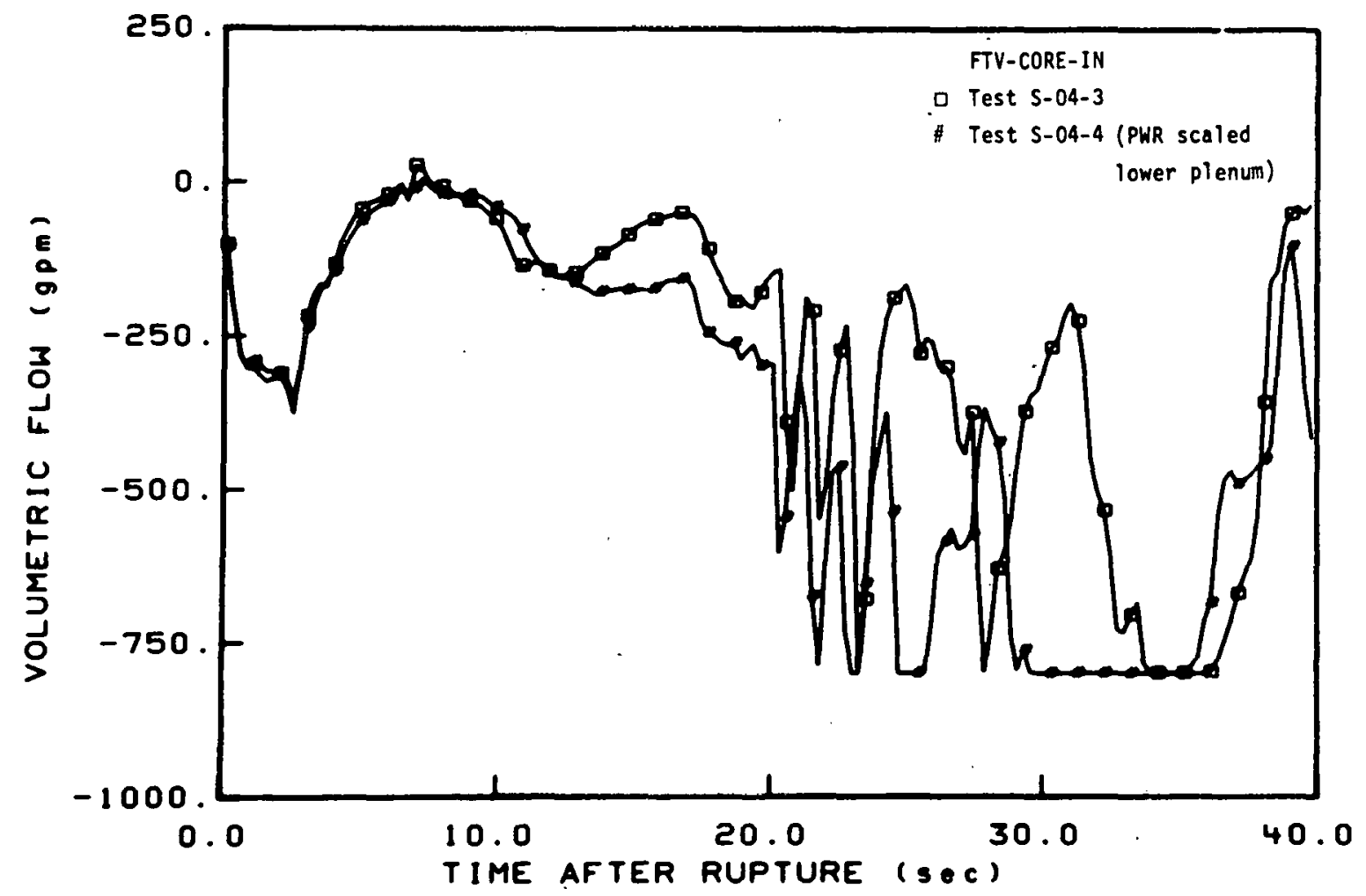

Fig. 22 Volumetric flow rate near the core inlet reflecting effect of lower plenum volume - Tests S-04-3 and S-04-4.

figure shows that prior to $9 \mathrm{sec}$ the core flows in the tests were about the same, indicating no effect from the different lower plenum geometries. This similarity in core flow also suggests that the trend in higher cladding temperatures in Test S-04-4 prior to $17 \mathrm{sec}$ was due to the slightly higher power per rod (Table II). However, shortly after the peak cladding temperatures were reached, a larger core flow rate was observed in Test S-04-4. A mass balance performed on the vessel (excluding the core) for this period indicated that the demand of the break for vessel fluid mass was the same in the two tests. Since less fluid mass was available in the lower plenum in Test S-04-4, the core flow had to supply a larger percentage of this mass demand. Consequently, the core flow increased when the smaller lower plenum fluid volume approached depletion. This higher core flow continued throughout the refill phase of the test and resulted in lower rod temperatures at initiation of core reflood than occurred in Test S-04-3.

As a result of lower plenum ECC injection, core reflood began at the same time in both tests. However, Figure 23 shows that the system in Test S-04-4 was at lower pressures than the system in Test S-04-3, indicating a higher system depressurization rate after rupture due to the smaller initial amount of water present in the lower plenum.

Due to the complex downcomer behavior during reflood with lower plenum injection (Section 1.2), no correlation of the events was attempted after reflood began. The complexity of the reflood events in tests of this nature is reflected in various times required for similar rod elevations to quench as listed in Table III. 


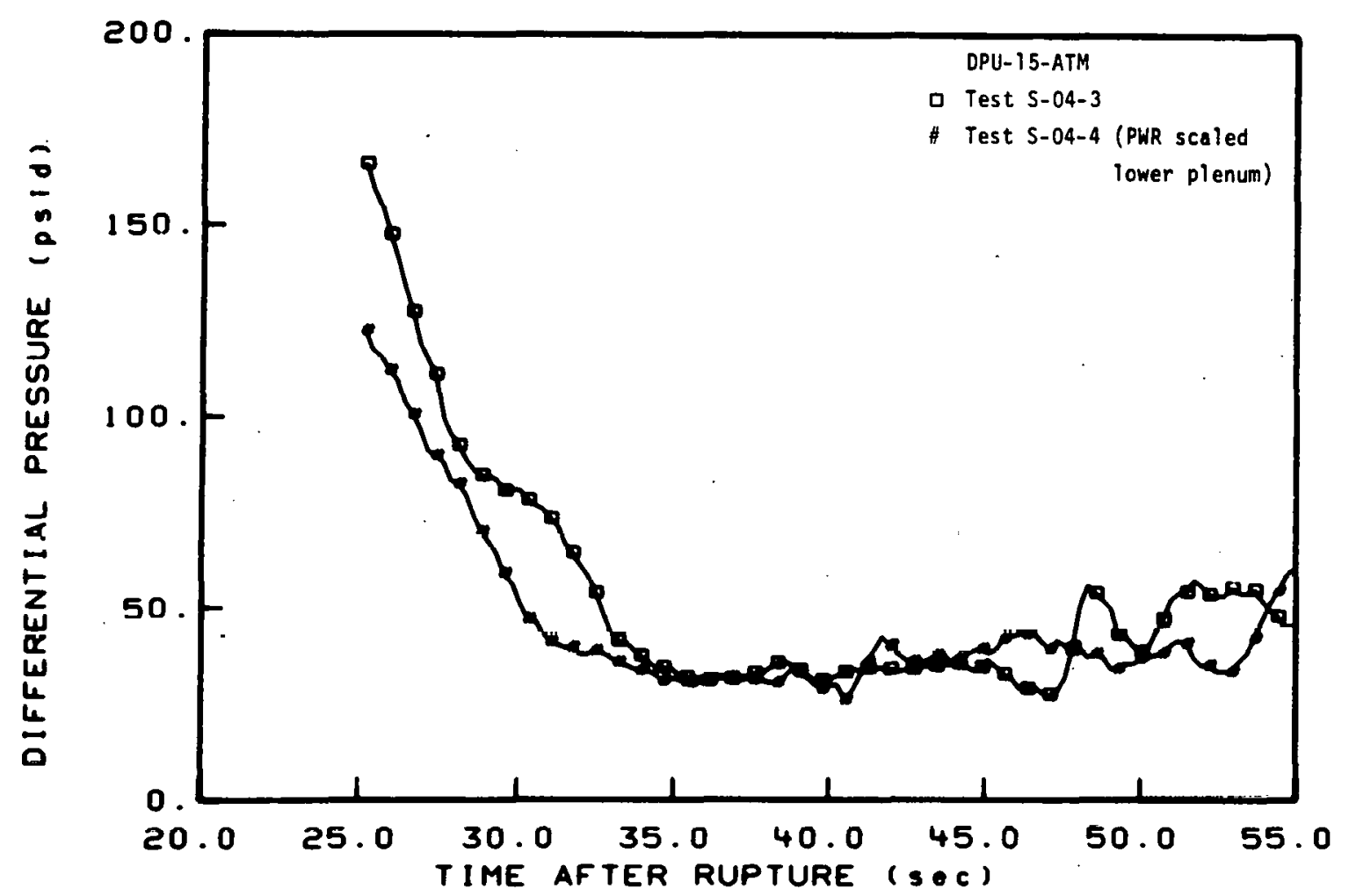

Fig. 23 System pressure near the intact loop vessel inlet - Tests S-04-3 and S-04-4.

In summary, the PWR scaled lower plenum (Test S-04-4) resulted in a higher core flow rate and better core heat transfer shortly after rupture than occurred with the LOFT scaled lower plenum (Test S-04-3). Furthermore, the smaller PWR scaled lower plenum resulted in a somewhat higher system depressurization rate which, although not affecting reflood times in these tests, would be an influencing factor in the initiation of core reflood in a test with only cold leg injection (as specified for future Mod-1 testing). Consequently, the Mod-1 system response appears to be sensitive to the method of lower plenum scaling and since the smaller lower plenum more closely represents the PWR scaled lower plenum, the results produced by it are considered more representative of results expected in a PWR. Therefore, the smaller lower plenum volume was specified for future Mod-1 testing. 


\section{EFFECTS OF UNPOWERED HEATER RODS ON THE MOD-1 SYSTEM RESPONSE}

Tests S-04-5 and S-04-6 were conducted specifically to determine the effects of unpowered heater rods on the Mod-1 core response and to determine whether unpowering Mod-1 heater rods is necessary to represent passive rod locations in a PWR core. To investigate the effect of unpowered heater rods on the Mod-1 core response, Test S-04-5 was conducted with all heater rods powered whereas Test S-04-6 was, as illustrated in Figure 24, conducted with four unpowered rods (the criterion for selecting the number and location of the unpowered rods is presented in Appendix C). An analysis of the results obtained from these two tests is presented in detail in Reference 2. A brief summary of the conclusions reached from that analysis follows.

The primary effect of unpowering Mod-1 heater rods in Test S-04-6 was the strong tendency to shift the DNB (departure from nucleate boiling) behavior on those rods that shared a subchannel with unpowered rods from early DNB toward delayed DNB or early DNB with rewet. For example, Figures 25 and 26 compare identical rod temperature measurement locations between Tests S-04-5 and S-04-6. In Test S-04-6 both of these rod locations shared a subchannel with unpowered rods and in one case the rod DNB behavior shifted from an early DNB to a delayed DNB and in the other case shifted from an early DNB to an early DNB with rewet. The result of this shift in DNB behavior in Test S-04-6 was that more energy was removed from the core shortly after rupture and lower rod temperatures were observed for the remainder of the test. This trend in lower rod temperatures in Test S-04-6 is illustrated in Figure 27 which shows the initial rod reflood temperatures up to the 29-in. core elevation in Tests S-04-5 and S-04-6. Also shown in this figure is the lesser extent to which rod locations not sharing subchannels with unpowered rods were affected by the unpowered rods. As discussed in Reference 2, the lower initial rod reflood temperatures in Test S-04-6 resulted in rod quenching taking place as much as $150 \mathrm{sec}$ earlier than in Test S-04-5.

Since the Mod- 1 core response was significantly influenced by the existence of passive heater rods and since a PWR fuel assembly contains numerous passive rod locations, unpowering Mod-1 heater rods was considered a necessary approach in future Mod-1 testing. However, as stated in Reference 2, rod DNB behavior is very complex and influenced by many variables including rod power densities and nearby fluid conditions. Therefore, although the general behavior may be the same, direct qualitative judgments of the DNB behavior in a PWR should not be based on the results of Test S-04-6. 


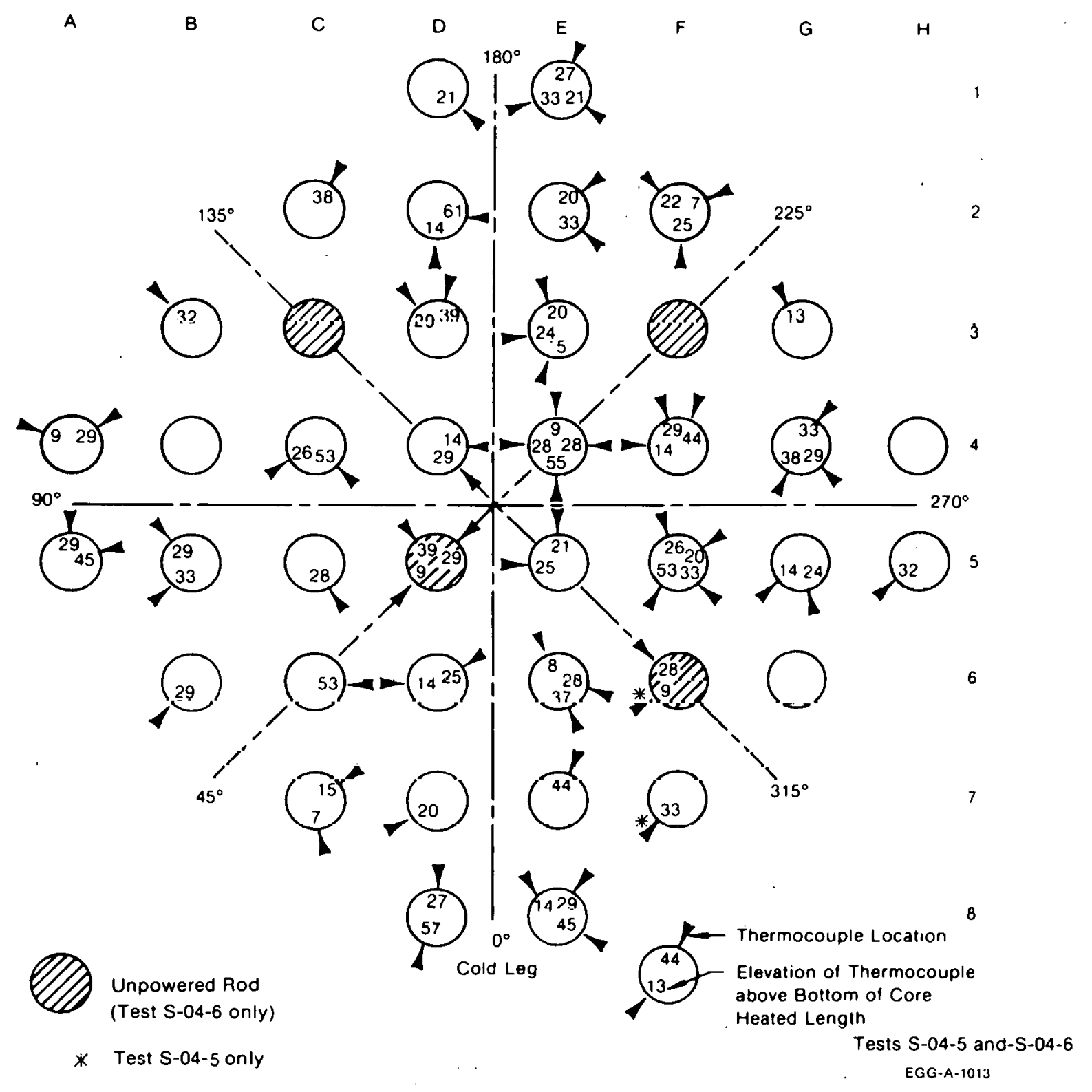

Fig. 24 Semiscale Mod-1 heated core - Tests S-04-5 and S-04-6. 


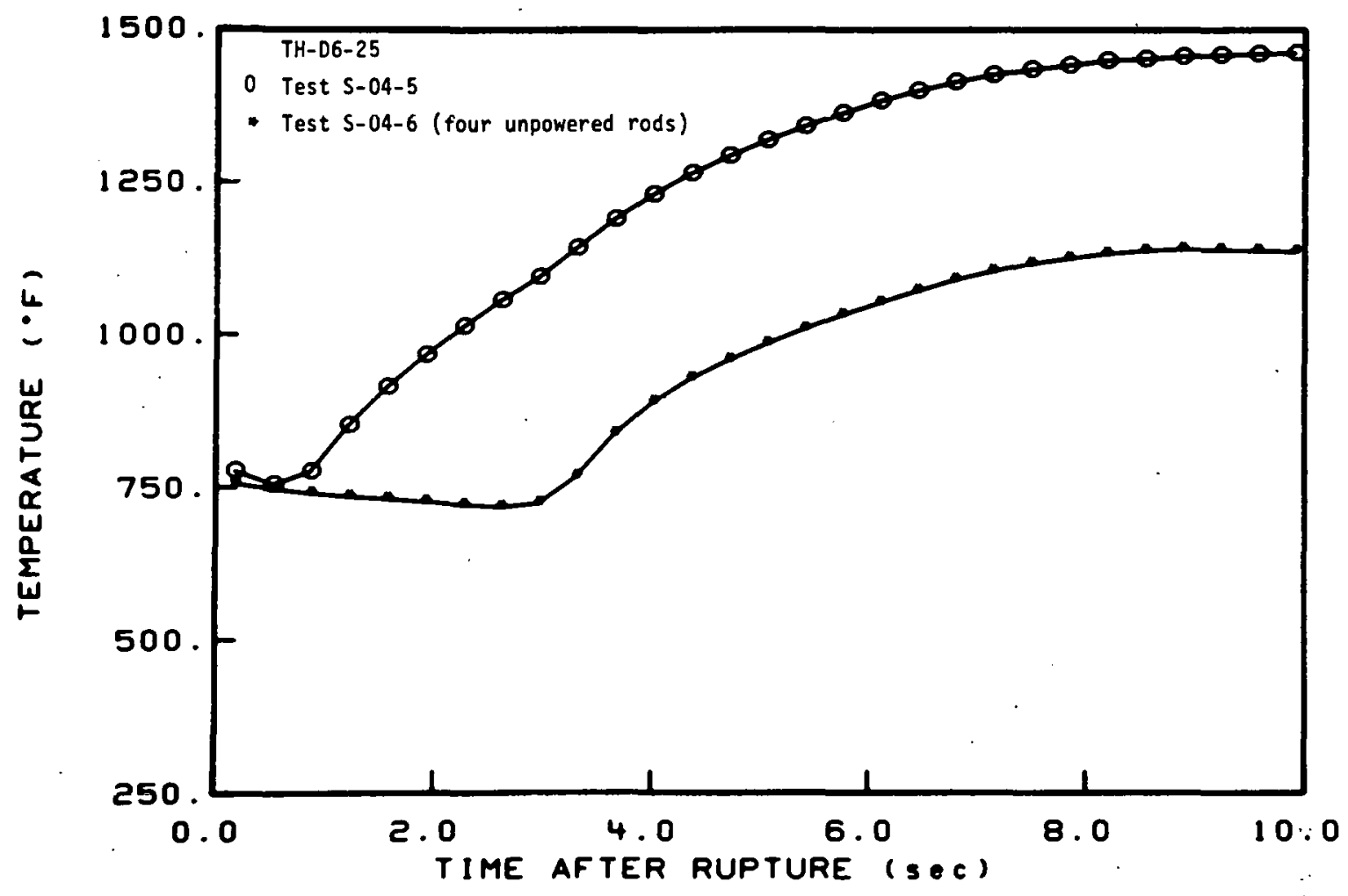

Fig. 25 Cladding temperature at the 25-in. elevation on Rod D6 - Tests S-04-5 and S-04-6.

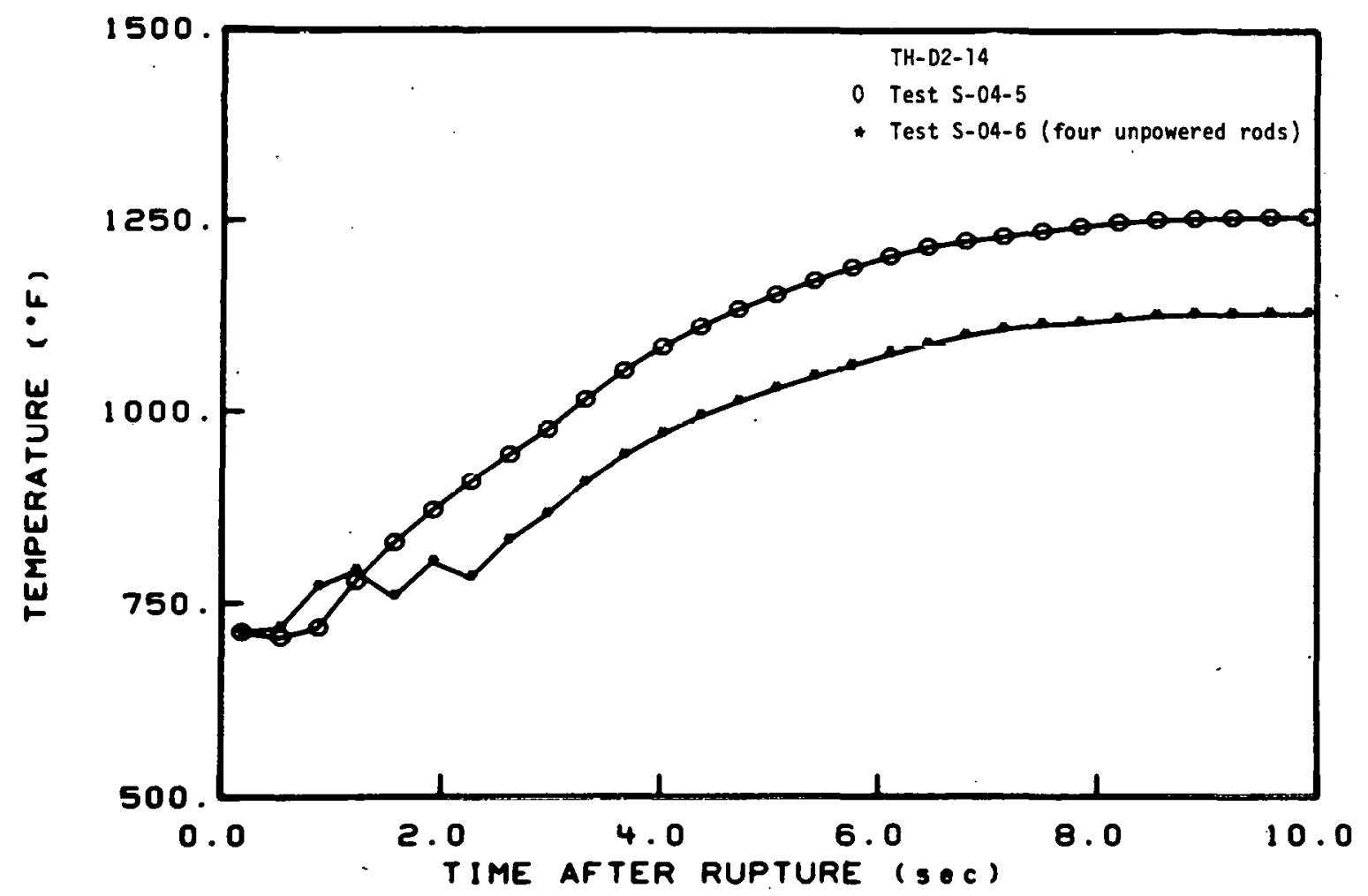

Fig. 26 Cladding temperature at the 14-in. elevation on Rod D2 - Tests S-04-5 and S-04-6. 


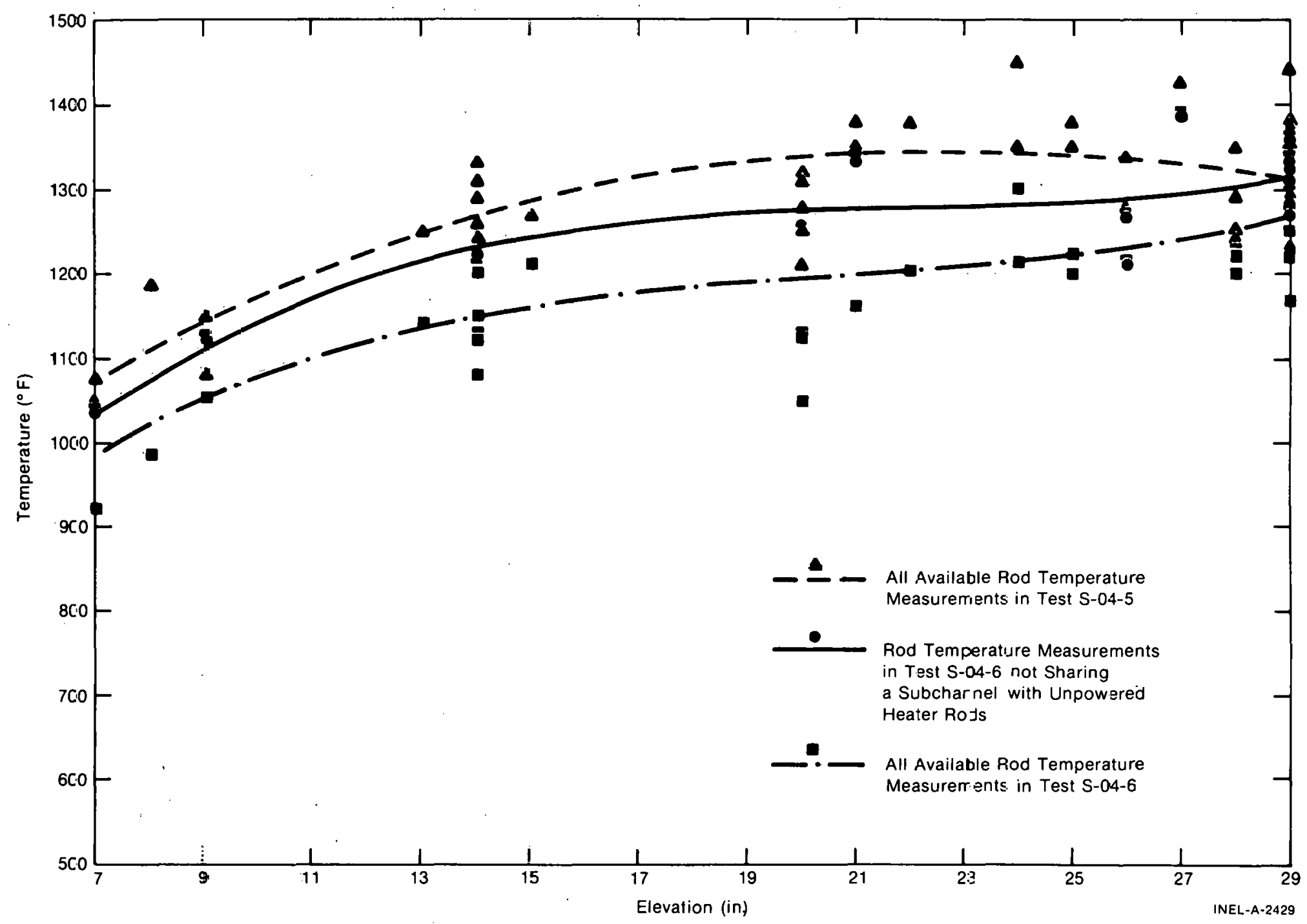

Fig. 27 Initial reflood clacding tempera1ures - Tests S-04-5 and S-04-6. 


\section{CONCLUSIONS}

The conclusions reached from evaluation of the baseline ECC series tests are as follows. (a) The Mod-1 high pressure injection system and accumulator flow rates should be system volume scaled from a PWR to provide a proper system depressurization rate and the low pressure injection system flow rate should be vessel area scaled so as to provide proper downcomer refill characteristics during the latter periods of core reflood. The water volume of the accumulator should be increased from the system volume scaled value to account for the oversized Mod-1 downcomer volume. (b) The Mod-1 lower plenum should be scaled from a PWR to provide typical core behavior and a representative system depressurization rate. (c) Four Mod-1 heater rods should be unpowered to simulate the influence of control rod guide tubes and instrumentation thimbles in a PWR core. Furthermore, the Mod-1 system should not incorporate lower plenum injection as a means of initiating core reflood at times consistent with PWR calculations, as this specification was seen to result in unduly complicated data.

Test S-04-6 of the baseline ECC test series was conducted under the preceding specifications and is therefore the Semiscale Mod-1 baseline ECC test. Results from this test will be used as the baseline for comparison with future ECC related Semiscale Mod-1 tests. 


\section{REFERENCES}

1. Quarterly Technical Report on Water Reactor Safety Programs Sponsored by the Nuclear Regulatory Commission's Division of Reactor Safety Research, January March 1975, ANCR-1254 (September 1975) pp 29-60.

2. J. M. Cozzuol, Thermal Hydraulic Analysis of the Semiscale Mod-1 Integral Blowdown Reflood Test (ECC Baseline Test Series), TREE-NUREG-1077 (March 1977).

3. D. J. Hanson et al, ECC Performance in the Semiscale Geometry, ANCR-1203 (August 1975).

4. H. S. Crapo, B. L. Collins, K. E. Sackett, Experiment Data Report for Semiscale Mod-1 Test S-04-1 (Baseline ECC Test), ANCR-NUREG-1330 (September 1976).

5. H. S. Crapo, B. L. Collins, K. E. Sackett, Experiment Data Report for Semiscale Mod-1 Test S-04-2 (Baseline ECC Test), ANCR-NUREG-1331 (September 1976).

6. H. S. Crapo, B. L. Collins, K. E. Sackett, Experiment Data Report for Semiscale Mod-1 Test S-04-2 (Baseline ECC Test), TREE-NUREG-1002 (October 1976).

7. H. S. Crapo, B. L. Collins, K. E. Sackett, Experiment Data Report for Semiscale Mod-1 Test S-04-4 (Baseline ECC Test), TREE-NUREG-1003 (October 1976).

8. H. S. Crapo, B. L. Collins, K. E. Sackett, Experiment Data Report for Semiscale Mod 1 Tests Sm04.5 and S.04.6 (Basoline ECC Tests), TREE-NUkEG-1045 (January 1977).

9. G. E. McCreery et al, Thermal-Hydraulic Analysis of Semiscale Mod-1 Reflood Test Series (Gravity Feed Tests), TREE-NUREG-1010 (January 1977). 
APPENDIX A

SEMISCALE MOD-1 SYSTEM DESCRIPTION FOR THE ECC BASELINE TEST SERIES 
THIS PAGE

\section{WAS INTENTIONALLY LEFT BLANK}




\section{APPENDIX A \\ SEMISCALE MOD-1 SYSTEM DESCRIPTION FOR THE ECC BASELINE TEST SERIES}

The Semiscale Mod-1 test apparatus is a high-pressure. system designed to operate at typical pressurized water reactor temperatures and pressures. The system consists of a pressure vessel with simulated reactor internals (upper plenum, core region, lower plenum, and downcomer); an intact loop with an active pump, steam generator, and pressurizer; a broken loop with a simulated steam generator, simulated pump, and pipe rupture assemblies; a pressure suppression system with a header and suppression tank; and a coolant injection system with injection pumps, accumulators, and delivery piping. The broken loop design is such as to allow the simulation of either hot or cold leg breaks. The experimental system configuration for the cold leg break test with numbered spool pieces is shown in Figure A-1. Descriptions of the system components, including volumes and flow resistances and details of the measurement and data acquisition systems, are contained in Reference A-1.

The core in the Semiscale system consists of 40 electrically heated rods of typical PWR fuel rod diameter ( 0.422 in.). A cross-sectional view of the vessel with the core layout is shown in Figure A-2. Figure A-3 illustrates the general construction of a Semiscale heater rod. The overall length of the rod is about $207 \mathrm{in}$. and the bottom of the $5.5-\mathrm{ft}$ heated section is about 142 in. below the vessel cold leg centerline as shown in Figure A-4. The rods extend from the bottom of the heated section through the upper plenum and pass out through the vessel upper head. The heating element shown in Figure A-3 was designed to produce an axial peaking factor of 1.58 and a normalized axial power profile as shown in Figure A-5.

The core rod bundle matrix showing typical thermocouple locations[a] is presented in Figure A-6. As shown in this figure, the heater rods are located within the matrix by reference to the row of letters across the top and the column of numbers down the side of the matrix. Similarly, the thermocouples are identified by the rod that they are on and by their elevation above the bottom of the heated length of the core. The thermocouple on Rod D5 at the 29-in. elevation is thus referred to as TH-D5-29, where TH means a core heater cladding temperature, D5 refers to the rod on which the thermocouple is located, and 29 gives the thermocouple elevation in inches above the core bottom. (The arrows in Figure A-6 indicate thermocouple azimuthal locations.)

The intact loop is a core area scaled simulation of three loops of a commercial four-loop PWR and consists of primary coolant piping, a steam generator, a pressurizer, and a circulating pump. The piping is primarily 3 -in. Schedule 160 pipe. The intact loop steam generator is a tube-in-shell heat exchanger.

[a] The locations shown in Figure A-6 are those actually used in Test S-04-1. 


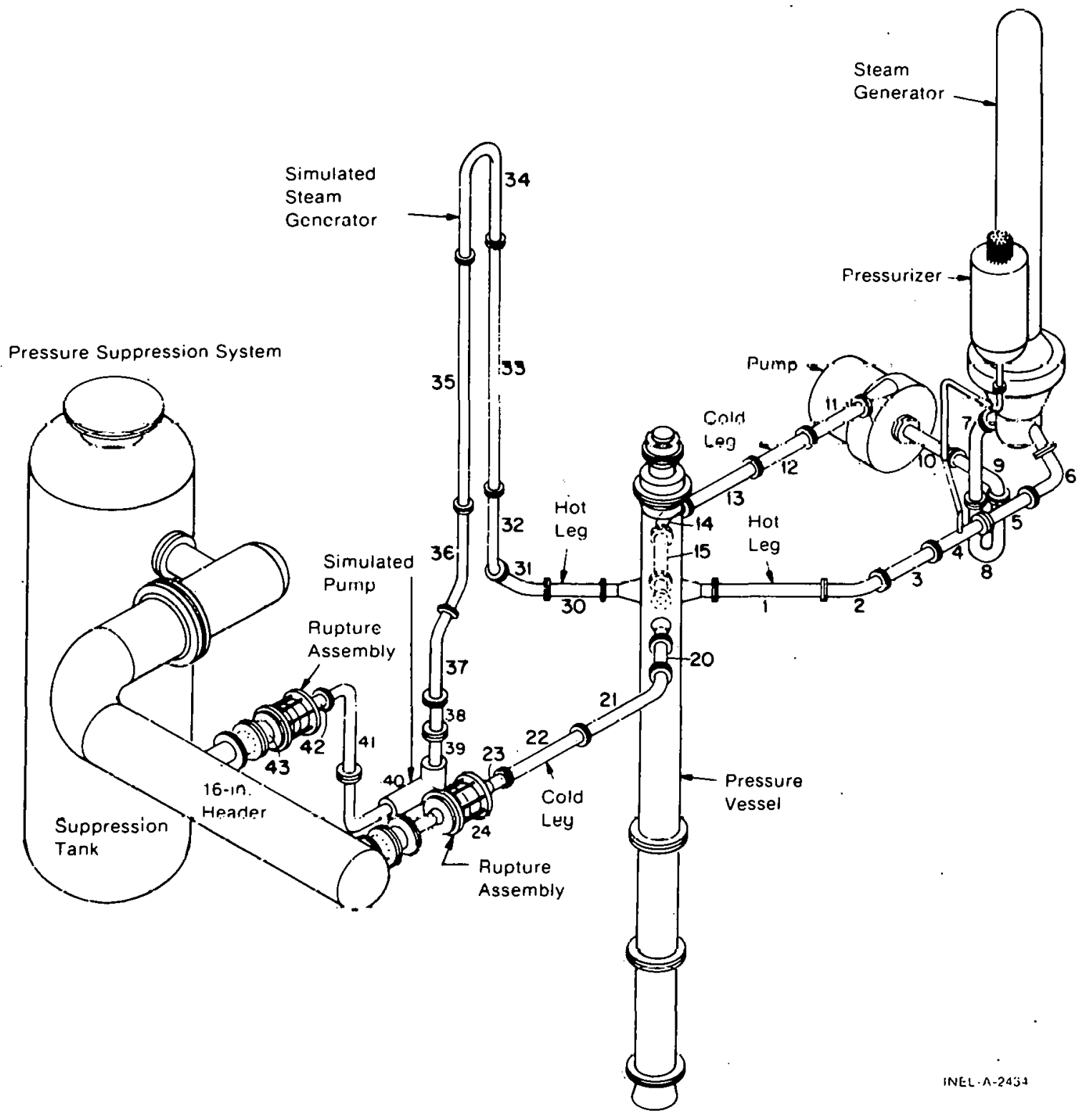

Fig. A-1 Semiscale Mod-1 system configuration for the baseline ECC test series.

The blowdown loop is a volume-scaled representation of one loop of a four-loop PWR and consists of passive pump and steam generator simulators, two discharge nozzles, and two rupture assemblies which provide for a simulated double-ended offset shear break. The associated piping is primarily 2 -in. Schedule 160 stainless steel. The steam generator and pump simulators consist of piping with inserted orifices to achieve the desired hydraulic resistances. The rupture assemblies contain a converging-diverging blowdown nozzle (to provide the desired break area) and two diaphragm rupture discs. The break nozzles used for all tests in this series were sized to represent $200 \%$ double-ended cold leg breaks. 


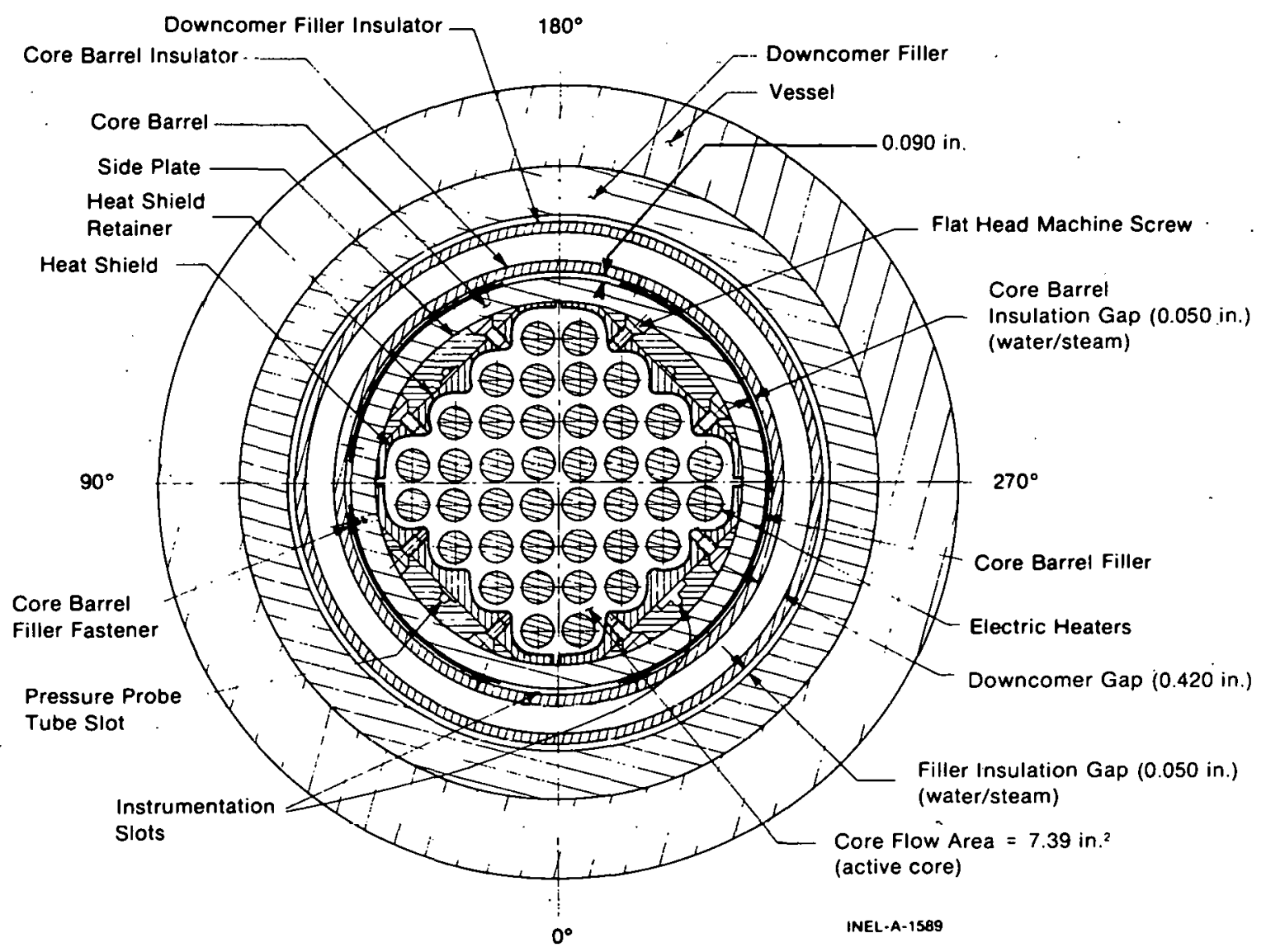

Fig. A-2 Vessel cross section and core layout.

The pressure suppression system consists of a $91.7-\mathrm{ft}^{3}$ pressure tank which is used to simulate the back pressure created by a containment building in a PWR system. The tank is maintained partially full of subcooled water, and the downcomer pipe projects below the water surface to accommodate the blowdown effluent. A 16-in. header connects the pressure suppression tank to the primary coolant system.

The ECC systems comprise an accumulator tank, high pressure injection system (HPIS) pumps, and low pressure injection system (LPIS) pumps. ECC was supplied to both the intact and broken loop cold legs. Two of the tests conducted (Tests S-04-3 and S-04-4) also included lower plenum accumulator injection.

Measurements taken in the system included volumetric flow rates, momentum flux, density, material and fluid temperatures, pressure drops, and pressure. Volumetric flow rates were measured using turbine flowmeters. Gamma densitometers were used to measure density. Thermocouples were used for the temperature measurements. The pressure and differential pressure drop measurements were made with calibrated pressure and differential pressure transducers. 


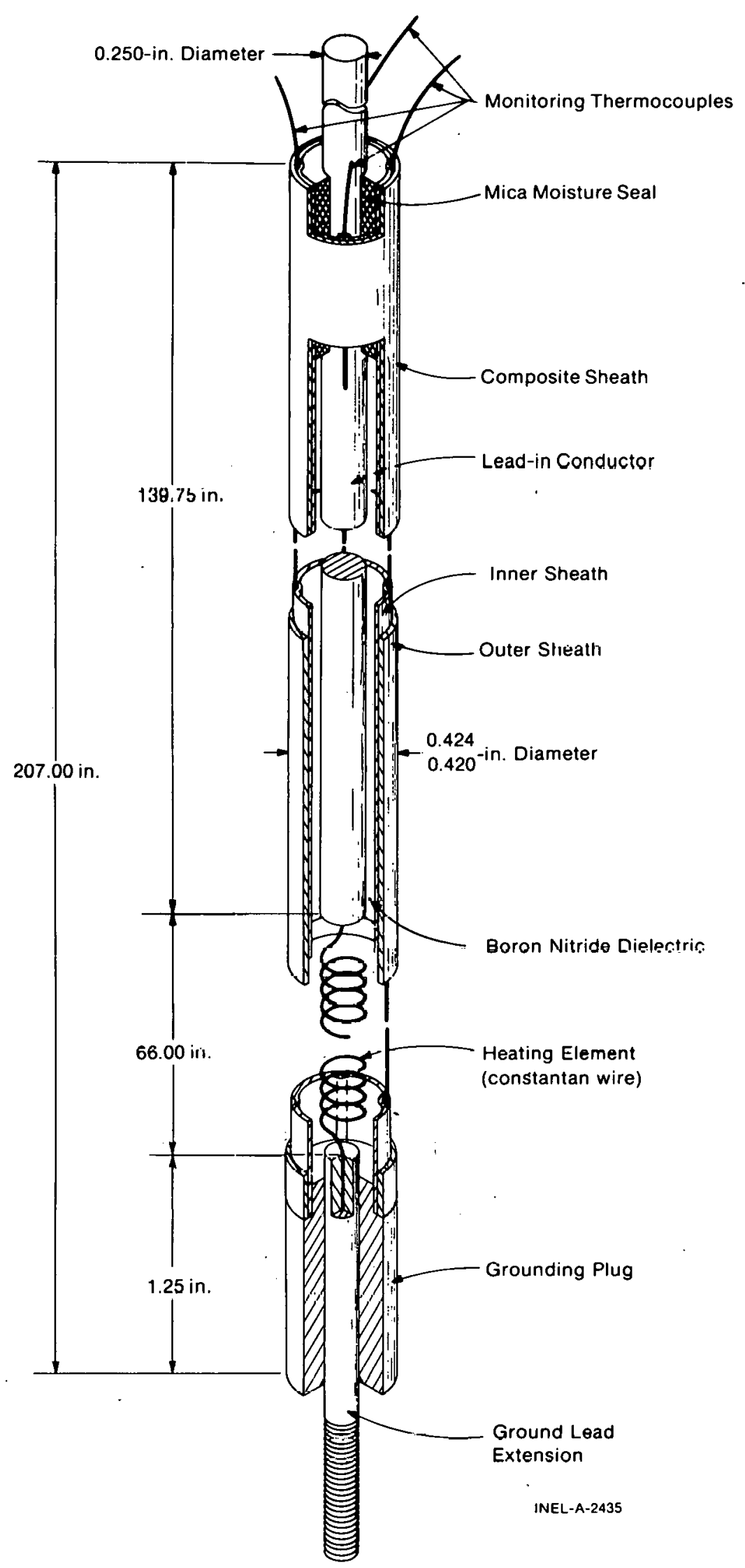

Fig. A-3 Semiscale Mod-1 electric heater rod. 


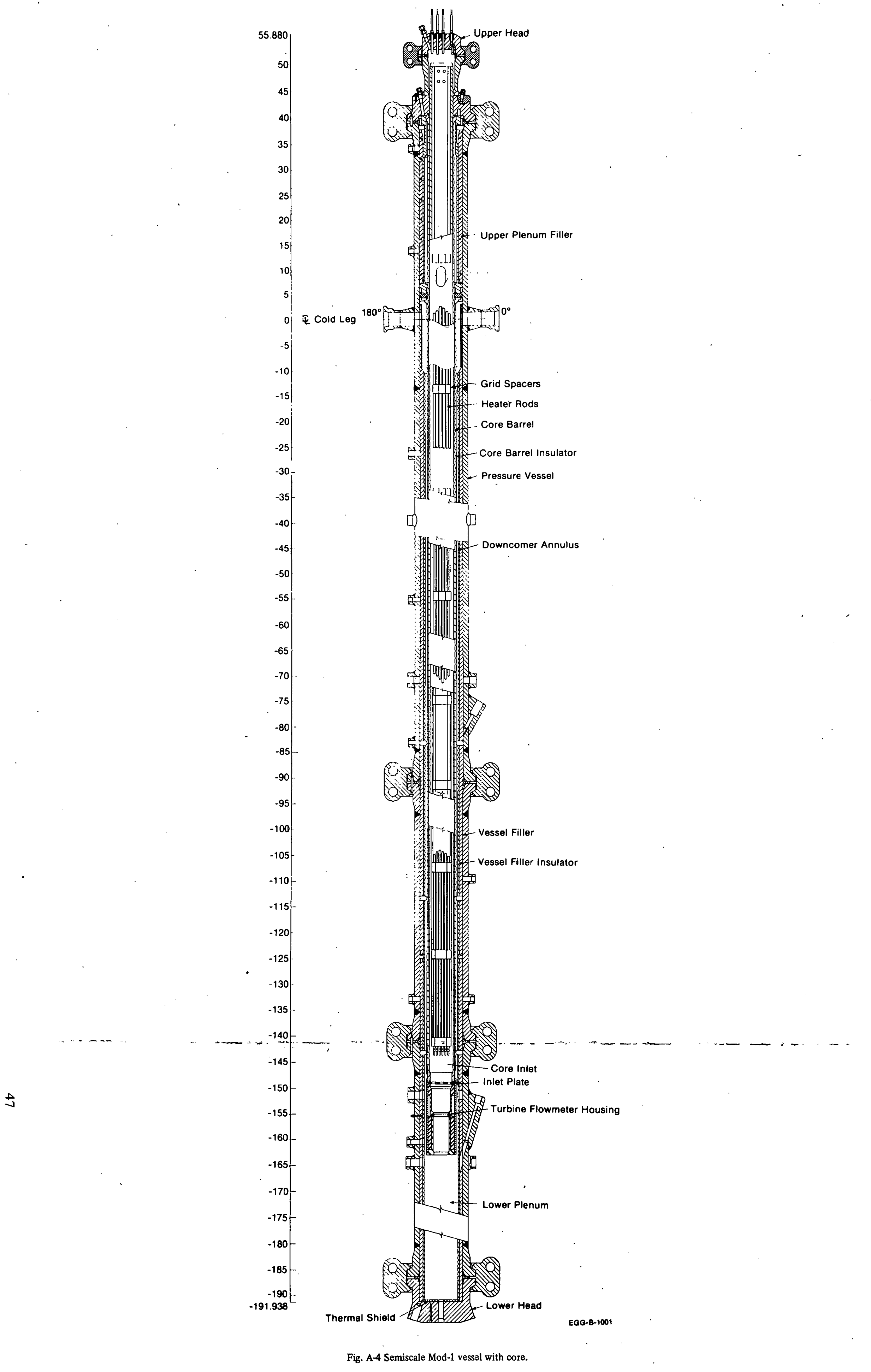




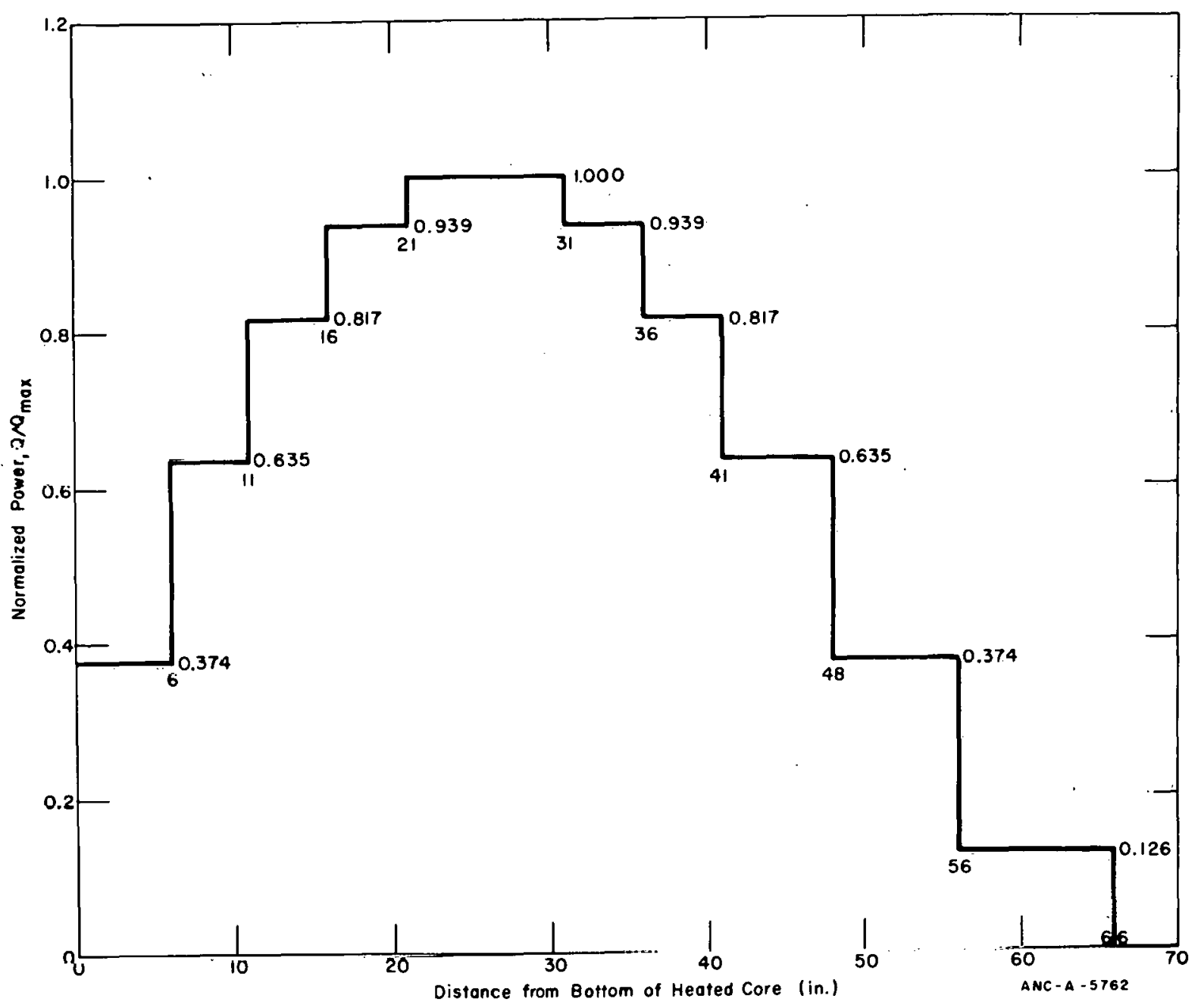

Fig. A-5 Scmiscale Mnde1 heater rọt arial prware diutribution. 


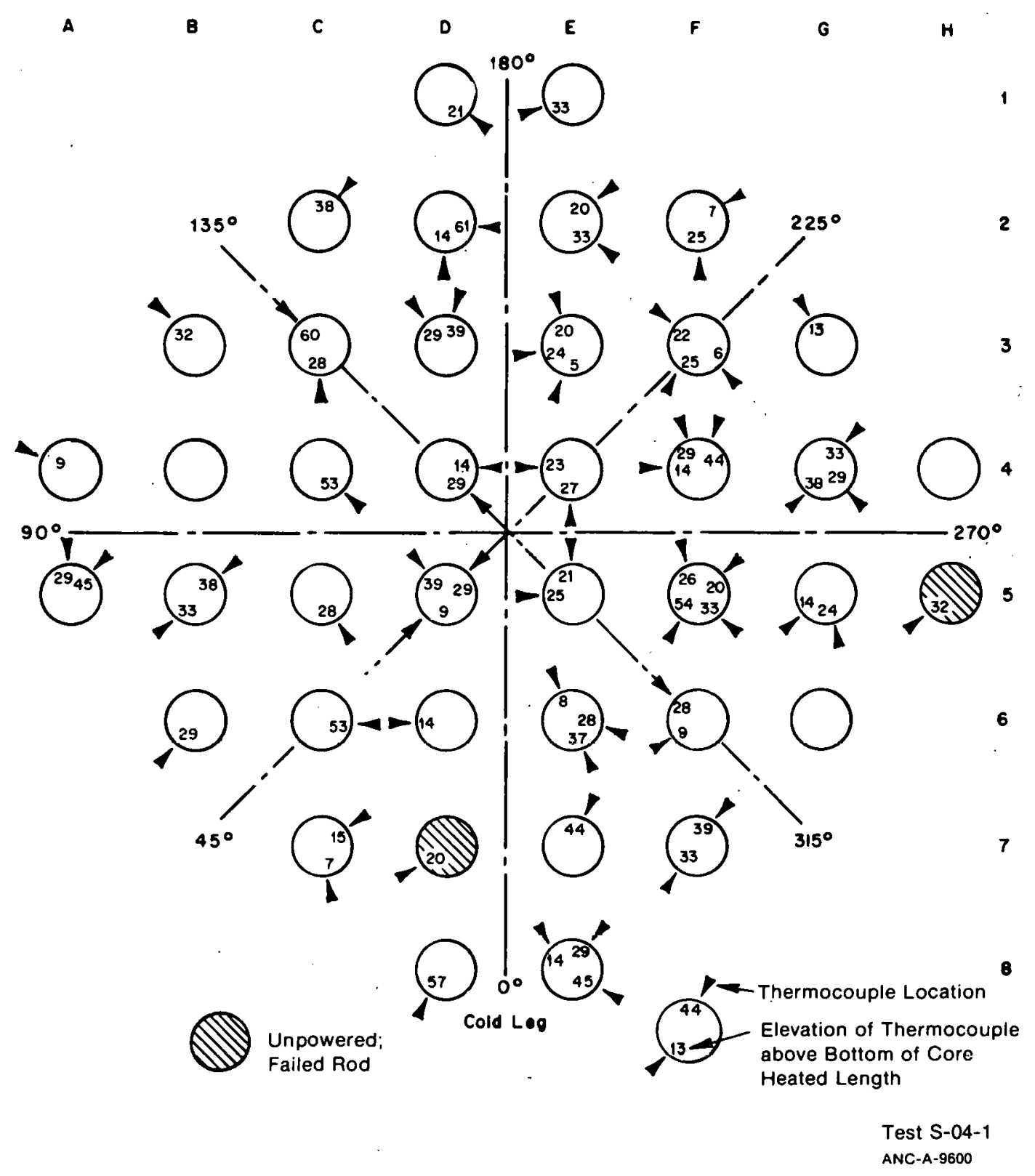

Fig. A.6 Somiscale Mod 1 hoater core, plan view showing instrumentation. 


\section{A-1. REFERENCE}

A-1. E. M. Feldman and D. J. Olson, Semiscale Mod-1 Program and System Description for the Blowdown Heat Transfer Tests (Series 2), ANCR-1 230 (August 1975). 
APPENDIX B

ECC SCALING METHODS FOR THE ECC BASELINE TEST SERIES 
THIS PAGE

\section{WAS INTENTIONALLY LEFT BLANK}




\section{APPENDIX B \\ ECC SCALING METHODS FOR THE ECC BASELINE TEST SERIES}

The Mod-1 system is volume scaled to a PWR such that the following ratio is true

$$
\frac{\text { Core Power }}{\text { System Volume }} \mid \text { Semiscale }=\frac{\text { Core Power }}{\text { System Volume }} \mid \text { PWR }
$$

Volume, rather than linear, scaling was used to design the Mod-1 system because this approach provided the same relative amount of fluid for energy exchange in the model as in the reference system and, through control of break size in the Mod-1 system, preserved the blowdown time scale of events. However, with respect to the ECC refill and reflood processes, strict system volume scaling of the ECC parameters to a PWR plant does not provide the proper time sequencing in Semiscale as that which would occur in the reference PWR plant due to distortions of the Semiscale downcomer and lower plenum. Strictly speaking, therefore, in order to adequately represent the phenomena occurring in the reference plant, the various phases of blowdown, refill, and reflood occurring within the Semiscale system would have to be considered separately when scaling the ECC system and would result in a different ECC injection rate for each phase of the simulated accident. However, the complexity of having various ECC injection rates during the ECC sequence of the baseline test is not in keeping with the goal of obtaining baseline data that are uncomplicated by multiple varying parameters. In addition, since future tests will investigate the effect on system response due to different ECC injection rates and location, the ECC baseline test should be as simple as possible in serving as a broad standard with which to compare results from more complex testing conditions. Each of the tests conducted in this series, therefore, was conducted with an ECC injection rate which was specified constant during the blowdown, refill, and reflood phases of each test. The preceeding constraint required that the ECC injection rate be based on a single scaling criterion as discussed in the subsequent paragraphs rather than a combination of criteria as would occur with a variable ECC injection rate.

\section{AC.CIIMIILATOR SC.AI.ING (INTACT L.OOP)}

Vendors of PWRs use parametric studies to size the volumes of the accumulators for their plants. Several techniques are available to scale from the PWR accumulator volume to the Semiscale Mod-1 accumulator volume. Of those methods available, the two extreme cases were chosen for sensitivity studies on the Mod-1 system and as possible options for the Mod-1 baseline ECC test. These methods are termed system volume scaling and downcomer volume scaling and the criteria governing these scaling techniques are discussed in this section. Included in this discussion is the method of sizing the Mod-1 
accumulator liquid volume; the method of determining the accumulator line hydraulic resistance, the method of accounting for Mod-1 hot wall effects, and the method of obtaining the correct accumulator tank backpressure. Also discussed are the compromises arrived at in final specification of the accumulator ECC parameters for the Mod-1 baseline ECC test (Test S-04-6).

\subsection{Scaling the Accumulator Liquid Volume}

The two scaling methods used to size the Mod-1 accumulator liquid volume during the Mod-1 baseline ECC test series were system volume scaling and downcomer volume scaling. The criteria governing these scaling methods and the rationale applied in their selection are discussed in the following paragraphs.

The criterion governing system volume scaling is

$$
\left.\frac{V_{\text {accumulator }}}{V_{\text {system }}}\right|_{\text {Semiscale }}=\left.\frac{V_{\text {accumulator }}}{V_{\text {system }}}\right|_{P W R}
$$

where

$$
\begin{aligned}
& \mathrm{V}_{\text {system }}(\text { Semiscale })=7.8 \mathrm{ft}^{3} \\
& \mathrm{~V}_{\text {accumulator }}(\mathrm{PWR})=3 \times 890 \mathrm{ft}^{3}=2670 \mathrm{ft}^{3[\mathrm{a}]} \\
& \mathrm{V}_{\text {system }}(\text { PWR }) \quad=11,952 \mathrm{ft}^{3} \text {. }
\end{aligned}
$$

This method of scaling was chosen because it is compatible with the overall Mod-1 system scaling criteria; that is, volume scaling, and was considered to provide the most realistic ECC injection rate and fluid for energy exchange such as condensation at the injection port and, therefore, provide a representative system depressurization. The Mod-1 intact loop accumulator volume based on this scaling method is $1.74 \mathrm{ft}^{3}$.

The criterion governing downcomer volume scaling is

$$
\left.\frac{V_{\text {accumulator }}}{V_{\text {downcomer }}}\right|_{\text {semiscale. }}=\left.\frac{V_{\text {accumulator }}}{V_{\text {downcomer }}}\right|_{\text {PWR }}
$$

where

$$
\begin{aligned}
& \mathrm{V}_{\text {downcomer }}(\text { Scmiscalc })-0.95 \mathrm{ft}^{3} \\
& \mathrm{~V}_{\text {downcomer }}(\mathrm{PWR})=724 \mathrm{ft}^{3} \text {. }
\end{aligned}
$$

[a] This volume represents three of the four accumulator tank liquid volumes in a 4-loop PWR. The liquid of one accumulator is assumed lost out the break. 
The volume of the Mod-1 downcomer is about twice as large as the scaled PWR value and, therefore, requires about twice the liquid to provide the correctly scaled downcomer head for driving core reflood. The preceding method of accumulator scaling takes into account the atypical large Mod-1 downcomer by specifying an initial accumulator liquid volume of $3.5 \mathrm{ft}^{3}$. However, to maintain the same injection period as would occur in the previous scaling method (system volume scaling), the accumulator line hydraulic resistance had to be decreased.

\subsection{Accumulator Line Resistance}

In order to maintain the same time of accumulator liquid injection in the Mod-1 system as expected to occur in a PWR, the accumulator line differential pressures must be the same in cach system. Therefore:

$$
\Delta P_{\text {Semiscale }}=\Delta P_{P W R}
$$

and from the Darcy-Weisbach equation

$$
\Delta P=\frac{\rho v^{2}}{(144)\left(2 g_{c}\right)}\left(f \frac{L}{D}\right)
$$

where

$$
\begin{aligned}
& \rho \quad=\text { liquid density, } \frac{\mathrm{lbm}}{\mathrm{ft}^{3}} \\
& \mathrm{v} \quad=\text { liquid velocity, } \frac{\mathrm{ft}}{\mathrm{sec}} \\
& \mathrm{f}=\text { pipe flow friction factor } \\
& \mathrm{L}=\text { pipe length, } \mathrm{ft} \\
& \mathrm{D}=\text { pipe diameter, } \mathrm{ft} \\
& \mathrm{g}_{\mathrm{c}}=\text { gravitational constant, } \frac{\mathrm{lbm}-\mathrm{ft}}{\mathrm{lbf}-\mathrm{sec}^{2}}
\end{aligned}
$$

which results in

$$
\frac{\rho v^{2}}{(144)\left(2 g_{c}\right)}\left(f \frac{L}{D}\right) \text { Semiscale }=\frac{\rho v^{2}}{(144)\left(2 g_{c}\right)}\left(f \frac{L}{D}\right)_{P W R^{*}}
$$

The accumulator liquid density will be the same in both systems resulting in the preceding relationship reducing to 


$$
\left(f \frac{L}{D}\right)_{\text {Semiscale }}=\left(f \frac{L}{D}\right)_{\text {PWR }} \frac{\left(v^{2}\right)_{\text {PWR }}}{\left(v^{2}\right)_{\text {Semiscale }}} .
$$

If

$$
K=\left(f \frac{L}{D}\right)
$$

then

$$
K_{\text {Semiscale }}=K_{P W R} \sqrt{\left(v^{2}\right) \frac{\left(v^{2}\right)_{P W R}}{\text { Semiscale }} .} .
$$

For a PWR, with

$$
\frac{L}{D}=550
$$

and

$$
f=0.0138 \text { (complete turbulence) }
$$

then

$$
\mathrm{K}_{\text {rWR }}=1.6 .
$$

Also

$$
\left(v^{2}\right)_{P W R}=\left(\frac{Q^{2}}{A^{2}}\right)_{P W R}
$$

where

$$
\begin{aligned}
& \mathrm{Q}=\text { accumulator volumetric flow rate, } \frac{\mathrm{ft}^{3}}{\mathrm{sec}} \\
& \mathrm{A}=\text { accumulator line cross-scctional area, } \mathrm{ft}^{2}
\end{aligned}
$$

and similarly for Semiscale:

$$
\left(v^{2}\right)_{\text {Semiscale }}=\left(\frac{Q^{2}}{A^{2}}\right)_{\text {Semiscale }} \cdot
$$

Therefore, 


$$
K_{\text {Semiscale }}=7.6 \frac{\left(\frac{Q^{2}}{A^{2}}\right)_{P W R}}{\left(\frac{Q^{2}}{A^{2}}\right)_{\text {Semiscale }}} .
$$

The accumulator line cross-sectional flow areas for the PWR and Semiscale systems are

$$
\begin{aligned}
& A_{P W R}=3 \frac{\pi D^{3}}{4} \frac{L}{D}=1.253 \mathrm{ft}^{2[\mathrm{a}]} \\
& A_{\text {Semiscale }}=0.0049 \mathrm{ft}^{2} .
\end{aligned}
$$

Substitution of these values into the preceding relationship with the injection time the same in both systems; that is, with

$$
\frac{Q_{P W R}^{2}}{Q_{\text {Semiscale }}^{2}}=\frac{(V)_{\text {accumulator }}^{2}-P W R}{(V)_{\text {accumulator }}^{2}-\text { Semiscale }}
$$

results in (for a system volume scaled Mod-1 accumulator liquid volume)

$$
K_{\text {Semiscale }}=273.67 \text {. }
$$

The Semiscale Mod-1 accumulator line hydraulic resistance under system volume scaling is

$$
R^{\prime}=\frac{K}{2 g_{C}(144) A^{2}}=1229 \frac{\mathrm{sec}^{2}}{\mathrm{in}^{2}-\mathrm{ft}^{3}}
$$

This line resistance corresponds to an average accumulator water injection rate of about 23 gprn.

For the case in which the accumulator liquid volume is downcomer volume scaled, the preceding calculations show that

$$
\mathrm{K}_{\text {Semiscale }}=67.66 \frac{\mathrm{sec}^{2}}{\mathrm{in}^{2}-\mathrm{ft}^{3}}
$$

and

$$
R_{\text {Semiscale }}^{\prime}=304 \text {. }
$$

[a] This value represents the combined flow area of the three PWR accumulator lines based on 10-in. Schedule-140 pipe. 
This line resistance corresponds to an average accumulator water injection rate of about $46 \mathrm{gpm}$.

\subsection{Downcomer Hot Wall Effects}

To account for the Mod-i hot wall delay time during which ECC bypasses and is lost from the system, the initial accumulator liquid volumes determined by the preceding methods had to be increased. The Mod-1 hot wall delay time was calculated to be between 10 and $15 \mathrm{sec}$ and, for the purpose of this analysis, was estimated to be $11 \mathrm{sec}$. Therefore, to account for the increase in ECC bypass time that results from this Mod-1 hot wall delay, the initial accumulator liquid volumes were increased as follows.

For the system volume scaled accumulator

$$
\mathrm{V}_{\text {accumulator }}=1.74+Q_{\text {accumulator }}\left(t_{\text {hot wall }}\right)
$$

where

$t_{\text {hot wall }}=$ Mod-1 hot.wall delay time

therefore

$$
V_{\text {accumulator }}=2.30 \mathrm{ft}^{3} \text {. }
$$

Similarly for the downcomer volume scaled accumulator

$$
\begin{aligned}
V_{\text {accumulator }} & =3.5+Q_{\text {accumulator }}\left(t_{\text {hot wall }}\right) \\
& =4.63 \mathrm{ft}^{3} .
\end{aligned}
$$

Although increasing the accumulator liquid volume produces longer injection times (Section 1.2), it also results in the correct scaled amount of liquid available at the initiation of vessel refill and is considered a necessary approach for proper assessment of the Mod-1 sensitivity to ECC scaling.

\subsection{Accumulator Gas Volume}

The Semiscale accumulator is typical of a PWR in that it uses an inert gas $\left(\mathrm{N}_{2}\right)$ to provide the backpressure for injection. The volume of gas should be scaled between the systems such that the proper transient backpressure results as the accumulator liquid is depleted. Therefore, assuming an isothermal expansion of a perfect gas

where

$$
P V_{g}=\text { constant }
$$

$$
\begin{aligned}
& \mathrm{P}=\text { accumulator tank pressure } \\
& \mathrm{V}_{\mathrm{g}}=\text { accumulator gas volume }
\end{aligned}
$$


therefore

$$
\frac{d\left(P V_{g}\right)}{d t}=0
$$

and

$$
\frac{1}{P} \frac{d P}{d t}=\frac{1}{V_{g}} \frac{d V_{g}}{d t}
$$

To maintain equal transient backpressures during depressurization in each system, therefore, the following ratio must hold

$$
\frac{V_{g} \text { (Semiscale) }}{V_{g}(\text { PWR })}=\frac{\left(d V_{g} / d t\right) \text { Semiscale }}{\left(d V_{g} / d t\right)^{\text {PWR }}} .
$$

Since water may be considered incompressible, this relationship can be written as

$$
\frac{V_{g}(\text { Semiscale })}{V_{g}(\text { PWR })}=\frac{Q(\text { Semiscale })}{Q(P W R)}
$$

where

$$
\mathrm{Q}=\text { volumetric flow rate of the accumulator liquid. }
$$

Using the form of the Darcy-Weisbach equation

$$
\Delta P=\frac{R^{\prime} Q^{2} \rho^{2}}{\rho}
$$

in solving for $Q$ and substituting $Q$ in the preceding expression results in

$$
\frac{V_{g}(\text { Semiscale })}{V_{g}(\text { PWR })}=\left(\frac{R^{\prime}(\text { PWR })}{R^{\prime}(\text { Semiscale })}\right)^{1 / 2}
$$

For system volume scaling and $\mathrm{V}_{\mathrm{g}}(\mathrm{PWR})=1500 \mathrm{ft}^{3}$ :

$$
v_{g}(\text { Semiscale })=0.98 \mathrm{ft}^{3} \text {. }
$$

Similarly for downcomer volume scaling:

$$
v_{g}(\text { Semiscale })=1.97 \mathrm{ft}^{3} .
$$




\subsection{Scaling Compromises for the Mod-1 Baseline ECC Tcst (Test S-04-6)}

The results from tests conducted in the ECC baseline test series indicated that system volume scaled accumulator parameters are preferable to downcomer volume scaled ECC parameters because a more representative system depressurization rate results. However, the Mod-1 system has an atypical large downcomer and, therefore, the initial accumulator liquid volume had to be increased to a value greater than the scaled value to ensure that sufficient accumulator liquid would be available at the initiation of lower plenum refill to completely fill the downcomer. The method used to increase the system volume scaled accumulator liquid volume was as follows.

From strict system volume scaling criteria (Section 1.1)

$$
\text { Volume accumulator }=1.74 \mathrm{ft}^{3}
$$

and when the Mod-1 hot wall delay time is taken into account (Section 1.3)

$$
\text { Volume } \text { accumulator }=2.30 \mathrm{ft}^{3} \text {. }
$$

This accumulator liquid volume resulted in the downcomer liquid level reaching to only about 60 in. below the cold leg centerline prior to reflood (Test S-04-1). In order to ensure that sufficient accumulator liquid would be available to completely fill the downcomer prior to reflood, the $2.3 \mathrm{ft}^{3}$ volume was increased as follows:

$$
\begin{aligned}
v_{\text {accumulator }}= & 2.3 \mathrm{ft}^{3}+\Sigma \text { remainder of the downcomer } \\
& \text { volume }+ \text { volume of the inlet annulus }+ \text { volume } \\
& \text { in the cold leg from the injection port to the } \\
& \text { inlet annulus, }
\end{aligned}
$$

which results in a total initial accumulator liquid volume of

$$
v_{\text {accumulator }}=3.0 \mathrm{ft}^{3} \text {. }
$$

This accumulator liquid volume was specified for the Mod-1 ECC baseline test (Test S-04-6). The accumulator injection rate was specified to remain at $23 \mathrm{gpm}$.

\section{SCALING THE HIGH PRESSURE INJECTION SYSTEM (HPIS) AND THE LOW PRESSURE INJECIIIUN SYS"IEM (LPIS)}

In the Mod-1 system, the HPIS and LPIS are designed to actuate at system pressures of $1800 \mathrm{psig}$ and $150 \mathrm{psig}$, respectively. With the exception of the final two tests in the Mod-1 baseline ECC test series, both the HPIS and LPIS had scaled flow rates which were based on the corresponding accumulator scaling method, that is, system volume or downcomer volume-scaling. However, the last two tests in the Mod-1 baseline ECC test series (Test S-04-5 and Test S-04-6) employed a new concept in scaling for the LPIS. This method of scaling is termed vessel area scaling, and the conclusion reached was that this method produced the best downcomer refill characteristics during the latter phases of the 
core reflood portion of a postulated LOCA. The methods used in scaling the HPIS and LPIS and the calculated flow rates obtained are discussed in the following sections.

\subsection{System Volume Scaling}

Under the system volume scaling method, the following ratio holds

$$
\left(\frac{Q}{V_{\text {system }}}\right)_{\text {Semiscale }}=\left(\frac{Q}{V_{\text {system }}}\right)_{\text {PWR }}
$$

where

$$
\begin{array}{ll}
\mathrm{Q} & =\text { volumetric flow rate for either the HPIS or the LPIS } \\
\mathrm{V}_{\text {system }} \text { (Semiscale) } & =7.8 \mathrm{ft}^{3} \\
\mathrm{~V}_{\text {system }} \text { (PWR) } & =11,952 \mathrm{ft}^{3} .
\end{array}
$$

If the approximation is made that

$$
Q_{\text {HPIS }}(P W R)=475 \mathrm{gpm}
$$

then

$$
Q_{\text {HPIS }}(\text { Semiscale })=0.31 \mathrm{gpm} \text {. }
$$

Similarly, if the approximation is made that

$$
Q_{\text {LPIS }}(P W R)=4650 \mathrm{gpm}
$$

then

$$
Q_{\text {LPIS }}(\text { Semiscale })=3.03 \mathrm{gpm} \text {. }
$$

\subsection{Downcomer. Volume Scaling}

Under the downcomer volume method of scaling, the following ratio holds

$$
\left(\frac{Q}{V_{\text {downcomer }}}\right)_{\text {Semiscale }}=\left(\frac{Q}{V_{\text {downcomer }}}\right)_{\text {PWR }}
$$

where

$$
\begin{aligned}
& \mathrm{V}_{\text {downcomer }}(\text { Semiscale })=0.95 \mathrm{ft}^{3} \\
& \mathrm{~V}_{\text {downcomer }}(\mathrm{PWR}) \quad=\quad 724 \mathrm{ft}^{3}
\end{aligned}
$$

and $Q$ has the same meaning as in Section 2.1. If the same approximations for $Q_{H P I S}(P W R)$ and $\mathrm{Q}_{\mathrm{LPIS}}(\mathrm{PWR})$ are made as in Section 2., 1 then 


$$
Q_{\text {HPIS }}(\text { Semiscale })=0.62 \mathrm{gpm}
$$

and

$$
Q_{\text {LPIS }}(\text { Semiscale) }=6.1 \mathrm{gpm} \text {. }
$$

\subsection{Vessel Area Scaling.}

This method of scaling was used only for specifying LPIS volumetric flow rates in the last two tests conducted during the Mod-1 baseline ECC test series. Under this method of scaling the following ratio holds

$$
\left(\frac{Q_{\text {LPIS }}}{A_{\text {vesse } 1}}\right)_{\text {Semiscale }}=\left(\frac{Q_{\text {LPIS }}}{A_{\text {vesse1 }}}\right)_{\text {PWR }}
$$

where

$$
\begin{array}{ll}
\mathrm{A}_{\text {vessel }} & =\text { downcomer flow area }+ \text { core flow area } \\
\mathrm{A}_{\text {vessel }}(\text { Semiscale }) & =0.11 \mathrm{ft}^{2} \\
\mathrm{~A}_{\text {vessel }}(\mathrm{PWR}) . & =108 \mathrm{ft}^{2}
\end{array}
$$

and, as in the preceding sections

$$
Q_{\text {LPIS }}(P W R)=4650 \mathrm{gpm} .
$$

Thereforc, under vessel area scaling

$$
Q_{\text {LPIS }}(\text { Semiscale })=4.73 \mathrm{gpm} .
$$


APPENDIX C

CORE ROD CONFIGURATION FOR THE MOD-1 BASELINE.

ECC TEST (TEST S-04-6) 
THIS PAGE

\section{WAS INTENTIONALLY \\ LEFT BLANK}




\title{
APPENDIX C \\ CORE ROD CONFIGURATION FÖ THE MOD-1 BASELINE ECC TEST (TEST S-04-6)
}

\begin{abstract}
A typical PWR $15 \times 15$ rod array assembly is shown in Figure C-1. The blacked out areas represent passive rod locations in the array such as control rod guide tubes or instrumentation spindles. Of the total 225 rod locations in this rod matrix configuration, 21 locations, or about $10 \%$, are passive rod locations. Since the PWR core may contain 200 such rod assemblies, duplication of the passive rod geometry in the 40-rod Mod-1 core is impossible. However, because a definite geometrical pattern of passive rod locations does exist in the PWR core, simulation of these locations in the Mod-1 core was desirable on the basis of obtaining core symmetry. However, another facet of this investigation made obtaining core symmetry impossible. This facet of the investigation was concerned with the effect on the PWR core response due to the increase in rod power on those rods adjacent to the passive rods. This increase in power is due to the increased neutron moderation caused by the liquid occupying the control rod guide tubes or instrumentation spindles. To simulate this effect in the Mod-1 core meant unpowering one of the four center rods. The four center rods are powered independently from the remaining core rods and if one of these rods were unpowered, the power of the remaining three could be increased to simulate the increase in power on rods adjacent to passive rods. Consequently, core symmetry was compromised in order to investigate the effect of unpowering one of the four center rods and increasing the power on the remaining three center rods. The final decision was, therefore, to unpower Rods C-3, F-3, F-6, and center Rod D-5 in Test S-04-6 as shown in Figure C-2. Accordingly, the power on Rods D-4, E-4, and E-5 was increased $5 \%$ above the power of the remaining 33 rods. This increased power corresponded to a peak power density of $11.5 \frac{\mathrm{kW}}{\mathrm{ft}}$ on 33 rods and $12.1 \frac{\mathrm{kW}}{\mathrm{ft}}$ on the remaining three center rods.
\end{abstract}

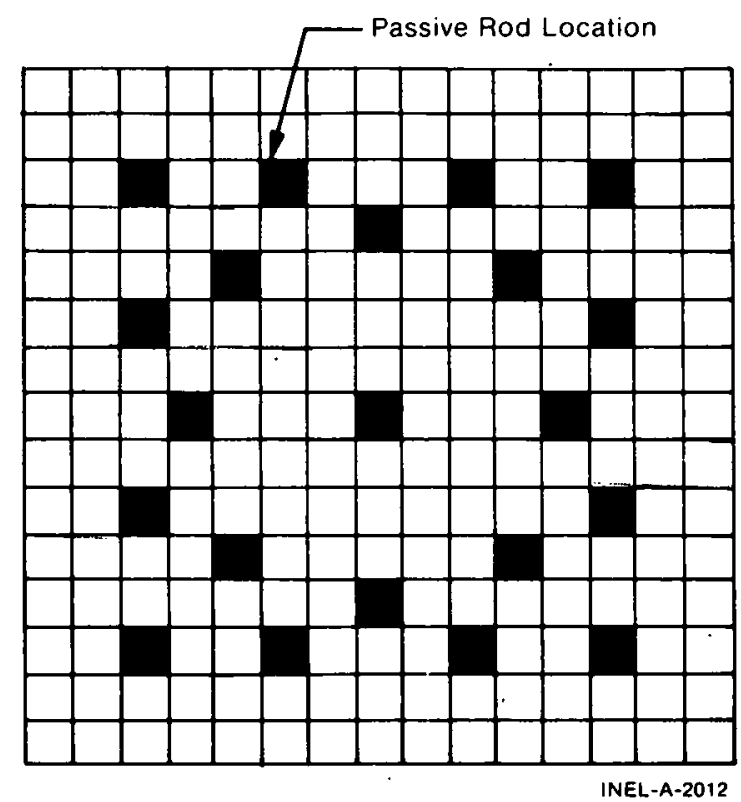

Fig. C-1 Typical $15 \times 15$ PWR rod array assembly showing passive rud loeations. 


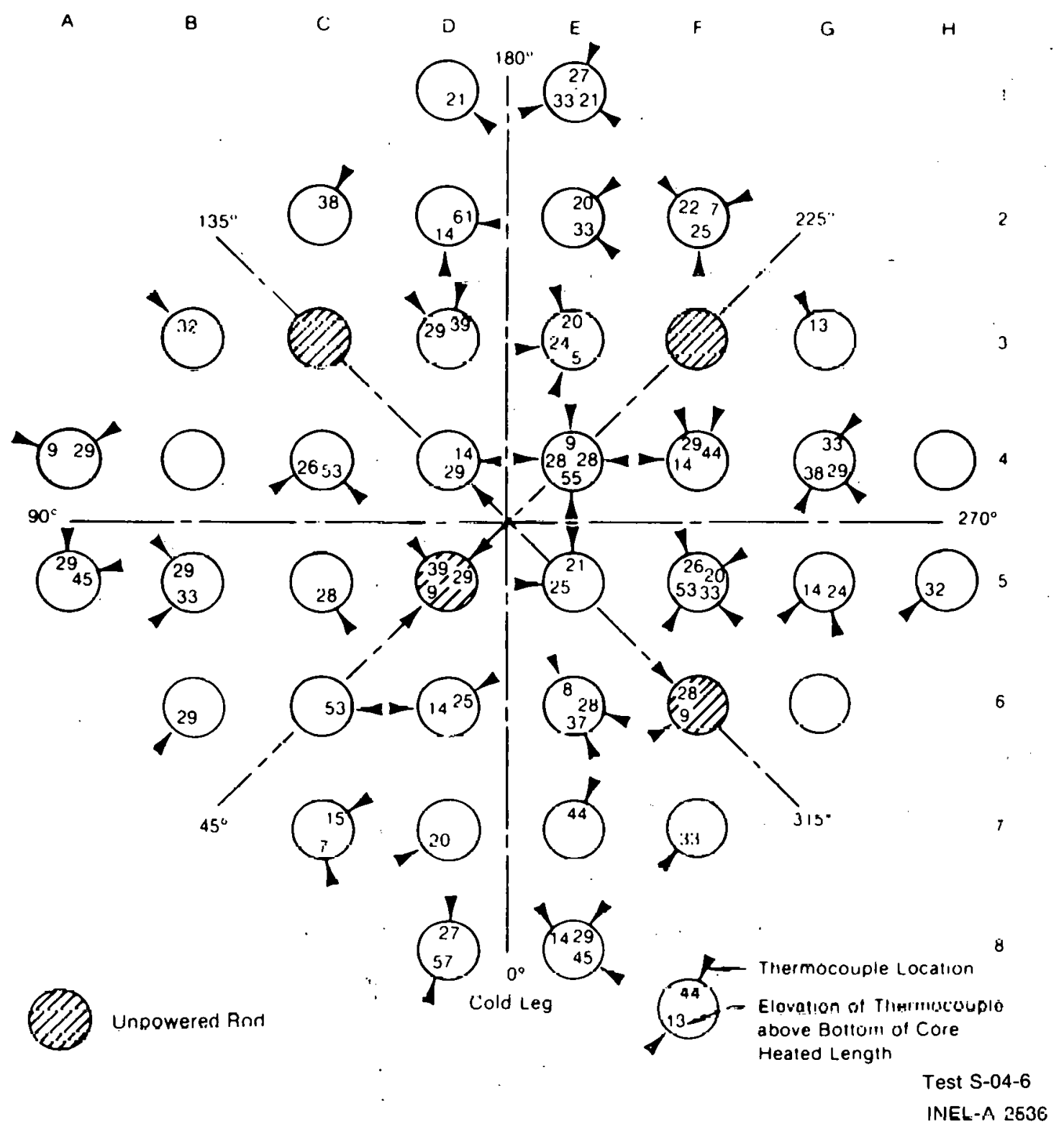

Fig C.2 Core heator ennfiginaliun for ECC bascline - Test S-04-6. 
- Internal Distribution

1 - Chicago Patent-Group - ERDA 9800 South Cass Avenue Argonne, Illinois 60439

2-4 - A. T. Morphew Classification and Technical Information Officer Idaho Operations Office - ERDA Idaho Falls, ID 8340 I

5 - R. J. Beers, ID

6 - P. E. Litteneker, ID

7 - R. E. Tiller, ID

8 - R. E. Wood, ID

9 - H. P. Pearson, Supervisor Technical Information

10-19 - INEL Technical Library

20-39 - Author

40-96 - Special Internal

\section{External Distribution}

97-98 - Saut Levine, Director Office of Nuclear Regulatory Research, NRC Washington, DC 20555

99-403 - Distribution under NRC-2, Water Reactor Safety Research Sys tems Engineering 